Nair Emmanuela da Silveira Pereira

\title{
Análise de parâmetros hidrodinâmicos e da clorofila $a$ no Atlântico Sul e Tropical a partir de modelagem numérica e observações remotas
}

\begin{abstract}
Dissertação apresentada ao Instituto Oceanográfico da Universidade de São Paulo, como parte dos requisitos para obtenção do título de Mestre em Ciências, Programa de Oceanografia, área de Oceanografia Física.
\end{abstract}

Orientador: Prof. Dr. Joseph Harari

São Paulo 


\title{
Universidade de São Paulo \\ Instituto Oceanográfico
}

\begin{abstract}
Análise de parâmetros hidrodinâmicos e da clorofila $a$ no Atlântico Sul e Tropical a partir de modelagem numérica e observações remotas
\end{abstract}

Nair Emmanuela da Silveira Pereira

Dissertação apresentada ao Instituto Oceanográfico da Universidade de São Paulo, como parte dos requisitos para obtenção do título de Mestre em Ciências, Programa de Oceanografia, área de Oceanografia Física.

\section{(VERSÃO REVISADA)}

Julgada em _ _ _

$\operatorname{Prof}(\mathrm{a}) \cdot \operatorname{Dr}(\mathrm{a})$.

Conceito

$\operatorname{Prof}(\mathrm{a}) . \operatorname{Dr}(\mathrm{a})$

Conceito

$\operatorname{Prof}(\mathrm{a}) . \operatorname{Dr}(\mathrm{a})$.

Conceito 


\section{SUMÁRIO}

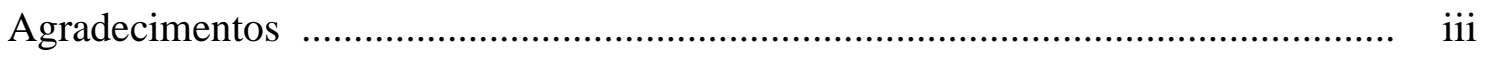

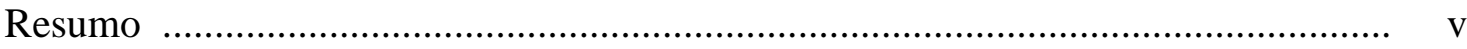

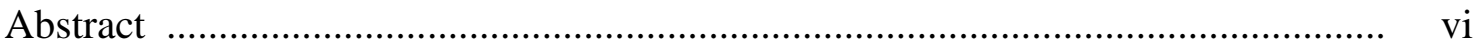

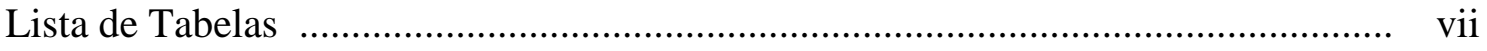

Lista de Figuras $\quad$.............................................................................................. viii

Lista de Acrônimos .......................................................................................... xiii

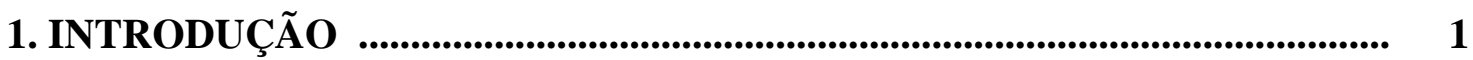

1.1. Modelagem numérica ......................................................................... 1

1.2. Sensoriamento remoto e clorofila $a$.................................................... 5

1.3. Justificativa e hipótese do trabalho $\quad$......................................................... 7

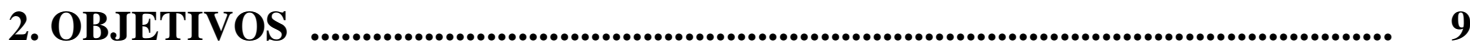

3. AREA DE ESTUDO

4. MÉTODOLOGIA …........................................................................................... 15

4.1. O modelo numérico hidrodinâmico e sua calibração $\quad$............................. 15

4.1.1. Condições iniciais e de contorno ............................................. 15

4.1.2. Dados de entrada .................................................................. 17

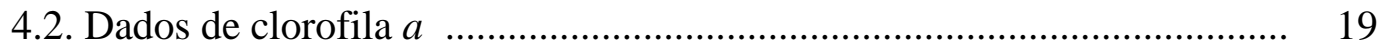

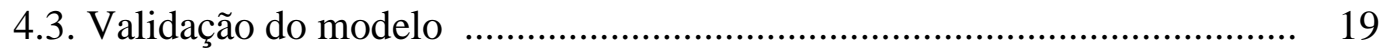

4.4. Processamento dos dados ............................................................ 20

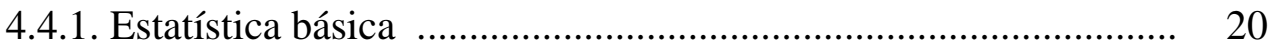

4.4.2. Correlações .......................................................................... 23 
4.4.3. Espectro de Fourier

4.4.2. Validação do modelo

5. RESULTADOS E DISCUSSÃO

5.1. Validação do modelo hidrodinâmico

5.2. Caracterização da clorofila $a$ e variáveis físicas

5.3. Correlação entre clorofila $a$ e variáveis físicas

5.4. Análise do transecto $20^{\circ} \mathrm{W}$

5.4.1. Comparação entre clorofila $a$ e elevação da superfície

5.4.2. Comparação entre clorofila $a$ e temperatura em superfície 


\section{Agradecimentos}

Primeiramente agradeço a todo IOUSP, minha segunda casa. Repleto de pessoas fantásticas que, não cabem nesse documento, mas que sabem como fizeram diferença em minha vida. A todos os funcionários que sempre me apoiaram em todos os momentos; em especial à Vanilde que, é capaz de parar seja lá o que estiver fazendo para auxiliar a todos. Aos professores que me ensinaram tanto e me fizeram entender o quanto eu não sei. Em especial agradeço ao professor Ricardo de Camargo pelo auxilio nesse trabalho e, é claro ao professor Joseph Harari por toda a dedicação e paciência infinita!

Agradeço a todos os parceiros e amigos do LabSIP, à minha turma de mestrado, amigos da graduação e, da vida que estiveram sempre tão presentes (cada um do seu jeito particular) de forma que, sempre que pensasse que estava só me mostravam que estavam sempre ali para me apoiar. Em especial, agradeço à Cecilia que joga todos os seus problemas de lado e jamais esquece o significado da palavra "amigo", dedicando-se ao máximo para te mostrar que você é especial exatamente pelo que é.

Agradeço à CAPES pelo auxilio financeiro que propiciou a realização desse trabalho.

Agradeço o apoio de toda a minha família (me perco de tão grande!), sempre tão unida e, sem a qual não estaria aqui hoje. Desde meus avós, sempre presentes, mesmo tão distante até a caçulinha Mariana. Ao meu pai, irmãos, tios, sobrinhos... À minha Dindinha, por ser tão especial e ter-me aberto seu coração e deixado que me apoderasse dele, de forma tão altruísta. Em especial agradeço à minha mãe e melhor amiga que antecipa minhas falas antes mesmo que comece a reclamar (e que, no fundo, sabe que a teimosia é hereditária) e ao meu esposo, amigo e companheiro de bons e maus momentos e que aprendeu a entender que atrás de ataques de fúria existe muito amor e carinho. São essas duas pessoas que aprenderam a compreender como ninguém que só um amor muito grande consegue revelar o meu "lado negro da força".

Finalmente agradeço à Sofia, que me ensinou a ter paciência, a enxergar e aproveitar cada pequeno traço de beleza que cruza meu caminho, sendo o motivo pelo

qual me levanto e sigo em frente todos os dias. É a essa pequena estrela, que torna minha vida mais brilhante a cada dia, que dedico esse trabalho. 
"Pior do que passar frio, subindo e descendo ondas do oceano Índico, seria não ter chegado até aqui." 


\section{Resumo}

Foi realizado um estudo com dados físicos em superfície provenientes de implementação do modelo numérico POM e dados de clorofila $a$ do sensor MODIS, no Atlântico Sul e Tropical, tendo como finalidade analisar as variações espaciais de suas correlações. O modelo hidrodinâmico foi submetido a uma validação com dados do Projeto PIRATA e do sensor MODIS, obtendo-se resultados satisfatórios, principalmente em superfície. A clorofila $a$ apresenta altos valores de correlação com variáveis físicas em superfície, porém esses valores são influenciados pela presença dos sinais anual e semianual nas séries temporais. Consequentemente, as análises foram desenvolvidas após a remoção desses sinais das séries. As correlações cruzadas entre as variáveis físicas e clorofila $a$ tiveram valores altos em módulo apresentando, de maneira geral, padrão espacial característico de correlações negativas no interior do Giro Subtropical e positivas nas demais regiões para temperatura e salinidade em superfície e elevação do nível do mar. Esse padrão espacial é mais evidente para elevação e temperatura em superfície, apresentando defasagem no tempo de resposta biológica de quase zero no interior do Giro Subtropical e Equador, com predomínio de atrasos nessa resposta nas demais regiões. A covariância cruzada foi calculada para alguns pontos ao longo do meridiano de $20^{\circ} \mathrm{W}$, para elevação de superfície e temperatura, verificando-se concordância com os resultados obtidos pela correlação cruzada. A análise espectral dessa covariância salientou a ocorrência de alguns sinais, dentre eles os sinais com períodos de 3,5 e 0,7 anos (que provavelmente estão associados aos fenômenos ENSO) e o período de 0,33 anos (que pode estar relacionado a ressonâncias do sinal anual). A assinatura desses sinais apresentou variabilidade latitudinal.

DESCRITORES: Atlântico Sul e Tropical, parâmetros hidrodinâmicos, clorofila $a$, modelagem numérica, sensoriamento remoto, correlações cruzadas, análise espectral. 


\section{Abstract}

A study was performed with physical data at the surface produced by the implementation of the numerical model POM and chlorophyll $a$ data from the MODIS sensor, in the Tropical and South Atlantic, with the aim of to analyze the spatial variations of their correlations. The hydrodynamic model was subjected to a validation with data of Project PIRATE and MODIS sensor, obtaining satisfactory results, especially at the surface. The chlorophyll $a$ values have high correlation with physical variables at the surface, but these values are influenced by the presence of annual and semiannual signals in the time series. Then, the analyses were carried out after removal of these signals from the series. The cross-correlations between physical variables and chlorophyll $a$ had high magnitudes showing, in general, characteristic spatial pattern of negative correlations within the Subtropical Gyre and positive in other regions, for surface temperature and salinity and sea surface level. This spatial pattern is most evident in surface elevation and temperature, presenting lag in the biological response time nearly zero within the Subtropical Gyre and Equator, with a predominance of delays of the responses in other regions. The cross-covariance is calculated for several points along the meridian of $20^{\circ} \mathrm{W}$ for surface elevation and surface temperature, verifying agreement with the results obtained by the cross correlation. Spectral analysis of this covariance shows the occurrence of some signals, including signals with periods of 3.5 and 0.7 years (which are probably associated with ENSO phenomena) and the period of 0.33 years (that can be related to resonances of the annual signal). The signature of these signals showed latitudinal variability.

KEYWORDS: Tropical and South Atlantic, hydrodynamic parameters, chlorophyll $a$, numerical modeling, remote sensing, cross-correlations, spectral analysis. 


\section{Lista de Tabelas}

1. Valores considerados como níveis $\sigma$

2. Parâmetros iniciais utilizados no modelo

3. Estatística comparativa entre resultados do modelo e medições do PIRATA, para temperatura em superfície, antes da remoção dos sinais anual e semianual

4. Estatística comparativa entre resultados do modelo e medições do PIRATA, para temperatura em superfície, após remoção dos sinais anual e semianual

5. Estatística comparativa entre dados do modelo e do PIRATA, nos perfis de temperatura dos pontos $8^{\circ} \mathrm{N}-38^{\circ} \mathrm{W}$ e $10^{\circ} \mathrm{S}-10^{\circ} \mathrm{W}$ para o ano de 2004

6. Estatística comparativa entre dados do modelo e do PIRATA, nos perfis de temperatura dos pontos $8^{\circ} \mathrm{N}-38^{\circ} \mathrm{W}$ e $4^{\circ} \mathrm{N}-38^{\circ} \mathrm{W}$ para o ano de 2006

7. Estatística comparativa entre modelo e MODIS das distribuições de parâmetros relacionado à temperatura residual (total menos sinais anual e semianual), para a região de estudo, no período de 2003 a 2009 


\section{Lista de Figuras}

1. Distribuição da função de corrente em simulação do POM com condições de contorno (A) aberto e (B) fechado, onde nota-se em A separação irrealista da corrente do Golfo (FONTE: Ezer e Mellor, 2000)

2. Variabilidade temporal da temperatura resultante de modelagem numérica e de observações, com os parâmetros de validação, para o ponto $10^{\circ} \mathrm{S}-10^{\circ} \mathrm{W}$ (FONTE: Pereira e Harari, 2010)

3 Área de estudo - Oceano Atlântico Sul e Tropical

4. Representação esquemática do Giro Subtropical do Atlântico Sul. (fonte: Cirano et al., (2006), adaptado de Peterson e Stramma (1991))

5. Distribuição horizontal das principais correntes da Água Superficial Tropical (TSW: 0-100m) para (a) outono e (b) primavera do Hemisfério Sul (Pereira (2009). Siglas em inglês: Água Tropical Superficial (TSW), Corrente Norte Equatorial (NEC), Domo da Guiné (GD), Contracorrente Norte Equatorial (NECC), Corrente da Guiné (GC), Corrente Sul Equatorial (SEC) e seus ramos Norte (nSEC), Equatorial (eSEC), Central (cSEC) e Sul (sSEC), Corrente Subsuperficial Equatorial (EUC), Corrente Norte do Brasil (NBC), Corrente Subsuperficial Gabão-Congo (GCUC), Giro de Angola (AG), Corrente de Angola (AC), Domo de Angola (AD), Contracorrente Sul Equatorial (SECC) e Corrente do Brasil (BC). A Frente Angola-Benguela (ABF) é representada com uma linha pontilhada. O símbolo u em um quadrado indica as possíveis áreas de ressurgência (não seus locais exatos) - adaptado de Stramma e Schott (1999)).

6. Distribuições das correlações cruzadas (à esquerda) e suas defasagens em meses (à direita) da clorofila a com a temperatura do mar, no Oceano Atlântico Sul e Tropical (Fonte: Pereira, 2009)

7. Localização das boias do projeto PIRATA com dados utilizados na validação do modelo, assinalados com triângulos vermelhos 
8. Exemplo de remoção do sinal anual e da tendência de uma série de temperatura

9. Séries temporais do modelo e do pirata com (acima) e sem (abaixo) a remoção dos sinais anual e semianual para o ponto $0^{\circ} \mathrm{N}-23^{\circ} \mathrm{W}$

10. Séries temporais do modelo e do pirata com (acima) e sem (abaixo) a remoção dos sinais anual e semianual para o ponto $0^{\circ} \mathrm{N}-35^{\circ} \mathrm{W}$

11. Séries temporais do modelo e do pirata com (acima) e sem (abaixo) a remoção dos sinais anual e semianual para o ponto $4^{\circ} \mathrm{N}-38^{\circ} \mathrm{W}$

12. Séries temporais do modelo e do pirata com (acima) e sem (abaixo) a remoção dos sinais anual e semianual para o ponto $6^{\circ} \mathrm{S}-10^{\circ} \mathrm{W}$

13. Séries temporais do modelo e do pirata com (acima) e sem (abaixo) a remoção dos sinais anual e semianual para o ponto $8^{\circ} \mathrm{N}-38^{\circ} \mathrm{W}$

14. Séries temporais do modelo e do pirata com (acima) e sem (abaixo) a remoção dos sinais anual e semianual para o ponto $12^{\circ} \mathrm{N}-38^{\circ} \mathrm{W}$

15. Perfis de temperatura do modelo e do PIRATA para os pontos $8^{\circ} \mathrm{N}-38^{\circ} \mathrm{W}$ (acima) e $10^{\circ} \mathrm{S}-10^{\circ} \mathrm{W}$ (abaixo) para os meses de janeiro (esquerda) e julho (direita) de 2004

16. Perfis de temperatura do modelo e do PIRATA para os pontos $8^{\circ} \mathrm{N}-38^{\circ} \mathrm{W}$ (acima) e $4^{\circ} \mathrm{N}-38^{\circ} \mathrm{W}$ (abaixo) para os meses de janeiro (esquerda) e julho (direita) de 2004

17. Distribuição espacial da média (acima) e da tendência (abaixo) da temperatura em superfície, com a remoção dos sinais anual e semianual, proveniente do modelo (à esquerda) e do sensor MODIS (à direita), no Atlântico Sul e Tropical, para o período de 2003 a 2009.

18. Distribuição espacial dos desvios padrão dos sinais anual e semianual (acima) e do sinal residual (abaixo) da temperatura em superfície, proveniente do modelo (à esquerda) e do sensor MODIS (à direita), no Atlântico Sul e Tropical, para o período de 2003 a 2009.

19. Distribuição espacial da média (acima, à esquerda) e da tendência (acima, à direita) da salinidade em superfície e seus respectivos desvios padrão, com a 44 
remoção dos sinais anual e semianual (abaixo, à esquerda) e apenas para os sinais anual e semianual (abaixo, à direita), no Atlântico Sul e Tropical, para o período de 2003 a 2009

20. Distribuição espacial da média (acima, à esquerda) e da tendência (acima, à direita) da elevação da superfície do mar e seus respectivos desvios padrão, com a remoção dos sinais anual e semianual (abaixo, à esquerda) e apenas para os sinais anual e semianual (abaixo, à direita), no Atlântico Sul e Tropical, para o período de 2003 a 2009

21. Distribuição espacial da média (acima, à esquerda) e da tendência (acima, à direita) da intensidade das correntes em superfície e seus respectivos desvios padrão, com a remoção dos sinais anual e semianual (abaixo, à esquerda) e apenas os sinais anual e semianual (abaixo, à direita), no Atlântico Sul e Tropical, para o período de 2003 a 2009

22. Distribuição espacial da média (acima, à esquerda) e da tendência (acima, à direita) da concentração de clorofila $a$ em superfície e seus respectivos desvios padrão, com a remoção dos sinais anual e semianual (abaixo, à esquerda) e apenas os sinais anual e semianual (abaixo, à direita), no Atlântico Sul e Tropical, para o período de 2003 a 2009

23. Distribuição espacial do coeficiente de correlação entre a clorofila $a$ e intensidade das correntes (à esquerda, acima), elevação do nível do mar (à direita, acima), salinidade (à esquerda, abaixo) e temperatura (à direita, acima), após remoção dos sinais anual e semianual, para o Atlântico Sul e Tropical, no período de 2003 a 2009

24. Distribuição espacial do coeficiente de correlação entre clorofila $a$ e intensidade das correntes (à esquerda, acima) e sua defasagem no tempo (à direita, acima), e entre clorofila $a$ e elevação do nível do mar (à direita, abaixo) e sua defasagem no tempo (à esquerda, abaixo), após remoção dos sinais anual e semianual, para o Atlântico Sul e Tropical, no período de 2003 a 2009

25. Distribuição espacial do coeficiente de correlação entre clorofila $a$ e salinidade (à esquerda, acima) e sua defasagem no tempo (à direita, acima), e entre clorofila $a$ e temperatura (à direita, abaixo) e sua defasagem no tempo (à 56 
esquerda, abaixo), após remoção dos sinais anual e semianual, para o Atlântico Sul e Tropical, no período de 2003 a 2009

26. Séries temporais de clorofila $a$ e de elevação da superfície completas ( ${ }^{\circ}$ gráfico de cima para baixo) e sem os sinais anual e semianual ( $2^{\circ}$ gráfico) e espectros de Fourier para clorofila $a$ ( $3^{\circ}$ gráfico) e elevação de superfície ( $4^{\circ}$ gráfico) sem os sinais anual e semianual, para o ponto $0^{\circ} \mathrm{N}-20^{\circ} \mathrm{W}$

27. Covariância cruzada das séries de clorofila $a$ e de elevação da superfície $\left(1^{\circ}\right.$ gráfico, de cima para baixo), seu respectivo espectro de Fourier ( $2^{\circ}$ gráfico), as defasagens desse espectro ( $3^{\circ}$ gráfico) e a correlação cruzada das séries $\left(4^{\circ}\right.$ gráfico), para o ponto $0^{\circ} \mathrm{N}-20^{\circ} \mathrm{W}$

28. Séries temporais de clorofila $a$ e de elevação da superfície completas $\left(1^{\circ}\right.$ gráfico de cima para baixo) e sem os sinais anual e semianual ( $2^{\circ}$ gráfico) e espectros de Fourier para clorofila $a$ ( $3^{\circ}$ gráfico) e elevação de superfície ( $4^{\circ}$ gráfico) sem os sinais anual e semianual, para o ponto $40^{\circ} \mathrm{S}-20^{\circ} \mathrm{W}$

29. Covariância cruzada das séries de clorofila $a$ e de elevação da superfície $\left(1^{\circ}\right.$ gráfico, de cima para baixo), seu respectivo espectro de Fourier ( $2^{\circ}$ gráfico), as defasagens desse espectro ( $3^{\circ}$ gráfico) e a correlação cruzada das séries $\left(4^{\circ}\right.$ gráfico), para o ponto $40^{\circ} \mathrm{S}-20^{\circ} \mathrm{W}$

30. Séries temporais de clorofila $a$ e de elevação da superfície completas $\left(1^{\circ}\right.$ gráfico de cima para baixo) e sem os sinais anual e semianual ( $2^{\circ}$ gráfico) e espectros de Fourier para clorofila $a\left(3^{\circ}\right.$ gráfico) e elevação de superfície ( $4^{\circ}$ gráfico) sem os sinais anual e semianual, para o ponto $60^{\circ} \mathrm{S}-20^{\circ} \mathrm{W}$

31. Covariância cruzada das séries de clorofila $a$ e de elevação da superfície ( $1^{\circ}$ gráfico, de cima para baixo), seu respectivo espectro de Fourier ( $2^{\circ}$ gráfico), as defasagens desse espectro ( $3^{\circ}$ gráfico) e a correlação cruzada das séries $\left(4^{\circ}\right.$ gráfico), para o ponto $60^{\circ} \mathrm{S}-20^{\circ} \mathrm{W}$

32. Séries temporais de clorofila $a$ e de temperatura da superfície completas $\left(1^{\circ}\right.$ gráfico de cima para baixo) e sem os sinais anual e semianual ( $2^{\circ}$ gráfico) e espectros de Fourier para clorofila $a$ ( $3^{\circ}$ gráfico) e elevação de superfície ( $4^{\circ}$ gráfico) sem os sinais anual e semianual, para o ponto $0^{\circ} \mathrm{N}-20^{\circ} \mathrm{W}$ 
33. Covariância cruzada das séries de clorofila $a$ e de temperatura da superfície $\left(1^{\circ}\right.$ gráfico, de cima para baixo), seu respectivo espectro de Fourier ( $2^{\circ}$ gráfico), as defasagens desse espectro ( $3^{\circ}$ gráfico) e a correlação cruzada das séries ( $4^{\circ}$ gráfico), para o ponto $0^{\circ} \mathrm{N}-20^{\circ} \mathrm{W}$

34. Séries temporais de clorofila $a$ e de temperatura da superfície completas $\left(1^{\circ}\right.$ gráfico de cima para baixo) e sem os sinais anual e semianual ( $2^{\circ}$ gráfico) e espectros de Fourier para clorofila $a$ ( $3^{\circ}$ gráfico) e elevação de superfície ( $4^{\circ}$ gráfico) sem os sinais anual e semianual, para o ponto $40^{\circ} \mathrm{S}-20^{\circ} \mathrm{W}$

35. Covariância cruzada das séries de clorofila $a$ e de temperatura da superfície $\left(1^{\circ}\right.$ gráfico, de cima para baixo), seu respectivo espectro de Fourier ( $2^{\circ}$ gráfico), as defasagens desse espectro ( $3^{\circ}$ gráfico) e a correlação cruzada das séries ( $4^{\circ}$ gráfico), para o ponto $40^{\circ} \mathrm{S}-20^{\circ} \mathrm{W}$

36. Séries temporais de clorofila $a$ e de temperatura da superfície completas $\left(1^{\circ}\right.$ gráfico de cima para baixo) e sem os sinais anual e semianual ( $2^{\circ}$ gráfico) e espectros de Fourier para clorofila $a$ ( $3^{\circ}$ gráfico) e elevação de superfície ( $4^{\circ}$ gráfico) sem os sinais anual e semianual, para o ponto $60^{\circ} \mathrm{S}-20^{\circ} \mathrm{W}$

37. Covariância cruzada das séries de clorofila $a$ e de temperatura da superfície $\left(1^{\circ}\right.$ gráfico, de cima para baixo), seu respectivo espectro de Fourier ( $2^{\circ}$ gráfico), as defasagens desse espectro ( $3^{\circ}$ gráfico) e a correlação cruzada das séries $\left(4^{\circ}\right.$ gráfico), para o ponto $60^{\circ} \mathrm{S}-20^{\circ} \mathrm{W}$

38 Variabilidade latitudinal para a longitude $20^{\circ} \mathrm{W}$ da amplitude do sinal do espectro de Fourier da covariância cruzada entre clorofila $a$ e intensidade das correntes [ a) ] e sua respectiva defasagem no tempo [ b) ], entre clorofila $a$ e elevação do nível do mar [ c) ] e sua defasagem no tempo [ d) ], entre clorofila $a$ e salinidade [ e) ] e sua defasagem [ f) ], e entre clorofila $a$ e temperatura [ g) ] e sua defasagem [ h) ], após remoção dos sinais anual e semianual, para o Atlântico Sul e Tropical, no período de 2003 a 2009 


\section{Lista de Acrônimos}

AVHRR Advanced Very High Resolution Radiometer

BODC British Oceanographic Data Centre

CAS Corrente do Atlântico Sul

CBM Confluência Brasil-Malvinas

CCA Corrente Circumpolar Antártica

CFSR Climate Forecast System Reanalysis

CM Corrente das Malvinas

CNB Corrente Norte do Brasil

cpm Ciclos por mês

CSE Corrente Sul Equatorial

ENOS El Niño - Oscilação Sul

GEBCO General Bathymetric Chart of the Oceans

GSAN Giro Subtropical do Atlântico Norte

GSAS Giro Subtropical do Atlântico Sul

IAG Instituto de Astronomia, Geofísica e Ciências Atmosféricas

IO Instituto Oceanográfico

IOS Índice de Oscilação Sul

MODIS Moderate Resolution Imaging Spectroradiometer

NASA National Aeronautics and Space Administration

NCEP National Center for Environmental Prediction

NOAA National Oceanic and Atmospheric Administration

NODC National Oceanographic Data Center

NOC National Oceanography Center

OAN Oscilação do Atlântico Norte

OCCAM Ocean Circulation and Climate Advanced Model

OSU Oregon State University

PIRATA Operational Pilot Research moored Array in the Tropical Atlantic 
POM Princeton Ocean Model

PPL Produtividade primária líquida

RCA Retroflexão da Corrente das Agulhas

SeaWiFS Sea-viewing Wide Field-of-view Sensor

USP Universidade de São Paulo

WOA World Ocean Atlas 


\section{INTRODUÇÃO}

Nosso conhecimento sobre os oceanos é limitado por sua grande extensão e consequente dificuldade de obtenção de dados in situ. Os desafios práticos para o estudo desse meio provêm justamente da necessidade de se obter dados de maneira contínua, tridimensional e em escalas de tempo e espaço compatíveis com os processos sob estudo (SOUZA, 2005).

Enquanto no passado medições das variáveis oceanográficas só podiam ser feitas por meio de coletas in situ, atualmente os avanços tecnológicos permitem a estimativa dessas variáveis por meio de informações obtidas por sensoriamento remoto ou através da modelagem numérica dos oceanos. Essas ferramentas têm sido constantemente aprimoradas para que seus resultados estejam cada vez mais próximos da realidade.

Os processos físicos nos oceanos ocorrem com certas variabilidades espaço temporais e afetam a dinâmica dos ecossistemas marinhos. Consequentemente, para a conservação e exploração dos ecossistemas, é necessária a correta compreensão dos fenômenos físicos e a forma como a biota responde às suas variabilidades. Dessa forma, para um adequado conhecimento científico dos processos físicos e biológicos nos oceanos e suas interações, é necessário que os dados, como os resultados de modelagem numérica e medições remotas, estejam de acordo com o que é encontrado na natureza e, também, que as informações sejam obtidas em escalas compatíveis com as necessidades do estudo.

\subsection{Modelagem numérica}

A modelagem numérica tem sido cada vez mais utilizada em Oceanografia como um método importante para análises, simulações e previsões da distribuição espaço-temporal de parâmetros hidrodinâmicos e termodinâmicos. Em resumo, esse método consiste na utilização de dados coletados e teorias sobre o comportamento dos oceanos, visando a reprodução e a previsão de diversos processos que neles ocorrem, através da aplicação de modelos matemáticos. 
Segundo O'Brien (1985), os modelos oceânicos são uma aproximação de teorias físicas nas quais muitas vezes simplificações são deliberadamente introduzidas. Como exemplo, temos o Princeton Ocean Model (POM), utilizado neste trabalho. Esse modelo, idealizado em 1977 para ser um modelo de previsão hidrodinâmica em regiões costeiras e estuarinas por Blumberg e Mellor (1987), tem sido largamente utilizado.

O POM é baseado em coordenadas verticais sigma, que considera a profundidade local como uma porcentagem da profundidade total, propiciando a manutenção da resolução vertical em regiões rasas. O uso desse tipo de coordenada vertical é adequado para regiões com grande variação topográfica, pois permite a representação precisa de sua hidrodinâmica. Como exemplos temos estudos em mesoescala, como nas simulações pioneiras de Blumberg e Mellor (1987) para regiões costeiras e também em grande escala, como nos trabalhos de Ezer e Mellor (1994, 1997, 2000) para o Atlântico Norte.

Foi realizada uma implementação do POM por Harari et al. (2005) e Camargo, Harari e França (2006), utilizada em grades de alta resolução para o Atlântico Sul e Tropical e a Plataforma Continental Brasileira, considerando simulações e previsões das circulações geradas por marés, ventos e variações de densidade. Essa versão tem sido utilizada com propósitos científicos e operacionais, permitindo o detalhamento da hidrodinâmica de qualquer subdomínio do Atlântico Sul e Tropical, através do aninhamento de grades, especialmente em regiões costeiras e de plataforma continental.

Para a correta aplicabilidade de um modelo, é necessário que o mesmo seja devidamente validado, através da comparação de seus resultados com medições ou resultados de outros modelos. A validação é parte de um processo que visa indicar a existência de possíveis erros no modelo, para que esse possa ser aperfeiçoado de maneira a aumentar o nível de confiança em sua habilidade de reproduzir os eventos de interesse (WILMOTT, 1981; LEWIS e ALLEN, 2009).

Há diversas fontes de erros em modelos que representam padrões oceânicos de larga escala, dentre elas a baixa resolução da grade, que pode fazer com que feições de mesoescala sejam representadas de forma errônea, ou o modo como são estabelecidas as condições de contorno. Um exemplo é o estudo de Ezer e Mellor (2000) que verificou uma separação irrealista da Corrente do Golfo em observações da distribuição das funções de corrente em simulações, considerando condições de contorno abertas (Figura 1). Condições iniciais ou dados oceanográficos periodicamente assimilados ao modelo, como informações climatológicas ou dados coletados na área de estudo em tempo real, 
também influenciam a confiabilidade das simulações e previsões (CHU, LU e CHEN, 2001).

(A) STREAM FUNC. YEAR 2 (CLOSED BC)

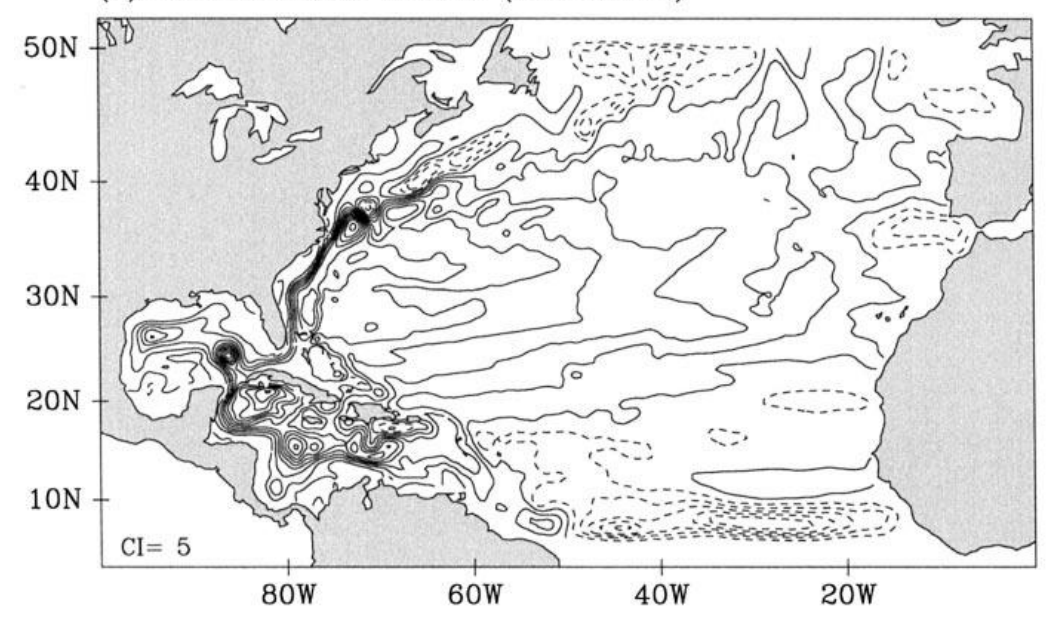

(B) STREAM FUNC. YEAR 2 (OPEN BC)

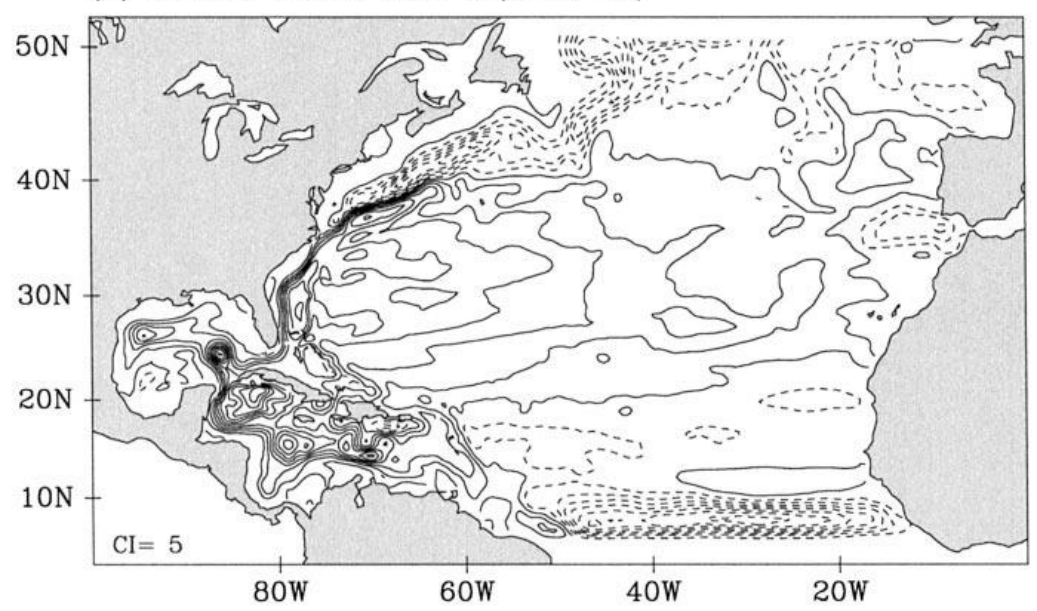

Figura 1: Distribuição da função de corrente em simulação do POM com condiçães de contorno (A) abertas e (B) fechadas, onde nota-se em A separação irrealista da corrente do Golfo (FONTE: Ezer e Mellor, 2000).

Uma boa opção de dados para validação da modelagem hidrodinâmica do Atlântico Tropical encontra-se no Programa Operational Pilot Research moored Array in the Tropical Atlantic (PIRATA), um esforço multinacional de Brasil, França e Estados Unidos para a obtenção de dados meteorológicos e oceanográficos, a partir de bóias fundeadas nessa região. Esse programa foi iniciado em 1997 e é mantido em caráter permanente (BOURLÈS et al., 2008). 
Pereira e Harari (2010) realizaram uma validação inicial da implementação do POM de Camargo e Harari (2001) e Camargo, Harari e França (2006), por meio da comparação entre as temperaturas produzidas pelo modelo hidrodinâmico e as coletadas por boias do Projeto PIRATA. Nessa validação, observou-se um padrão de variabilidade temporal muito semelhante, constatado na ocorrência de altos valores de coeficiente de correlação linear e parâmetro de Wilmott (WILMOTT, 1981) e índices de erros relativamente baixos (Figura 2). Entretanto, a comparação indicou uma subestimação das temperaturas calculadas pelo modelo, com diferenças de até $2,7^{\circ} \mathrm{C}$ e um aparente atraso de fase pelo modelo. Ademais, apesar do padrão sazonal da variabilidade ser reproduzido de maneira satisfatória, flutuações de maior frequência demonstraram diferenças importantes, salientando a necessidade de um estudo desconsiderando essa sazonalidade marcante.

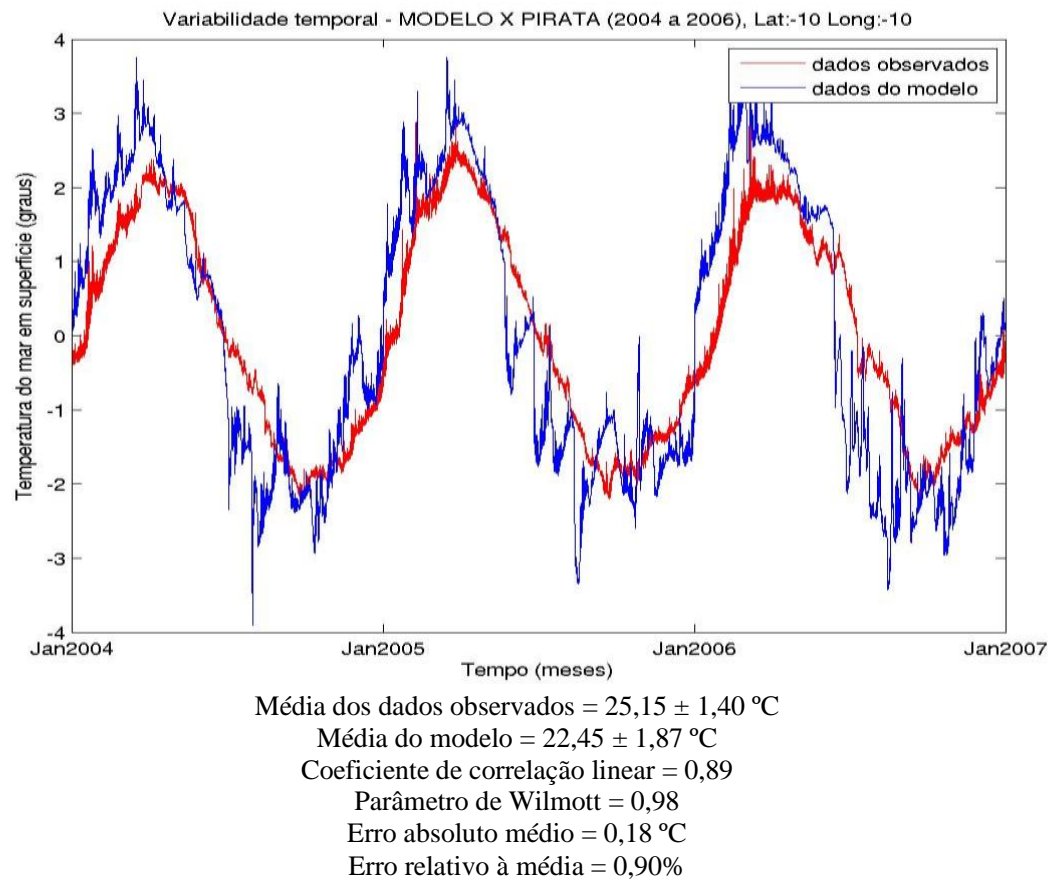

Figura 2: Variabilidade temporal da temperatura resultante de modelagem numérica e de observações, com os parâmetros de validação, para o ponto $10^{\circ} \mathrm{S}-10^{\circ} \mathrm{W}$ (FONTE: Pereira e Harari, 2010). 


\subsection{Sensoriamento remoto e clorofila $a$}

Satélites artificiais são utilizados na obtenção de dados como temperatura da superfície do mar, características das ondas e concentração de clorofila, em modo bidimensional e quase sinótico. Porém, medições in situ possuem importante papel na validação desses dados (METSAMAA e KUTSER, 2008).

A utilização do sensoriamento remoto da cor do oceano no estudo de fenômenos biológicos tem sido cada vez mais frequente. A clorofila $a$, por exemplo, possui um comportamento espectral bem definido, havendo um pico de absorção na faixa do azul. Essas medições remotas têm demonstrado bons resultados, como em estudo realizado por Kampel et al. (2005), onde estimativas das concentrações de clorofila $a$ por sensoriamento remoto (algoritmos do sensor SeaWiFS), quando comparadas a medições in situ na região costeira sudeste brasileira, apresentaram boa consistência.

Atualmente, há uma gama de sensores acoplados a satélites artificiais que são utilizados para estudos de fenômenos terrestres, atmosféricos e oceânicos. Um deles é o sensor Moderate Resolution Imaging Spectroradiometer (MODIS), que é um instrumento chave acoplado aos satélites artificiais Terra (EOS AM) e Aqua (EOS PM) da National Aeronautics and Space Administration (NASA). Esses satélites fazem uma cobertura completa do globo, num período de 2 dias, captando dados em 36 bandas espectrais em resolução moderada (0,25 a 1 km) (ALVALÁ et al., 2006).

A clorofila $a$ está presente em todos os eucariontes fotossintetizantes e nas cianobactérias, sendo que todos os pigmentos de um fotossistema são capazes de absorver fótons, porém, somente um par específico de moléculas de clorofila $a$ pode utilizar a energia da reação fotossintética (RAVEN, EVERT e EICHHORN, 2001). A produção primária consiste na fixação de átomos de carbono do ambiente, através da atividade biológica, sendo que, no ambiente marinho, a maior parte do carbono é incorporada a tecidos vivos através da fotossíntese (PEREIRA e SOARES-GOMES, 2002).

Segundo Pereira e Soares-Gomes (2002) o plâncton é composto por comunidades de organismos com poder de locomoção limitado, sendo assim, transportado passivamente pelas correntes ou demais movimentos d'água. $\mathrm{O}$ fitoplâncton é parte dessa comunidade, constituída, predominantemente, por algas microscópicas autotróficas (que produzem seu próprio alimento, a partir da fixação de 
dióxido de carbono, por meio da fotossíntese) sendo, portanto, considerado produtor primário de matéria orgânica. A partir dessa informação, observa-se que a obtenção de dados sobre a concentração de clorofila $a$ na água do mar possibilita a estimativa da abundância dessa comunidade, uma vez que esse pigmento (ou outras variações próximas) se encontra presente em todas as células de fitoplâncton (SOUZA, 2005).

Segundo Metsama e Kutser (2008), a quantidade de fitoplâncton, usualmente expressa como a concentração de clorofila $a$, é um dos mais importantes parâmetros na descrição de corpos d'água, sendo constatado que a correlação entre dados provenientes do sensor MODIS e resultados de medidas in situ tem sido elevada, como verificado por Carder et al. (2004). Algoritmos utilizados na inferência da concentração de clorofila apresentam resultados relativamente precisos em águas do Caso I (região oceânica). No entanto, muitas vezes, eles falham em águas do Caso II (região costeira ), como mostra estudo de Metsamaa e Kutser (2008) com dados do sensor MODIS para a região do Mar Báltico.

A disponibilidade de nutrientes, radiação solar e a temperatura são fatores limitantes no desenvolvimento do fitoplâncton em regiões oceânicas, sendo processos físicos, como ressurgências, subsidências e turbulências, atuantes no transporte e mistura de nutrientes na coluna d'água (HARRISON e COTA, 1991). Dessa forma, variações nos parâmetros meteorológicos e oceanográficos influenciam na distribuição da clorofila $a$ no oceano. Um exemplo é o fato de que sobre a plataforma continental Sul Americana, que se caracteriza por uma ampliação gradual para sul, há regiões onde ressurgências de águas frias e ricas em nutrientes, ocorrem impulsionadas por ventos sazonais. Isso é um elemento importante na circulação de plataforma e tem como principal impacto o aumento da produtividade biológica como, por exemplo, na região de Cabo Frio (CAMPOS et al., 1995).

Processos físicos, como a ressurgência citada, podem ser detectados pela observação de alterações em variáveis oceânicas como temperatura superficial ou elevação da superfície, podendo-se estabelecer uma relação entre essas variáveis e a variabilidade da clorofila $a$. Garcia et al. (2004) demonstraram haver boa concordância entre variações da clorofila a e de dados físicos, como temperatura da superfície do mar e o nível do mar, sendo o sinal anual predominante. Por exemplo, na região do Mar Negro foi encontrado um valor de correlação entre clorofila e temperatura em superfície de $60 \%$, sendo a compreensão dessa correlação útil, por exemplo, em estudos sobre o impacto de mudanças climáticas na biota marinha (KAVAK e KARADOGAN, 2012). 
A clorofila $a$ possui correlação com a elevação do nível do mar, sugerindo que o aumento das concentrações de clorofila $a$ seria resultante do soerguimento da termoclina, o que aumenta o suprimento de nutrientes para a superfície (WILSON e ADAMEC, 2001). Como exemplo, anomalias negativas do nível do mar (como os que ocorrem em eventos de La Ninã ou vórtices ciclônicos) são associadas com o soerguimento de isopicnais na nutriclina, resultando em aumento da clorofila $a$ (KAHRU, M. et al. 2007). O inverso ocorre em eventos de El Niño e vórtices anticiclônicos, sendo essa relação entre anomalia do nível do mar e clorofila $a$ verificada no campo espectral, com presença de sinais relacionados ao fenômeno de El Niño - Oscilação Sul (ENOS).

\subsection{Justificativa e hipótese do trabalho}

O estudo das relações entre a produção primária e parâmetros abióticos permite a inferência de possíveis relações no comportamento de variáveis oceânicas, fornecendo subsídios para uma melhor manutenção e uso dos recursos marinhos. Como exemplo, pode ser citado um estudo realizado por Harari e Abreu (2007), onde foi observado que há correlações altas entre os recursos pesqueiros desembarcados no Estado de São Paulo e variáveis abióticas.

Dentre as variáveis físicas no mar, a temperatura em superfície destaca-se como importante variável oceânica, pois atua como indicador de distribuição de grande variedade de parâmetros biológicos (TEIXEIRA et al., 2009), dentre elas a clorofila $a$. Seu comportamento também é um importante traçador de processos oceânicos que possuem uma assinatura termal na superfície, além de possuir papel significativo no estudo de interações entre o oceano e a atmosfera.

A utilização de dados físicos no oceano provenientes de modelos numéricos hidrodinâmicos requer a devida calibração e validação desses modelos. Dessa forma, é necessário que sejam feitas as correções e os aperfeiçoamentos dos modelos, visando sua utilização plena e quantificando os desvios entre as saídas dos modelos e medições independentes. Somente após esta etapa a análise dos fatores que afetam as distribuições das correlações entre parâmetros biológicos e físicos pode ser feita de maneira adequada.

Assim, o presente trabalho adota as seguintes hipóteses: 
- O modelo implementado representa de maneira realística padrões de comportamento das variáveis físicas (temperatura, salinidade, elevação da superfície livre e intensidade das correntes) encontrados na natureza;

- Os parâmetros físicos apresentam correlação significativa com a clorofila $a$, mesmo com a remoção dos sinais anual e semianual; sendo assim, a temperatura do mar na superfície se correlaciona com a variação da clorofila $a$, num padrão espacial específico no Atlântico Sul e Tropical, de maneira mais evidente que os demais parâmetros. 


\section{OBJETIVOS}

O projeto em questão possui como principal objetivo:

- Determinar padrões de variação espacial das correlações entre a clorofila $a$ e parâmetros físicos oceânicos provenientes de modelagem numérica, como temperatura da superfície do mar e elevação da superfície no Oceano Atlântico Sul e Tropical.

Dessa forma, para alcançar esse objetivo principal, foram considerados alguns objetivos específicos:

- Calibrar o modelo numérico hidrodinâmico utilizado, com base nos dados de boias fundeadas do PIRATA;

- Validar o modelo utilizado, por meio de comparação estatística entre os resultados do modelo e os dados de boias fundeadas do PIRATA e dados provenientes de sensoriamento remoto;

- Verificar a assinatura da sazonalidade, tanto nas variáveis físicas analisadas como na clorofila $a$, observando-se o desvio padrão do sinal anual e semianual;

- Comparar os dados produzidos pelo modelo com clorofila $a$, focando a variabilidade espacial das correlações e covariâncias cruzadas para as diferentes variáveis físicas consideradas. 


\section{3. ÁREA DE ESTUDO}

A área sob estudo nesse projeto é o Oceano Atlântico Sul e Tropical, compreendendo as longitudes de $70^{\circ} \mathrm{W}$ a $25^{\circ} \mathrm{E}$ e as latitudes de $85^{\circ} \mathrm{S}$ a $30^{\circ} \mathrm{N}$, cuja distribuição batimétrica é mostrada na figura 3. Sua fisiografia é destacada pela presença da Dorsal Mesoatlântica. Além dessa, destacam-se as formações de mesma zona de fratura, o Elevado Rio Grande e a Cadeia Walvis (KUMAR, 1979), bem como o Arco da Scotia, que contém relevos positivos da cordilheira andina e estruturas ao norte da Península Antártica (CANALS et al., 1992). A plataforma continental com extensão significativa no Sul do continente americano também se destaca.

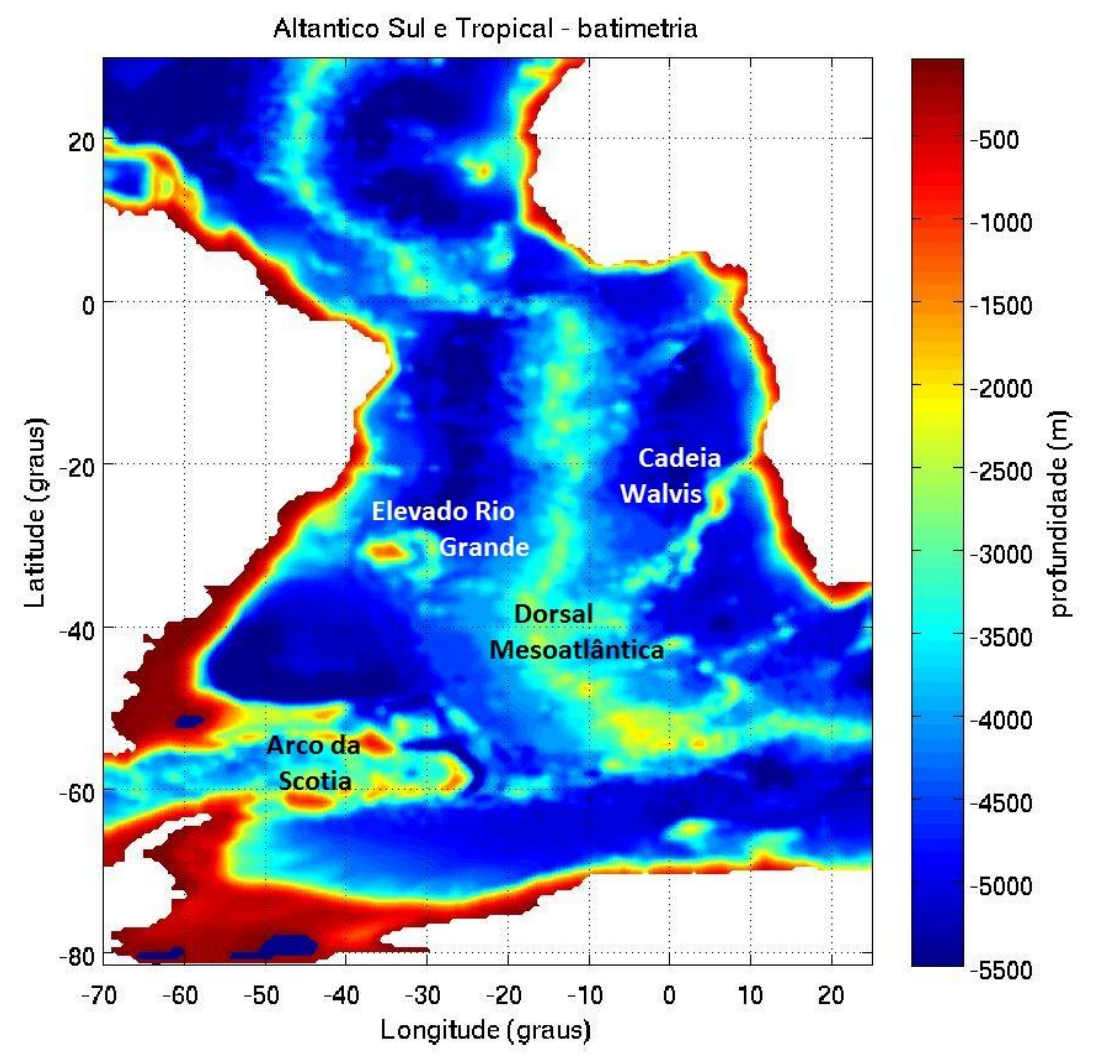

Figura 3: Área de estudo - Oceano Atlântico Sul e Tropical.

Essa região é caracterizada por feições e eventos em escala de bacia oceânica de grande relevância, como o Giro Subtropical do Atlântico Sul, a Confluência BrasilMalvinas e fenômenos atmosféricos de grande interesse, como a Zona de Convergência 
do Atlântico Sul e a Zona de Convergência Intertropical. A interação entre esses fenômenos atmosféricos e oceânicos compõe um sistema complexo que rege o clima na região.

O Oceano Atlântico Sul possui um sistema complexo de correntes superficiais (FIGURA 4), caracterizado pela presença de um giro anticiclônico forçado, principalmente, pelo vento. Associado a esse giro encontra-se, a oeste, a Corrente do Brasil que se origina da bifurcação da Corrente Sul Equatorial (ao norte, na região equatorial) e flui para sul, percorrendo a costa brasileira onde forma a confluência com a Corrente das Malvinas e se afasta da costa, dando origem à Corrente do Atlântico Sul (CIRANO et al., 2006). Esta flui para leste e deflete para norte ao encontrar a corrente das Agulhas ao sul do continente africano, formando a Corrente de Benguela que vai de encontro à Corrente Sul Equatorial.

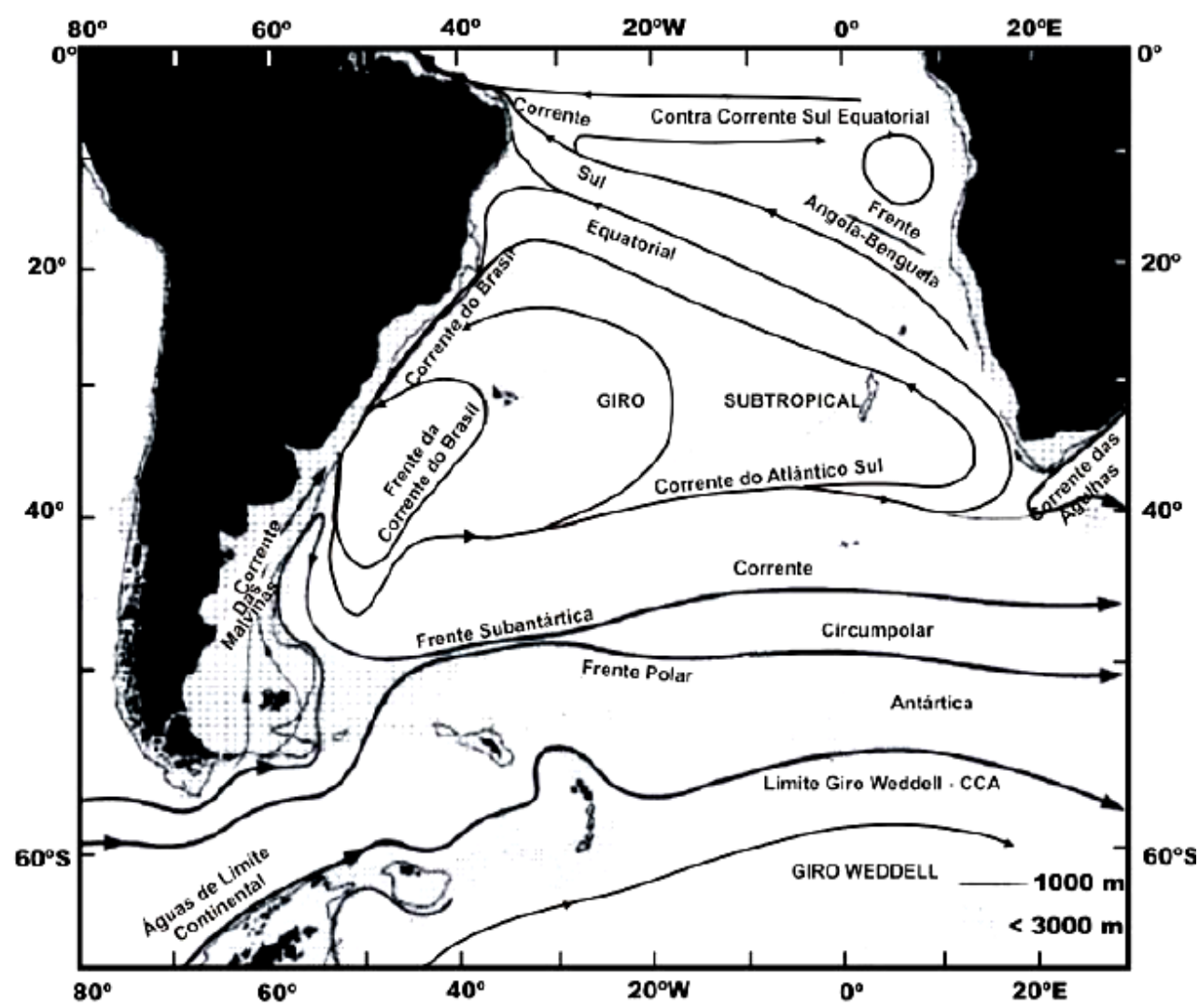

Figura 4: Representação esquemática do Giro Subtropical do Atlântico Sul. (fonte: Cirano et al., (2006), adaptado de Peterson e Stramma (1991)). 
A bifurcação da Corrente Sul Equatorial gera, também, a Corrente Norte do Brasil que flui em direção ao Equador. À nordeste do Giro Subtropical do Atlântico Sul encontra-se a Frente Angola-Benguela e, ao norte desta, se tem o giro ciclônico subequatorial, o Giro de Angola, associado a uma região de ressurgência na costa africana. Complementando a circulação de superfície do Atlântico Sul, ao sul do giro subtropical, encontra-se a Corrente Circumpolar Antártica.

Uma feição importante, ocorrente ao Sul do continente africano, é a Retroflexão da Corrente das Agulhas (RCA) por conta das trocas interoceânicas de massas d'água que ocorrem nessa região (PETERSON e STRAMMA,1991). Outra é a confluência entre as correntes do Brasil e das Malvinas ao longo da margem continental da América do Sul formando um padrão complexo de meandros e vórtices (GORDON, 1989).

Nas regiões sul e tropical do Oceano Atlântico há uma grande variabilidade sazonal das correntes superficiais e das regiões de ressurgência (STRAMMA e SCHOTT, 1999), que pode ser verificada na Figura 5 e, também, de salinidade e temperatura, às quais podem ser relacionadas variações de forçantes atmosféricas (como vento e radiação solar) que também apresentam variabilidade de caráter sazonal significativa (BAPTISTA, 2000).

As variabilidades dos sistemas de correntes e dos campos de temperatura, salinidade e densidade no Atlântico Sul e Tropical podem induzir variações das respostas biológicas, o que torna seu estudo de grande relevância nas ciências do mar.

Pereira e Harari (2010) observaram distribuições de concentração de clorofila $a$ e produtividade primária líquida (PPL) na região (provenientes de dados do sensor MODIS), verificando valores elevados nas regiões costeiras, especialmente próximo à foz de grandes rios e em regiões de ressurgência e confluência de correntes, com marcante variação sazonal. As variáveis físicas apresentaram altos valores de correlação cruzada com clorofila $a$ e PPL, com distribuição de caráter fortemente latitudinal e variabilidade no tempo da resposta biológica (FIGURA 6), valor esse, porém, muito influenciado pela alta sazonalidade dos parâmetros físicos. 


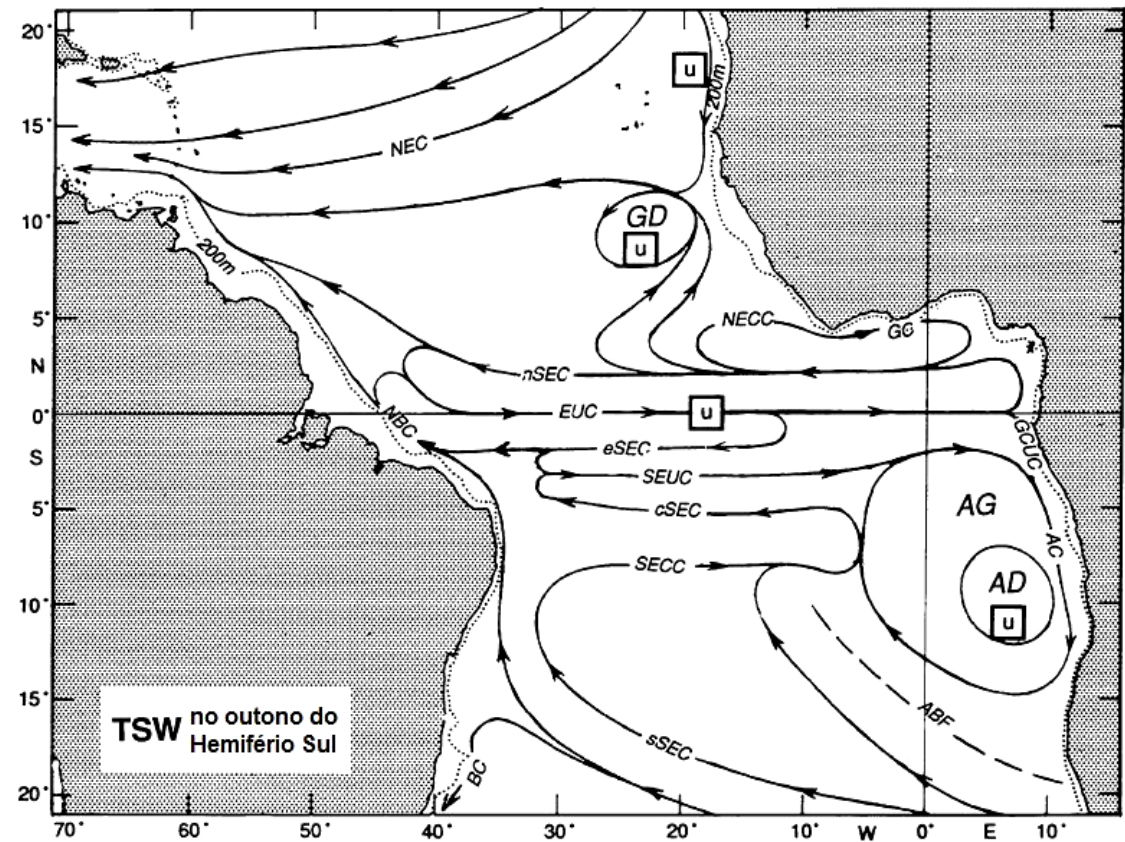

(a)

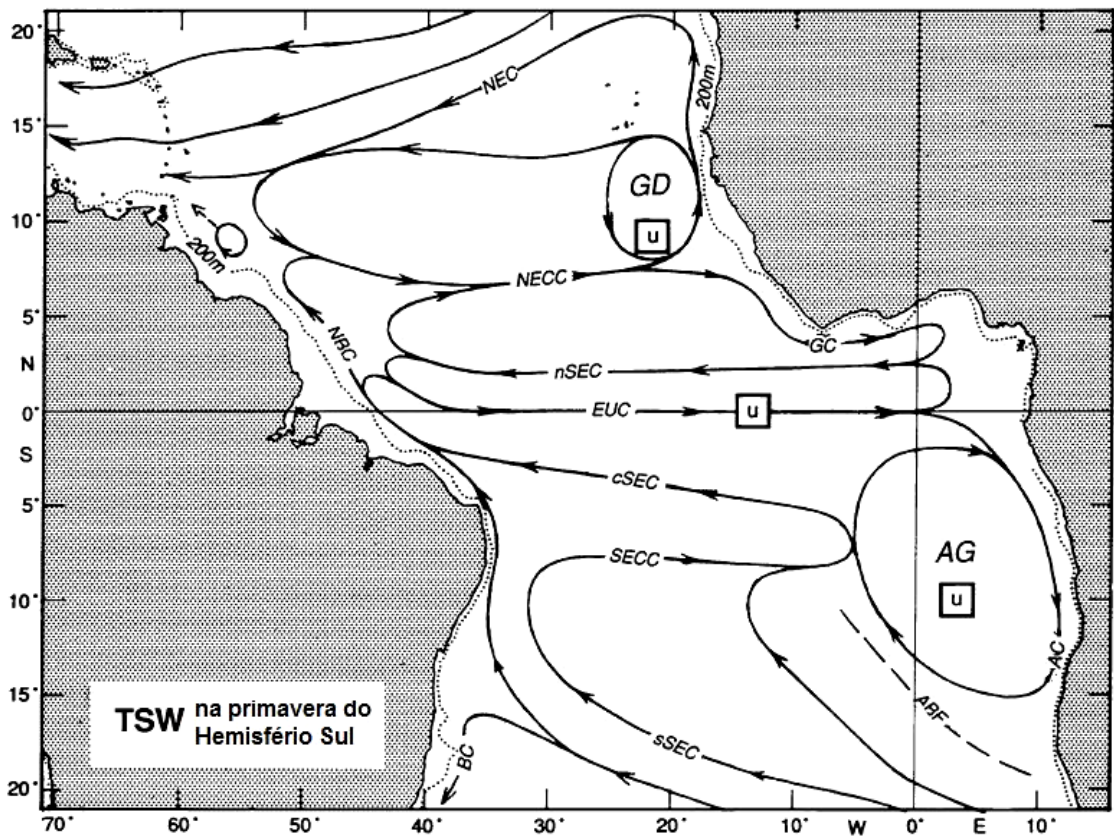

(b)

Figura 5: Distribuição horizontal das principais correntes da Água Superficial Tropical (TSW: 0-100m) para (a) outono e (b) primavera do Hemisfério Sul (Pereira (2009). Siglas em inglês: Água Tropical Superficial (TSW), Corrente Norte Equatorial (NEC), Domo da Guiné (GD), Contracorrente Norte Equatorial (NECC), Corrente da Guiné (GC), Corrente Sul Equatorial (SEC) e seus ramos Norte (nSEC), Equatorial (eSEC), Central (cSEC) e Sul (sSEC), Corrente Subsuperficial Equatorial (EUC), Corrente

Norte do Brasil (NBC), Corrente Subsuperficial Gabão-Congo (GCUC), Giro de Angola (AG), Corrente de Angola (AC), Domo de Angola (AD), Contracorrente Sul Equatorial (SECC) e Corrente do Brasil (BC). A Frente Angola-Benguela (ABF) é representada com uma linha pontilhada. O símbolo u em um quadrado indica as possíveis áreas de ressurgência (não seus locais exatos) - adaptado de Stramma e 

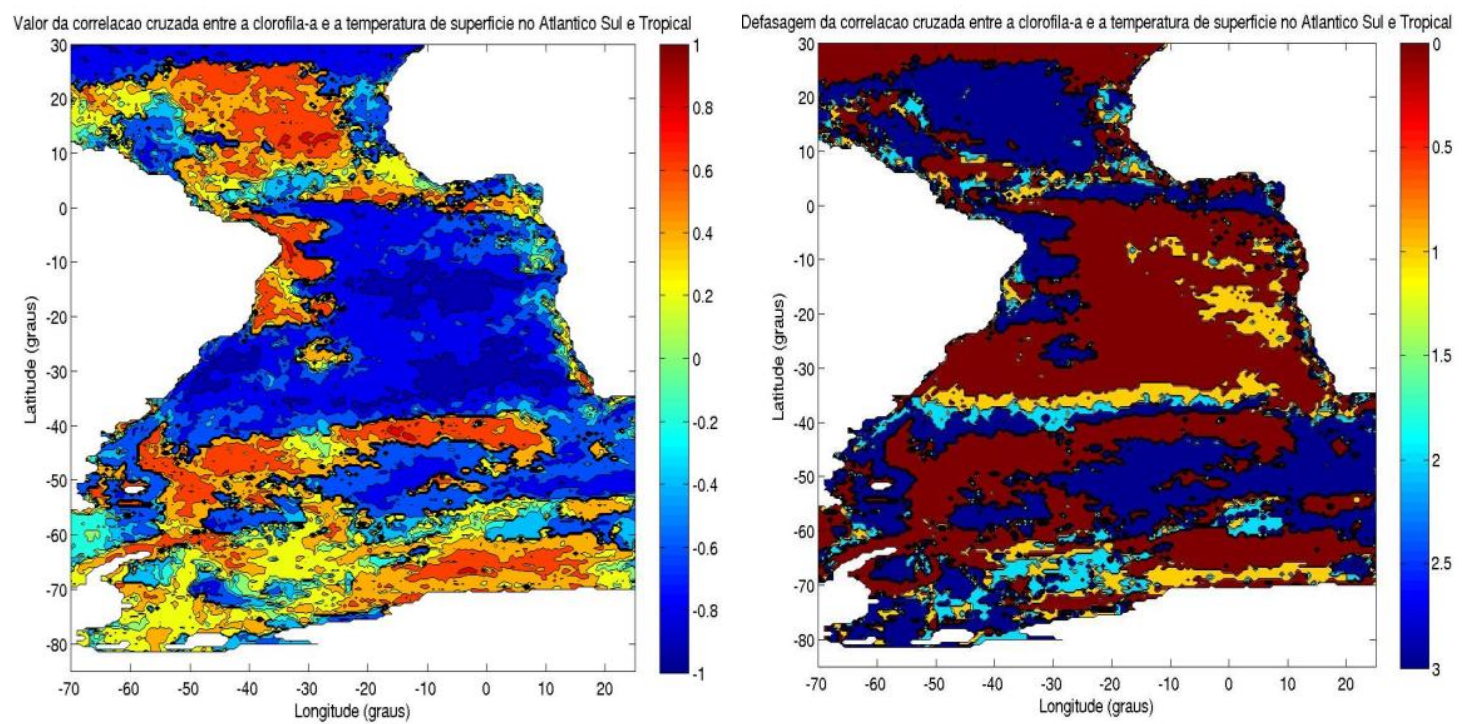

Figura 6: Distribuições das correlações cruzadas (à esquerda) e suas defasagens em meses (à direita) da clorofila $a$ com a temperatura do mar, no Oceano Atlântico Sul e Tropical (Fonte: Pereira, 2009). 


\section{METODOLOGIA}

\subsection{O modelo numérico hidrodinâmico e sua calibração}

O modelo hidrodinâmico utilizado é uma versão do Princeton Ocean Model (POM), escrito por Blumberg e Mellor (1987), otimizada e descrita por Harari et al. (2005), cujos resultados operacionais encontram-se disponíveis no endereço eletrônico: http://master.iag.usp.br/ind.php?inic=00\&prod=ondas .

O POM é um modelo tridimensional que considera a superfície livre e resolve um conjunto de equações primitivas do movimento tridimensionais não lineares, discretizadas pelo método de diferenças finitas e que utiliza separação de modos. É por meio dessa separação de modos que o transporte de volume (modo externo) e o cisalhamento da velocidade na vertical (modo interno) são resolvidos separadamente, economizando tempo de computação.

As equações hidrodinâmicas completas são escritas na forma de fluxo e são consideradas as aproximações de Boussinesq e hidrostática. São considerados, também: um fechamento turbulento de segunda ordem para os coeficientes de viscosidade e difusão vertical; parametrização de Smagorinsky para viscosidade e difusão horizontal; utilização de esquema de leapfrog para integração no tempo e horizontal no espaço; e integração com esquema implícito na vertical. Para o esquema de diferenciação espacial, o modelo usa uma grade alternada do tipo C de Arakawa, apropriada para modelos de alta resolução (menos de $50 \mathrm{Km}$ de resolução espacial).

Foi realizada uma análise dos desvios das previsões do modelo em relação a medições do projeto PIRATA, com base em trabalho realizado por Pereira \& Harari (2010) e outros.

\subsubsection{Condições iniciais e de contorno}

O modelo foi processado para uma simulação de 31 anos (inicio de 1979 a fim de 2009), sendo descartado o primeiro (de modo a se evitar a influência de condições iniciais de repouso). A grade horizontal foi configurada com resolução horizontal de 
$0,5^{\circ}$ em longitude e latitude, e resolução vertical de 22 níveis sigma $(\sigma)$ de espessura variada, estando as 8 primeiras com pouco mais de $10 \%$ da profundidade (tabela 1).

O potencial de maré foi incluído nos processamentos e todos os resultados do modelo foram filtrados a cada passo de tempo, com médias de 5 pontos, de modo a eliminar ruídos. As condições de contorno para as correntes foram fixadas como não gradientes. As demais condições de borda foram parcialmente fixadas como radiacionais, com borda dupla para marés, sendo que a condição de contorno de marés nas bordas foi parcialmente fixada com período de restauração equivalente ao passo de tempo baroclínico.

Tabela 1: Valores considerados como níveis $\sigma$.

\begin{tabular}{c|c}
\hline \hline Níveis $\boldsymbol{\sigma}$ & Valores \\
\hline \hline 1 & 0,0000 \\
\hline 2 & $-0,0017$ \\
\hline 3 & $-0,0035$ \\
\hline 4 & $-0,0069$ \\
\hline 5 & $-0,0139$ \\
\hline 6 & $-0,0278$ \\
\hline 7 & $-0,0556$ \\
\hline 8 & $-0,1111$ \\
\hline 9 & $-0,2222$ \\
\hline 10 & $-0,3333$ \\
\hline 11 & $-0,4444$ \\
\hline \hline
\end{tabular}

\begin{tabular}{c|c}
\hline \hline Níveis $\boldsymbol{\sigma}$ & Valores \\
\hline \hline 12 & $-0,5555$ \\
\hline 13 & $-0,6666$ \\
\hline 14 & $-0,7777$ \\
\hline 15 & $-0,8888$ \\
\hline 16 & $-0,9443$ \\
\hline 17 & $-0,9720$ \\
\hline 18 & $-0,9859$ \\
\hline 19 & $-0,9928$ \\
\hline 20 & $-0,9963$ \\
\hline 21 & $-0,9981$ \\
\hline 22 & $-1,0000$ \\
\hline \hline
\end{tabular}

$\mathrm{Na}$ tabela a seguir são descritas algumas das condições as quais o modelo foi configurado para o inicio de seu processamento: 
Tabela 2: Parâmetros iniciais utilizados no modelo.

\begin{tabular}{l|c}
\hline \multicolumn{1}{c|}{ Parâmetros do modelo } & Valores \\
\hline \hline Passo de tempo interno (integração) & 1800 s (baroclínico) \\
\hline Passo de tempo externo (integração) & 30 s (barotrópico) \\
\hline Coeficiente de relaxação para temperatura do mar em superfície climatológica & $100 \mathrm{~W} / \mathrm{m}^{2} / \mathrm{K}$ \\
\hline Constante na difusividade horizontal de Smagorinsky & 0,08 \\
\hline Valor inicial do coeficiente de difusão de Smagorinsky & 100 \\
\hline Inverso da difusividade horizontal do número de Prandtl & 1 \\
\hline Coeficiente de relaxação dos cálculos do modelo (para todos os níveis $\sigma)$ & $10^{-3}$ \\
\hline Interpolador (constante no tempo) & 0,8 \\
\hline \hline
\end{tabular}

O valor dado ao interpolador (Tabela 2) equivale ao peso atribuído ao ponto central, no processo de médias espaciais. Esse interpolador tem o objetivo de suavizar possíveis instabilidades numéricas, sendo esse peso fixado com valor constante no tempo.

\subsubsection{Dados de entrada}

Os dados batimétricos utilizados no modelo são provenientes da General Bathymetric Chart of the Oceans (GEBCO). Esses dados são disponibilizados pelo British Oceanographic Data Centre (BODC) no endereço eletrônico:

https://www.bodc.ac.uk/data/online_delivery/gebco/ .

As forçantes de nível médio do mar nas bordas são inseridas no modelo em intervalos de $24 \mathrm{~h}$, sendo correspondentes a médias climatológicas (interpoladas para cada dia do ano) do modelo global Ocean Circulation and Climate Advanced Model (OCCAM), do National Oceanography Center (NOC), Southampton, no endereço eletrônico:

http://www.noc.soton.ac.uk/JRD/OCCAM/EMODS/.

As constantes harmônicas de maré, nos contornos abertos, provêm do modelo TPXO7.1, versão do modelo oceânico de marés que utiliza dados altimétricos 
provenientes da missão TOPEX/POSEIDON (EGBERT et al., 1994). Esses dados encontram-se disponíveis no endereço eletrônico:

http://volkov.oce.orst.edu/tides/global.html .

Os dados de temperatura e salinidade climatológica anual são inseridos no modelo no instante inicial, a cada ponto de grade, nos níveis sigma de cada coluna. Esses dados foram, também, utilizados na relaxação dos resultados do modelo, com ponderação de $10^{-3}$. As condições de contorno de temperatura e salinidade, consideradas como médias climatológicas mensais, são inseridas mensalmente no modelo, no inicio de cada mês e mantidas constantes no decorrer do mês. Dados de temperatura e salinidade nas descargas de rios são inseridos em três dimensões como médias climatológicas anuais. Todos os dados de temperatura e salinidade, acima descritos, são provenientes do World Ocean Atlas (WOA) em sua versão 2008 (WOA08), sendo disponibilizados pelo National Oceanographic Data Center (NODC) da National Oceanic and Atmospheric Administration (NOAA) no endereço eletrônico: http://www.nodc.noaa.gov/OC5/SELECT/woaselect/woaselect.html .

Foram, também, inseridos nos processamentos do modelo dados de superfície de temperatura e salinidade, em intervalos de 6h, obtidos pelo Climate Forecast System Reanalysis (CFSR). Esses dados são descritos por Saha et al. (2010), os quais se encontram disponibilizados pelo National Center for Environmental Prediction (NCEP) da NOAA, no endereço eletrônico:

http://nomads.ncdc.noaa.gov/data.php\#cfs-reanal .

Foram, também, utilizados dados de fluxos de calor na superfície (ondas longas, ondas curtas, sensível e latente, em intervalos de 3 horas) e dados das componentes zonal e meridional do vento a $10 \mathrm{~m}$ de altura (em intervalos de $1 \mathrm{~h}$ ). Esses dados constituem resultados da reanálise da previsão operacional do modelo atmosférico global do National Center for Environmental Prediction (NCEP)/National Center for Atmospheric Research (NCAR), descrito por Kalnay et al. (1996) e disponibilizado pelo Earth System Research Laboratory (ESRL) da NOAA, no endereço eletrônico:

http://www.esrl.noaa.gov/psd/data/gridded/data.ncep.reanalysis.html .

Fluxos de sal na superfície foram calculados a partir dos resultados de fluxos pela interface ar-mar do modelo do NCEP / NCAR, sendo renovados a cada $3 \mathrm{~h}$ de processamento do modelo hidrodinâmico. 


\subsection{Dados de clorofila $a$}

Os dados biológicos utilizados nesse trabalho são de distribuição horizontal da concentração de clorofila $a$ e baseiam-se em algoritmo de distribuição lognormal descrito por CAMPBELL (1995). Esses dados são provenientes de sensoriamento remoto, através do sensor (MODIS), em resolução espacial de 0.5 graus de latitude e longitude e resolução temporal de 8 dias. Foram utilizados, no presente trabalho, os dados referentes ao período completo de 2003 a 2009 (7 anos), em médias de 8 dias, com interpolações para pontos sem dados devido à cobertura de nuvens. Esses dados são produtos de nível 3, disponibilizados pela Oregon State University (OSU) em sua base de dados de produtividade oceânica, que se encontra no endereço eletrônico: http://www.science.oregonstate.edu/ocean.productivity/ .

\subsection{Validação do modelo}

Os dados utilizados para a validação do modelo hidrodinâmico são provenientes de boias fundeadas na região tropical do Oceano Atlântico pelo projeto PIRATA, descrito por Bourlès et al. (2008) e disponibilizados no endereço eletrônico: http://www.pmel.noaa.gov/data_deliv . Foram utilizados os dados referentes ao período de 1997 a 2009.

A validação do modelo foi feita por meio de comparação estatística entre os dados do PIRATA e as saídas do modelo nas simulações consideradas, sendo essas especificadas na próxima seção. Essas análises foram efetuadas para os dados de temperatura das boias, cuja localização se encontra na Figura 7, sendo utilizadas series temporais para a superfície e perfis (com resolução temporal de $1 \mathrm{~h}$ reduzidos a médias mensais). O critério para a escolha dos pontos foi a maior resolução temporal dos dados, aliado a uma menor quantidade de interrupções nas séries temporais.

Foram também utilizados na validação da modelagem os dados de temperatura em superfície provenientes do sensor MODIS, numa resolução espacial de 0.5 graus de latitude e longitude e numa resolução temporal de 8 dias, sendo considerados no presente trabalho os do período de 2003 a 2009 (7 anos completos, com médias de 8 
dias). Esses dados são disponibilizados pela Oregon State University (OSU) em sua base de dados de produtividade oceânica, no endereço eletrônico:

http://www.science.oregonstate.edu/ocean.productivity/ .

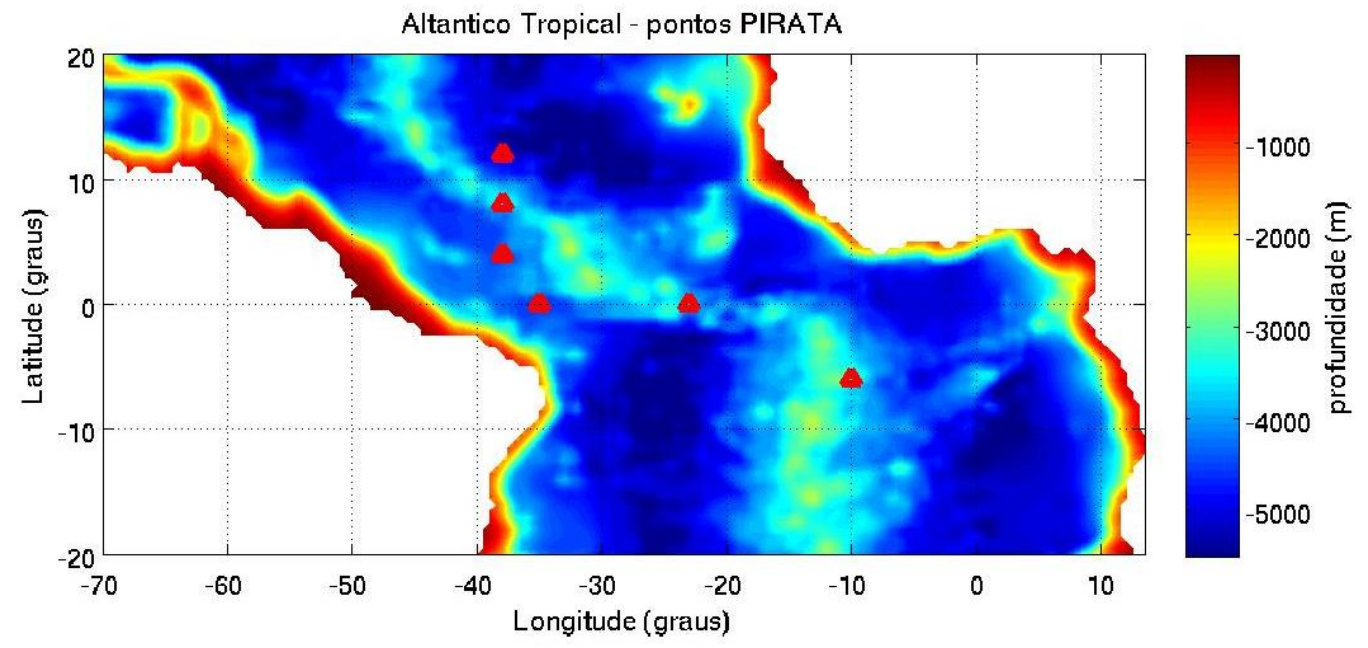

Figura 7: Localização das boias do projeto PIRATA com dados utilizados na validação do modelo hidrodinâmico, assinalados com triângulos vermelhos.

\subsection{Processamento dos dados}

Para a comparação entre os parâmetros físicos e biológicos, todos os dados oceanográficos físicos (provenientes de modelagem numérica) e clorofila $a$ (originários de sensoriamento remoto) serão referentes ao período de janeiro de 2003 a dezembro de 2009 , na forma de médias semanais, para as longitudes de $70^{\circ} \mathrm{W}$ a $25^{\circ} \mathrm{E}$ e as latitudes de $85^{\circ} \mathrm{S}$ a $30^{\circ} \mathrm{N}$, interpolados para intervalos de $0.5^{\circ} \times 0.5^{\circ}$, em latitude e longitude. Como as saídas do modelo foram obtidas em intervalos de $6 \mathrm{~h}$, seus resultados foram reorganizados em médias de 8 dias, para comparação com as séries temporais de clorofila $a$, nas mesmas posições de pontos de grade do modelo hidrodinâmico. 


\subsubsection{Estatística básica}

As médias referentes ao período de análise de cada variável $x_{i}(1)$ e seus respectivos desvios padrão em relação à média (2), para $N$ dados que compõem uma série temporal, foram calculados segundo Vuolo (1992):

$$
\begin{gathered}
\bar{x}=\frac{1}{N} \sum_{i=1}^{N} x_{i} \\
\sigma=\sqrt{\frac{1}{N} \sum_{i=1}^{N}\left(x_{i}-\bar{x}\right)^{2}}
\end{gathered}
$$

Para prevenção de erros, devidos a valores discrepantes nas séries temporais de clorofila $a$ e temperatura em superfície provenientes do sensor MODIS, foi realizada a remoção de dados com valores em módulo superiores a três vezes o desvio padrão das séries, os quais foram substituídos através de interpolação linear simples no tempo.

Foi aplicado o método de mínimos quadrados para a obtenção de tendência e sinais anual e semianual das séries, onde foi formulado um modelo linear de estimativa (3) em termos matriciais (EMERY e THOMSON, 2001).

$$
y_{i}=b_{0}+b_{1} X_{i 1}+\ldots+b_{k} X_{i k}
$$

Podem ser feitas $N$ observações independentes de $Y\left(y_{1}, y_{2}, \ldots, y_{N}\right)$, sendo essas descritas na forma matricial por (4), com solução em (5):

$$
\begin{gathered}
Y=\left(\begin{array}{l}
y_{1} \\
y_{2} \\
\ldots \\
y_{N}
\end{array}\right), \quad B=\left(\begin{array}{l}
b_{0} \\
b_{1} \\
\ldots \\
b_{k}
\end{array}\right) \text { e } \quad X=\left(\begin{array}{cccc}
x_{0} & x_{11} & \ldots & x_{1 k} \\
x_{0} & x_{21} & \ldots & \ldots \\
\ldots & \ldots & \ldots & \ldots \\
x_{0} & x_{N 1} & \ldots & x_{N k}
\end{array}\right) \\
Y=B . X \quad \rightarrow \quad X^{\prime} . Y=B .\left(X^{\prime} X\right) \quad \rightarrow \quad B=\left(X^{\prime} X\right)^{-1} X^{\prime} . Y
\end{gathered}
$$


Nesse caso específico, para se conseguir uma reta de ajuste a uma solução ondulatória com período $(T)$, se tem como modelo:

$$
\begin{gathered}
y=b_{0}+b_{1} \cdot t+b_{3} \cdot \sin (\omega \cdot t)+b_{4} \cdot \cos (\omega \cdot t) \\
Y=\left(\begin{array}{l}
y_{1} \\
y_{2} \\
\ldots \\
y_{N}
\end{array}\right) \quad, \quad B=\left(\begin{array}{l}
b_{0} \\
b_{1} \\
b_{3} \\
b_{4}
\end{array}\right) \quad \mathrm{e} \quad X=\left(\begin{array}{cccc}
1 & t_{1} & \sin \left(\omega \cdot t_{1}\right) & \cos \left(\omega \cdot t_{1}\right) \\
1 & t_{2} & \sin \left(\omega \cdot t_{2}\right) & \cos \left(\omega \cdot t_{2}\right) \\
\ldots & \ldots & \ldots & \ldots \\
1 & t_{N} & \sin \left(\omega \cdot t_{N}\right) & \cos \left(\omega \cdot t_{N}\right)
\end{array}\right)
\end{gathered}
$$

Sendo $\omega=\frac{2 . \pi}{T}$ a frequência angular, $b_{0}$ o coeficiente angular da reta de ajuste, $b_{1}$ o coeficiente linear da reta de ajuste, b3 e $b 4$ os coeficientes relacionados respectivamente às senóides e cossenóides de ajuste e $t_{N}$ um instante de tempo determinado. A seguir, a Figura 8 mostra o resultado da subtração de sinal anual e cálculo da tendência linear, como explicado acima.
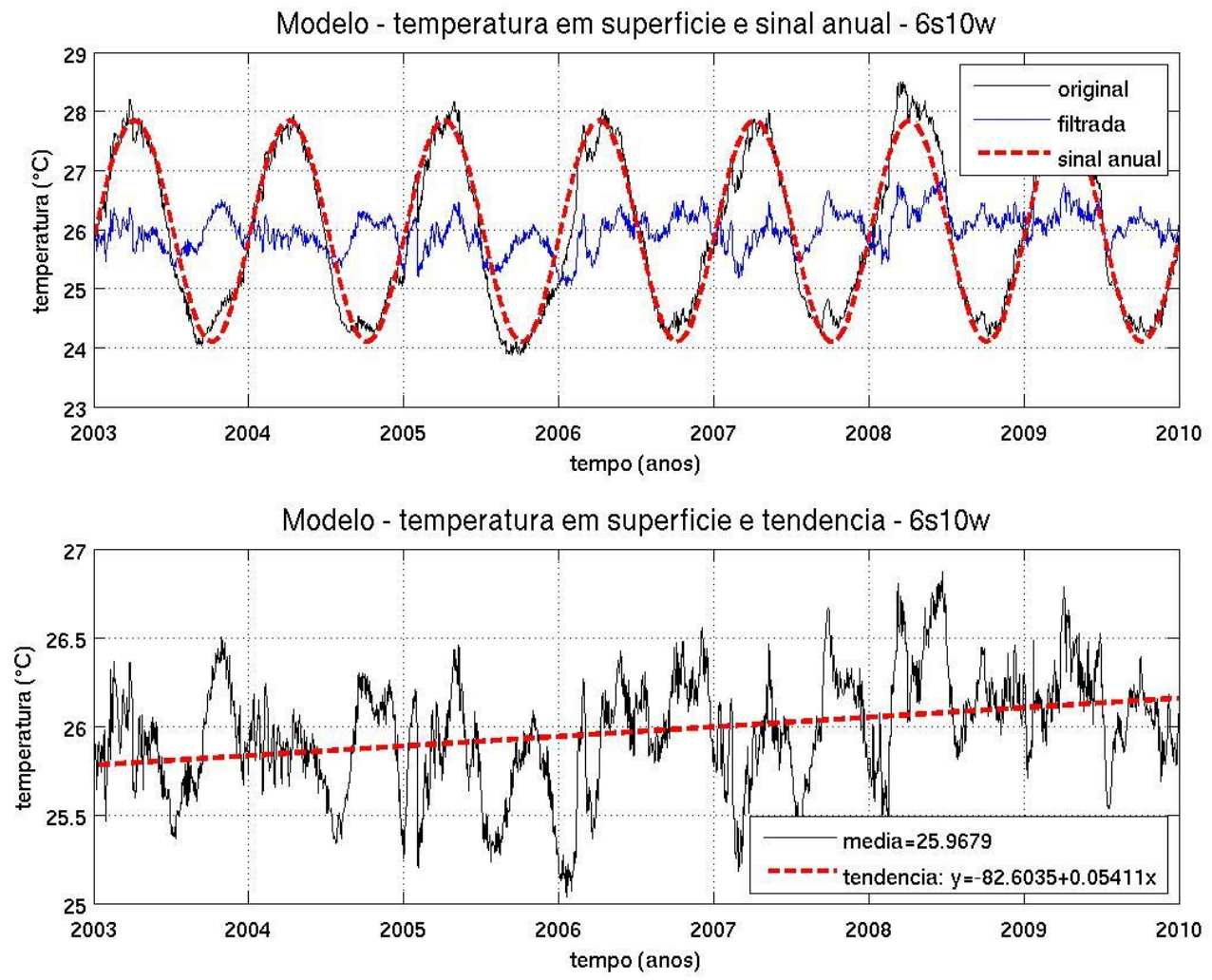

Figura 8: Exemplo de remoção do sinal anual e da tendência de uma série de temperatura. 


\subsubsection{Correlações}

Para o calculo das correlações foram removidos os sinais anual e semianual para que esses, uma vez que são bem conhecidos, não interfiram nos resultados das análises, superestimando as correlações. As tendências lineares também foram previamente removidas das séries.

Para a realização das comparações entre os parâmetros físicos e clorofila $a$, foram calculadas as correlações cruzadas relativas os períodos de análise, entre a clorofila $a$ e as variáveis físicas. As funções de covariância e correlação cruzada são utilizadas para examinar as relações entre diferentes séries no domínio do tempo. A base matemática para esses cálculos é fornecida a seguir (SPIEGEL, 1992), por meio das definições de média (1) e desvio padrão (2) de uma série e a covariância entre séries X e $\mathrm{Y}$, que pode ter deslocamentos no tempo h (defasagens no tempo ou "lags", $h=\ldots,-2$, $1,0,1,2, \ldots$ meses) $(8)$.

$$
\operatorname{cov}(X, Y, h)=\sum_{i=1}^{N} \frac{\left(x_{i+h}-\bar{x}\right)\left(y_{i}-\bar{y}\right)}{N}
$$

Os cálculos dos coeficientes de correlação linear entre séries são feitos considerando as defasagens, no tempo, entre as séries ("lags") $h$ (9).

$$
\operatorname{cor}(X, Y, h)=\frac{\operatorname{cov}(X, Y, h)}{\sigma_{x} \sigma_{y}}
$$

O coeficiente de correlação sugere a dependência linear dos dados comparados, uma vez que os valores indicam o grau de dispersão dos mesmos em torno de uma função de ajuste que, no caso da correlação linear, equivale a uma reta. Os valores oscilam entre 1 e -1 , sendo que valores próximos de zero indicam que as variáveis em questão não estão relacionadas. Esse parâmetro estima a interdependência linear de duas séries, onde valores positivos altos indicam um comportamento similar das variáveis, enquanto valores fortemente negativos indicam um comportamento oposto. 


\subsubsection{Espectro de Fourier}

Para a análise de Fourier das séries temporais, primeiramente foram removidas as médias e tendências das séries segundo Emery e Thomson (2001). Quando a média e a tendência da série não são removidos anteriormente à execução da análise espectral, elas podem distorcer as componentes de baixa frequência do espectro. Ademais, foram também removidos os sinais anual e semianual, tendo em vista seu alto valor de amplitude do sinal nas séries, o que dificultaria a observação dos sinais para os demais períodos nos resultados das comparações.

No campo das frequências, a Transformada de Fourier de uma série temporal $f(t)$ é definida como (10):

$$
\Phi\left(\omega_{n}\right)=\frac{1}{\sqrt{2 \pi}} \sum_{t} f(t) e^{-i \omega_{n} t}
$$

Onde $\omega_{n}$ e $T_{n}$ são definidos a partir do período de observação $T$.

$$
\begin{gathered}
\omega_{n}=\frac{2 \pi}{T_{n}} \\
T_{n}=\frac{T}{n}
\end{gathered}
$$

Finalmente, o espectro cruzado é definido pela transformada de Fourier da função de covariância cruzada (9), cujos picos das amplitudes indicam as frequências nas quais há maior inter-relação entre as séries e as fases indicam os respectivos atrasos (no tempo).

$$
\Phi_{X Y}\left(\omega_{n}\right)=\frac{1}{\sqrt{2 \pi}} \sum_{h} \operatorname{cov}(X, Y, h) e^{-i \omega_{n} h}
$$




\subsubsection{Validação do modelo}

Para a validação do modelo com os dados das boias do PIRATA, como esses foram considerados na forma de médias diárias, as séries temporais resultantes do modelo foram reorganizadas na forma de médias diárias.

Para a verificação da correspondência entre cálculos de um modelo e medições, são calculados determinados parâmetros de comparação, sendo eles o coeficiente de correlação linear $(9)$, o erro absoluto médio $(\Theta)(14)$, o erro relativo à média $\left(\Theta_{r}\right)(16)$ e o parâmetro de Wilmott (1981) (17).

O erro absoluto médio é calculado da seguinte forma:

$$
\Theta=\frac{\sum\left|V_{\text {mod }}-V_{o b s}\right|}{N}
$$

onde $V_{\text {mod }}$ é a variável resultante de modelagem, $V_{\text {obs }}$ é a variável observada e $N$ é o número de amostras. Com base no valor de $\Theta$ pode-se calcular o erro relativo à média $\left(\Theta_{r}\right)$ (16) utilizando a média das observações $\overline{V_{o b s}}$ (15). O valor de $\Theta_{r}$ avalia a proporção do erro em relação à média observada podendo, também, ser fornecido em valores percentuais, multiplicando o valor obtido em (16) por 100:

$$
\begin{gathered}
\overline{V_{o b s}}=\frac{\sum\left|V_{o b s}\right|}{N} \\
\Theta_{r}=\frac{\Theta}{\overline{V_{o b s}}}
\end{gathered}
$$

O parâmetro de Wilmott (1981) (WILM) é calculado como:

$$
W I L M=1-\frac{\sum\left(\mid V_{\mathrm{mod}}-V_{o b s}\right)^{2}}{\sum\left(\left|V_{\mathrm{mod}}-\overline{V_{o b s}}\right|+\left|V_{o b s}-\overline{V_{o b s}}\right|\right)^{2}}
$$

onde o valor 1 representa o perfeito ajuste entre os resultados obtidos pelo modelo e os observados, enquanto 0 representa um completo desajuste. Enquanto a correlação indica 
a interdependência das séries (grau de dispersão das séries em relação ao ajuste linear), o parâmetro de Wilmott é um indicativo da aproximação dos dados comparados, estando relacionado ao afastamento dos valores estimados em relação aos observados. 


\section{RESULTADOS E DISCUSSÃO}

\subsection{Validação do modelo hidrodinâmico}

Uma vez estabelecida a metodologia de processamento e análise dos dados, foram realizadas as comparações das séries temporais de temperatura do modelo com as medições em superfície de boias do projeto PIRATA. Foram escolhidos seis pontos com mais de 5 anos de dados contínuos, sendo exibidas nas Figuras de 9 a 14 tanto as séries originais como as séries após remoção dos sinais anual e semianual referentes a esses pontos.

Inicialmente observa-se visualmente um comportamento muito semelhante das séries de dados coletados com os resultados obtidos pelo modelo, destacando-se a semelhança na variabilidade em altas frequências com um nítido comportamento de suavização das saídas do modelo em relação aos dados coletados.

A observação das séries originais permite notar a existência de uma concordância no comportamento dos ciclos anual e semianual das séries, sendo que, após a remoção desses sinais, também se pode observar um comportamento oscilatório de frequências interanuais coerente nas séries comparadas. Isso demonstra que esses sinais de baixa frequência não só apresentam amplitudes semelhantes como, também, se encontram em fase. Outro ponto marcante é a subestimação das médias de temperaturas, calculadas pelo modelo em vários dos pontos analisados.

As Tabelas 3 e 4 apresentam dados estatísticos comparativos entre as séries apresentadas, considerando as séries originais e as séries após remoção dos sinais anual e semianual.

As séries, ao manter os sinais anual e semianual apresentam, para os dados do PIRATA, valor médio de $27,11 \pm 0,70{ }^{\circ} \mathrm{C}$, enquanto os do modelo tiveram média de $26,55 \pm 0,78{ }^{\circ} \mathrm{C}$ (Tabela 3). Essas séries apresentam uma diferença média de 0,56 $\pm 0,44$ ${ }^{\circ} \mathrm{C}$, que representa uma ligeira subestimação das temperaturas calculadas pelo modelo em relação às observações, fato esse já constatado visualmente. A maior diferença foi no ponto $0^{\circ} \mathrm{N}-35^{\circ} \mathrm{W}$, com $1,35^{\circ} \mathrm{C}$, e a menor, no ponto $6^{\circ} \mathrm{S}-10^{\circ} \mathrm{W}$, com $0,15^{\circ} \mathrm{C}$. 

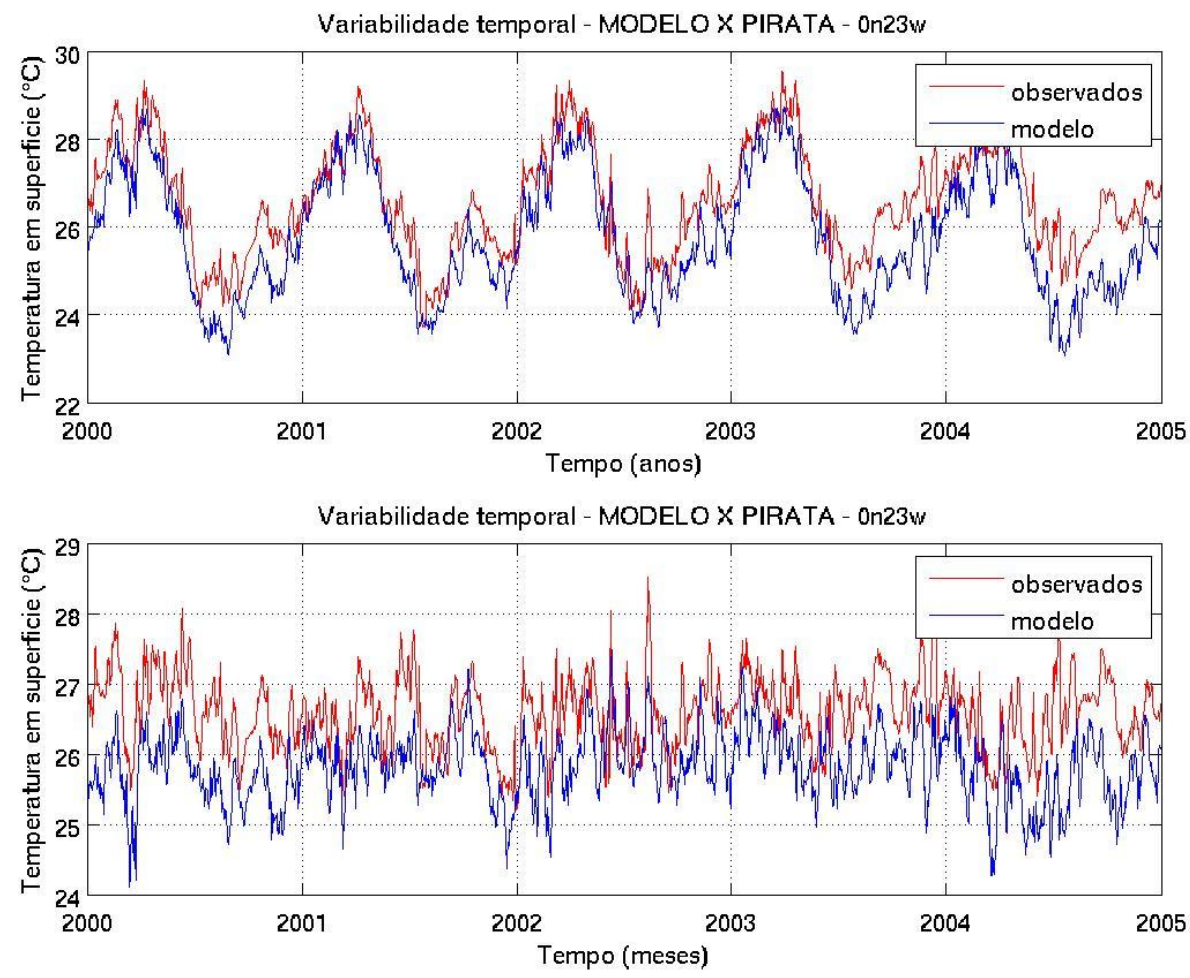

Figura 9: Séries temporais do modelo e do PIRATA com (acima) e sem (abaixo) a remoção dos sinais anual e semianual, para o ponto $0^{\circ} \mathrm{N}-23^{\circ} \mathrm{W}$.
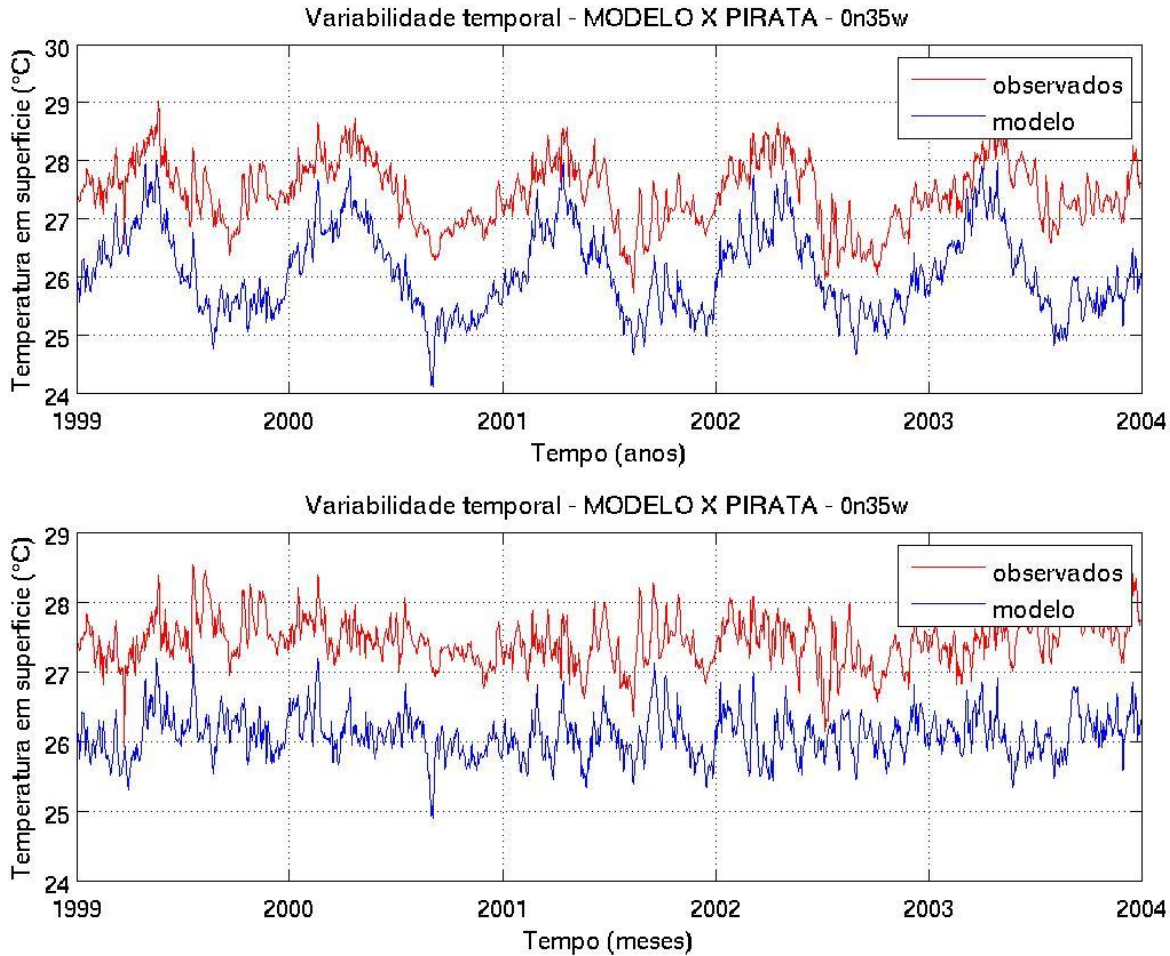

Figura 10: Séries temporais do modelo e do PIRATA com (acima) e sem (abaixo) a remoção dos sinais anual e semianual, para o ponto $0^{\circ} \mathrm{N}-35^{\circ} \mathrm{W}$. 

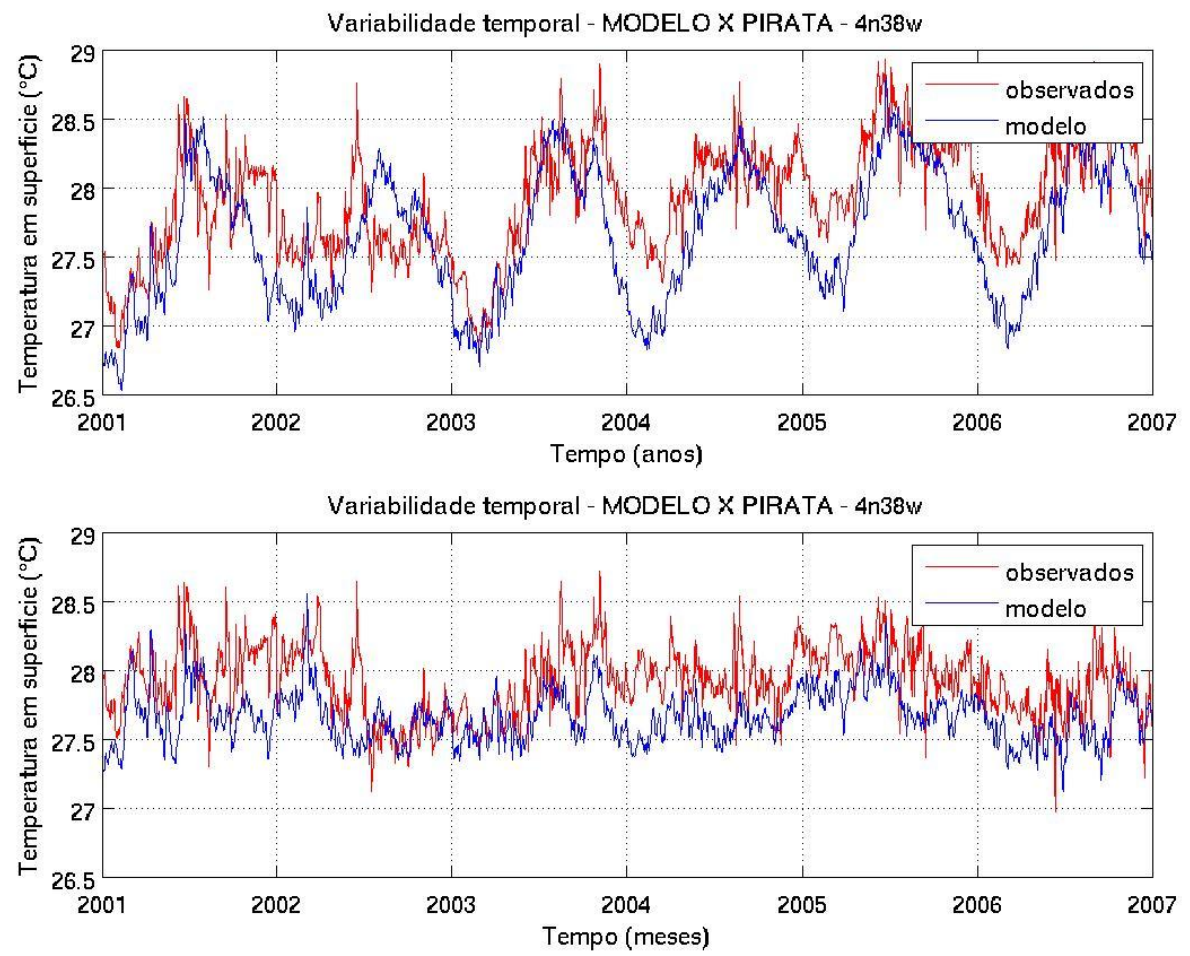

Figura 11: Séries temporais do modelo e do PIRATA com (acima) e sem (abaixo) a remoção dos sinais anual e semianual, para o ponto $4^{\circ} \mathrm{N}-38^{\circ} \mathrm{W}$.
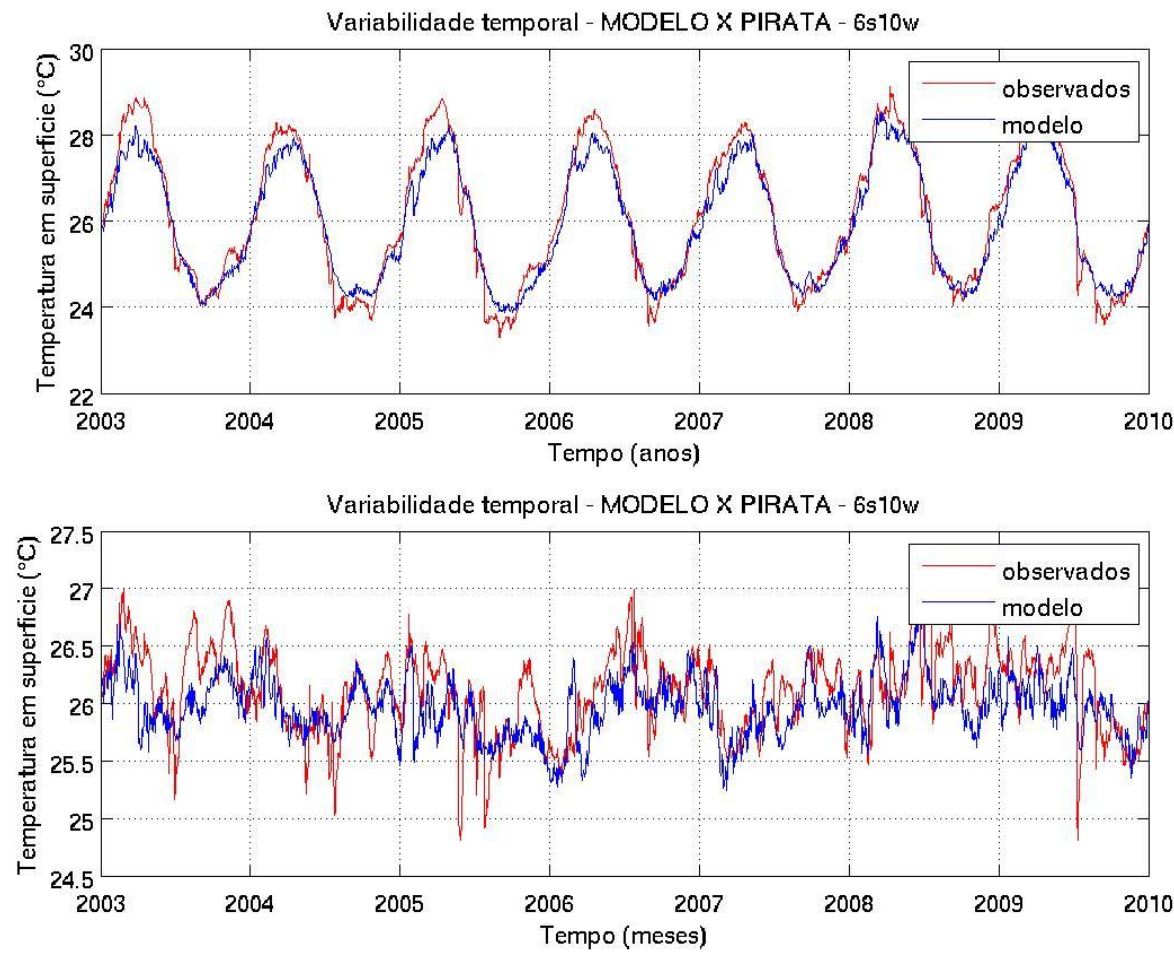

Figura 12: Séries temporais do modelo e do PIRATA com (acima) e sem (abaixo) a remoção dos sinais anual e semianual, para o ponto $6^{\circ} \mathrm{S}-10^{\circ} \mathrm{W}$. 

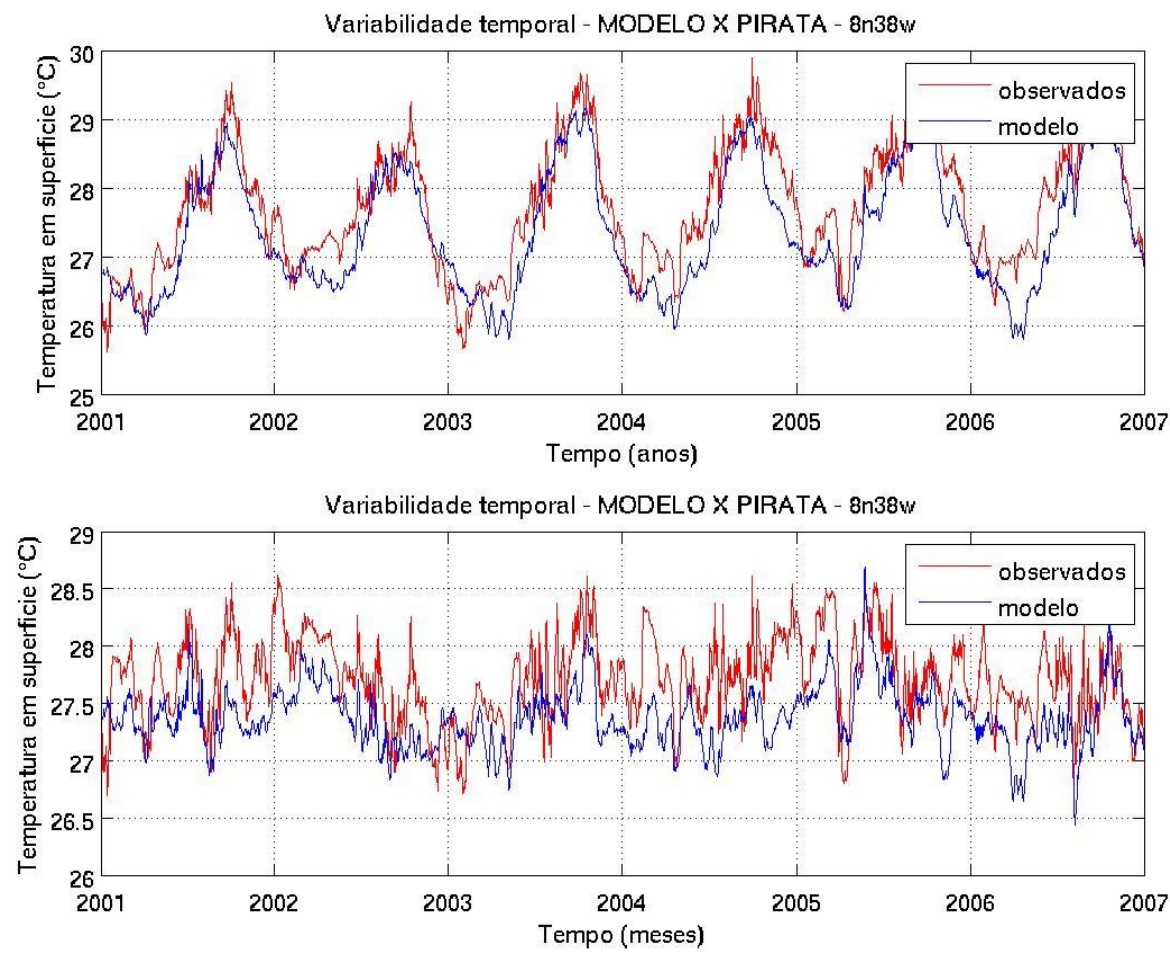

Figura 13: Séries temporais do modelo e do PIRATA com (acima) e sem (abaixo) a remoção dos sinais anual e semianual, para o ponto $8^{\circ} \mathrm{N}-38^{\circ} \mathrm{W}$.
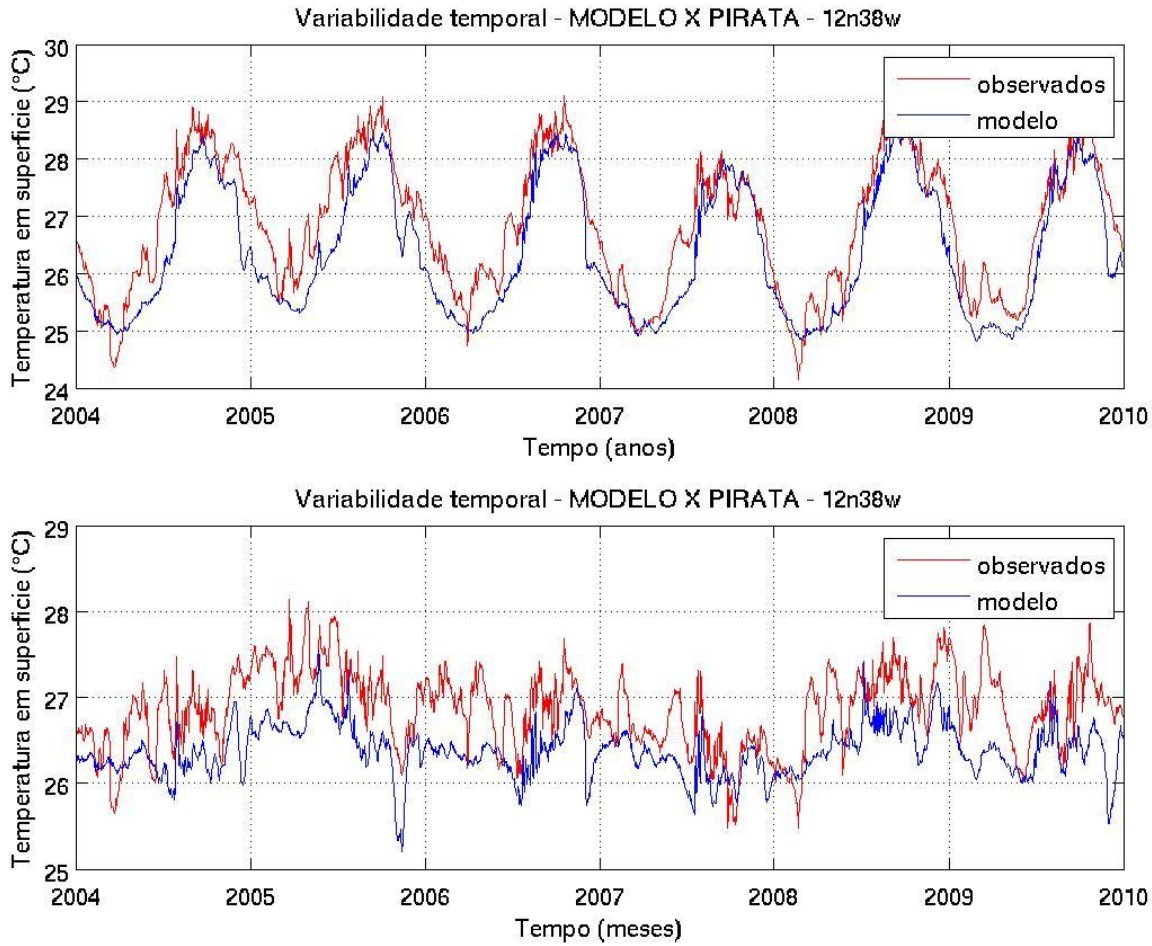

Figura 14: Séries temporais do modelo e do PIRATA com (acima) e sem (abaixo) a remoção dos sinais anual e semianual, para o ponto $12^{\circ} \mathrm{N}-38^{\circ} \mathrm{W}$. 
Note-se que, no processamento do modelo, a cada passo de tempo se tem uma relaxação para a climatologia média anual com coeficiente de ponderação igual a 0,001 .

As séries, após a remoção dos sinais anual e semianual, apresentam média com menor desvio padrão, uma vez que grande parte da variância do sinal era proveniente justamente desses sinais (Tabela 4). Em geral, a maior parte dessas diferenças encontrase dentro do desvio padrão, mesmo após remoção dos sinais anual e semianual.

Evidentemente, ao manter os sinais anual e semianual, os coeficientes de correlação linear apresentaram altos valores nos pontos analisados, com média de 0,89 \pm 0,08, e sempre positivos, sendo o menor valor encontrado (no ponto $4^{\circ} \mathrm{N}-35^{\circ} \mathrm{W}$ ) superior a 0,8 . O maior valor foi encontrado no ponto $6^{\circ} \mathrm{S}-10^{\circ} \mathrm{W}(0,98)$, mesmo ponto no qual foi encontrada a menor diferença nas médias. Com a remoção dos sinais anual e semianual, esse coeficiente reduz sua média para 0,59 $\pm 0,07$, apresentando menor valor, de 0,5 para o ponto $0^{\circ} \mathrm{N}-35^{\circ} \mathrm{W}$, e maior valor, de 0,66 , para o ponto $12^{\circ}$ $\mathrm{N}-38^{\circ} \mathrm{W}$.

Tabela 3: Estatística comparativa entre resultados do modelo e medições do PIRATA, para temperatura em superfície, antes da remoção dos sinais anual e semianual.

\begin{tabular}{|c|c|c|c|}
\hline Pontos & 0n23w & 0n35w & $4 n 38 w$ \\
\hline Média PIRATA & $26,59 \pm 1,25^{\circ} \mathrm{C}$ & $27,44 \pm 0,57^{\circ} \mathrm{C}$ & $27,92 \pm 0,41^{\circ} \mathrm{C}$ \\
\hline Média modelo & $25,82 \pm 1,40^{\circ} \mathrm{C}$ & $26,09 \pm 0,72{ }^{\circ} \mathrm{C}$ & $27,66 \pm 0,47^{\circ} \mathrm{C}$ \\
\hline Coeficiente de correlação & 0,92 & 0,83 & 0,77 \\
\hline Parâmetro Wilmott & 0,88 & 0,49 & 0,80 \\
\hline Erro absoluto médio & $0,81{ }^{\circ} \mathrm{C}$ & $1,35^{\circ} \mathrm{C}$ & $0,35^{\circ} \mathrm{C}$ \\
\hline Erro relativo à média & $3,04 \%$ & $4,94 \%$ & $1,25 \%$ \\
\hline Pontos & $6 s 10 w$ & $8 n 38 w$ & $12 n 38 w$ \\
\hline Média PIRATA & $26,12 \pm 1,60^{\circ} \mathrm{C}$ & $27,71 \pm 0,88^{\circ} \mathrm{C}$ & $26,86 \pm 1,15^{\circ} \mathrm{C}$ \\
\hline Média modelo & $25,97 \pm 1,35^{\circ} \mathrm{C}$ & $27,37 \pm 0,89^{\circ} \mathrm{C}$ & $26,37 \pm 1,15^{\circ} \mathrm{C}$ \\
\hline Coeficiente de correlação & 0,98 & 0,91 & 0,94 \\
\hline Parâmetro Wilmott & 0,98 & 0,92 & 0,93 \\
\hline Erro absoluto médio & $0,34{ }^{\circ} \mathrm{C}$ & $0,42{ }^{\circ} \mathrm{C}$ & $0,53{ }^{\circ} \mathrm{C}$ \\
\hline Erro relativo à média & $1,30 \%$ & $1,52 \%$ & $1,99 \%$ \\
\hline
\end{tabular}


Tabela 4: Estatística comparativa entre resultados do modelo e medições do PIRATA, para temperatura em superfície, após remoção dos sinais anual e semianual.

\begin{tabular}{|c|c|c|c|}
\hline Pontos & 0n23w & 0n35w & $4 n 38 w$ \\
\hline Média PIRATA & $26,59 \pm 0,59^{\circ} \mathrm{C}$ & $27,44 \pm 0,34^{\circ} \mathrm{C}$ & $27,92 \pm 0,24^{\circ} \mathrm{C}$ \\
\hline Média modelo & $25,82 \pm 0,50{ }^{\circ} \mathrm{C}$ & $26,09 \pm 0,32^{\circ} \mathrm{C}$ & $27,66 \pm 0,19^{\circ} \mathrm{C}$ \\
\hline Coeficiente de correlação & 0,54 & 0,50 & 0,52 \\
\hline Parâmetro Wilmott & 0,54 & 0,30 & 0,59 \\
\hline Erro absoluto médio & $0,80{ }^{\circ} \mathrm{C}$ & $1,35^{\circ} \mathrm{C}$ & $0,29^{\circ} \mathrm{C}$ \\
\hline Erro relativo à média & $3,02 \%$ & $4,93 \%$ & $1,03 \%$ \\
\hline Pontos & $6 s 10 w$ & $8 n 38 w$ & $12 n 38 w$ \\
\hline Média PIRATA & $26,12 \pm 0,37^{\circ} \mathrm{C}$ & $27,71 \pm 0,37^{\circ} \mathrm{C}$ & $26,86 \pm 0,45^{\circ} \mathrm{C}$ \\
\hline Média modelo & $25,97 \pm 0,26^{\circ} \mathrm{C}$ & $27,37 \pm 0,27^{\circ} \mathrm{C}$ & $26,37 \pm 0,30^{\circ} \mathrm{C}$ \\
\hline Coeficiente de correlação & 0,64 & 0,60 & 0,66 \\
\hline Parâmetro Wilmott & 0,74 & 0,63 & 0,61 \\
\hline Erro absoluto médio & $0,26^{\circ} \mathrm{C}$ & $0,39^{\circ} \mathrm{C}$ & $0,51^{\circ} \mathrm{C}$ \\
\hline Erro relativo à média & $0,99 \%$ & $1,39 \%$ & $1,91 \%$ \\
\hline
\end{tabular}

O parâmetro de Wilmott, para a série total, também apresentou valores altos (média de $0,83 \pm 0,18$ ), com menor valor no ponto $0^{\circ} \mathrm{N}-35^{\circ} \mathrm{W}$, em torno de 0,5 , mesmo ponto em que se encontrou a maior diferença entre as médias das séries. Para o sinal residual (após a remoção das sazonalidades), esse parâmetro apresenta média de $0,57 \pm 0,15$, com valor máximo de 0,74 , no ponto $6^{\circ} \mathrm{S}-10^{\circ} \mathrm{W}$, e mínimo de 0,30 , no ponto $0^{\circ} \mathrm{N}-35^{\circ} \mathrm{W}$.

Não há valores de referência estabelecidos para o parâmetro de Wilmott, mas valores típicos em torno de 0,5 indicam que o modelo reproduz cerca de metade da variância observada (HETLAND e DIMARCO, 2012). Dessa forma, pode-se considerar que valores superiores a 0,5 são significativos, uma vez que a maior parte da variância já foi desconsiderada com a remoção dos sinais anual e semianual.

$\mathrm{O}$ erro absoluto médio com os sinais anual e semianual apresentou um valor médio de $0,63 \pm 0,40{ }^{\circ} \mathrm{C}$ e o erro relativo à média, valor médio de $2,34 \pm 0,01 \%$. 
Ambos apresentaram maiores valores no ponto $0^{\circ} \mathrm{N}-35^{\circ} \mathrm{W}$ (que já apresentara maior diferença nas médias) e menores valores no ponto $6^{\circ} \mathrm{S}-10^{\circ} \mathrm{W}$ (que apresentara menor diferença nas médias). Esse mesmo parâmetro, após remoção dos sinais anual e semianual, apresentou um valor médio de $0,61 \pm 0,40{ }^{\circ} \mathrm{C}$ e o erro relativo à média com valor de 2,21 $\pm 0,02 \%$. Isso quantifica um erro da modelagem em relação aos dados de pouco mais de $0,6{ }^{\circ} \mathrm{C}$, de forma que, para análises mais generalistas, como tendências e aspectos de larga escala, o modelo pode ser considerado plenamente confiável.

A seguir são apresentados perfis médios de temperatura para os meses de janeiro e julho dos anos de 2004 e 2006, para pontos selecionados de boias do projeto PIRATA e do modelo (Figuras 15 e 16), juntamente com Tabelas de estatísticas comparativas (Tabelas 5 e 6 ).

Nos perfis de temperatura, tal como nas séries temporais em superfície, podese observar um padrão semelhante das curvas e uma subestimação da temperatura pelo modelo. Nota-se, porém, que a subestimação é maior em profundidade. Os dados do PIRATA tiveram temperatura média nos perfis de $19,25 \pm 1,51^{\circ} \mathrm{C}$, enquanto o modelo teve média de $16,15 \pm 0,18{ }^{\circ} \mathrm{C}$ com uma diferença média de temperaturas, entre os perfis, de $3,09 \pm 1,58^{\circ} \mathrm{C}$.

O coeficiente de correlação linear e o parâmetro de Wilmott apresentaram valores altos, com médias respectivas de 0,94 $\pm 0,06$ e de 0,99 $\pm 0,00$. Esses valores eram esperados, uma vez que refletem o comportamento geral das curvas comparadas. $\mathrm{O}$ erro absoluto médio apresentou valor médio $0,19 \pm 0,14{ }^{\circ} \mathrm{C}$ e o erro relativo à média, valor de 1,38 $\pm 0,99 \%$, valores esses relativamente baixos. Nesse caso a quantidade de pontos é muito pequena, o que prejudica o cálculo.

Ponto marcante na observação dos perfis é que não há só uma subestimação na temperatura do perfil como um todo, mas a profundidade da termoclina também é subestimada, mostrando que o modelo apresenta na região um padrão de estreitamento da camada de mistura.

Essas discrepâncias na profundidade da termoclina provavelmente são devidas a erros nos dados dos fluxos de calor e sal especificados como condições de contorno para os processamentos. 

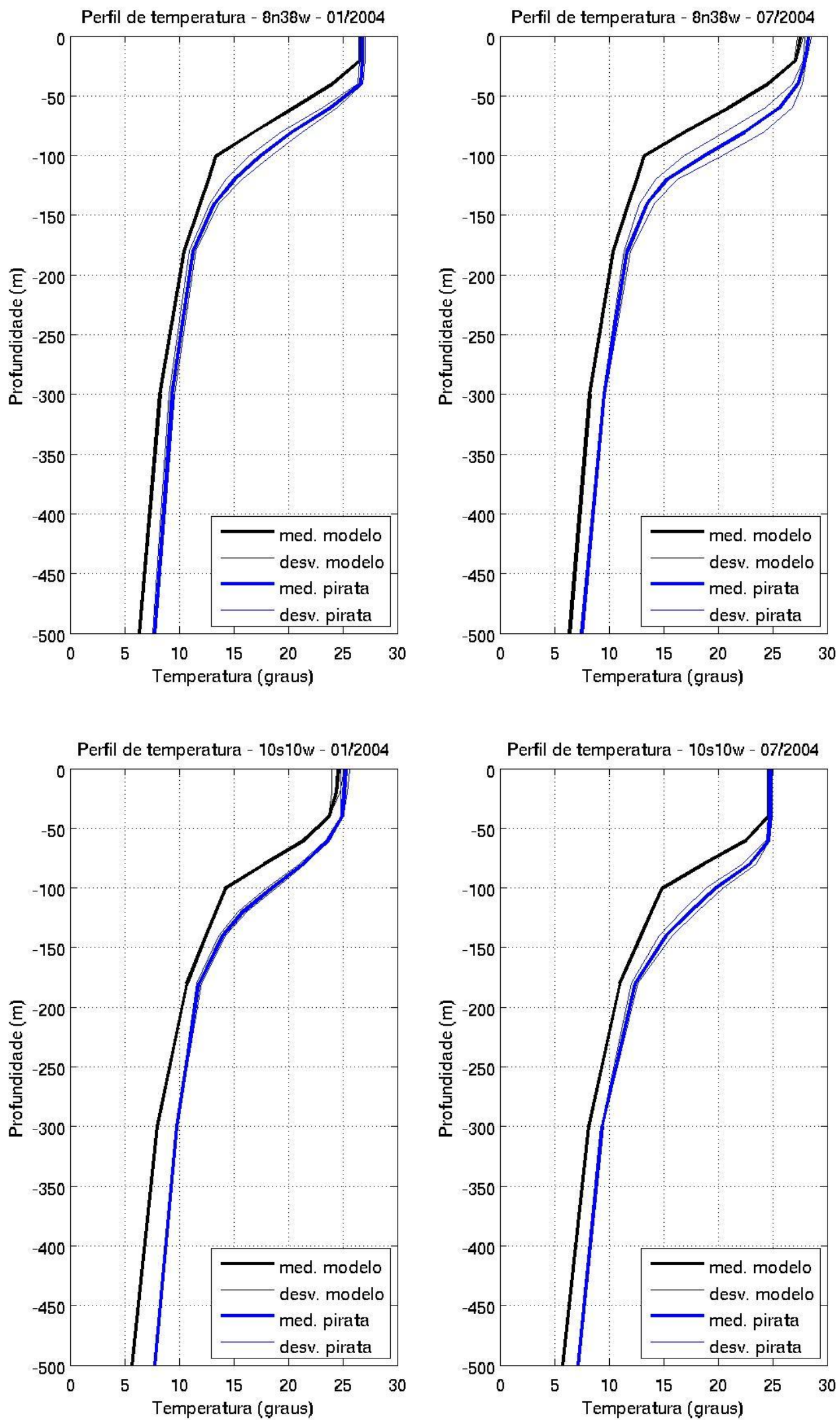

Figura 15: Perfis de temperatura do modelo e do PIRATA, para os pontos $8^{\circ} \mathrm{N}-38^{\circ} \mathrm{W}$ (acima) e $10^{\circ} \mathrm{S}$ $10^{\circ} \mathrm{W}$ (abaixo), para os meses de janeiro (esquerda) e julho (direita) de 2004. 

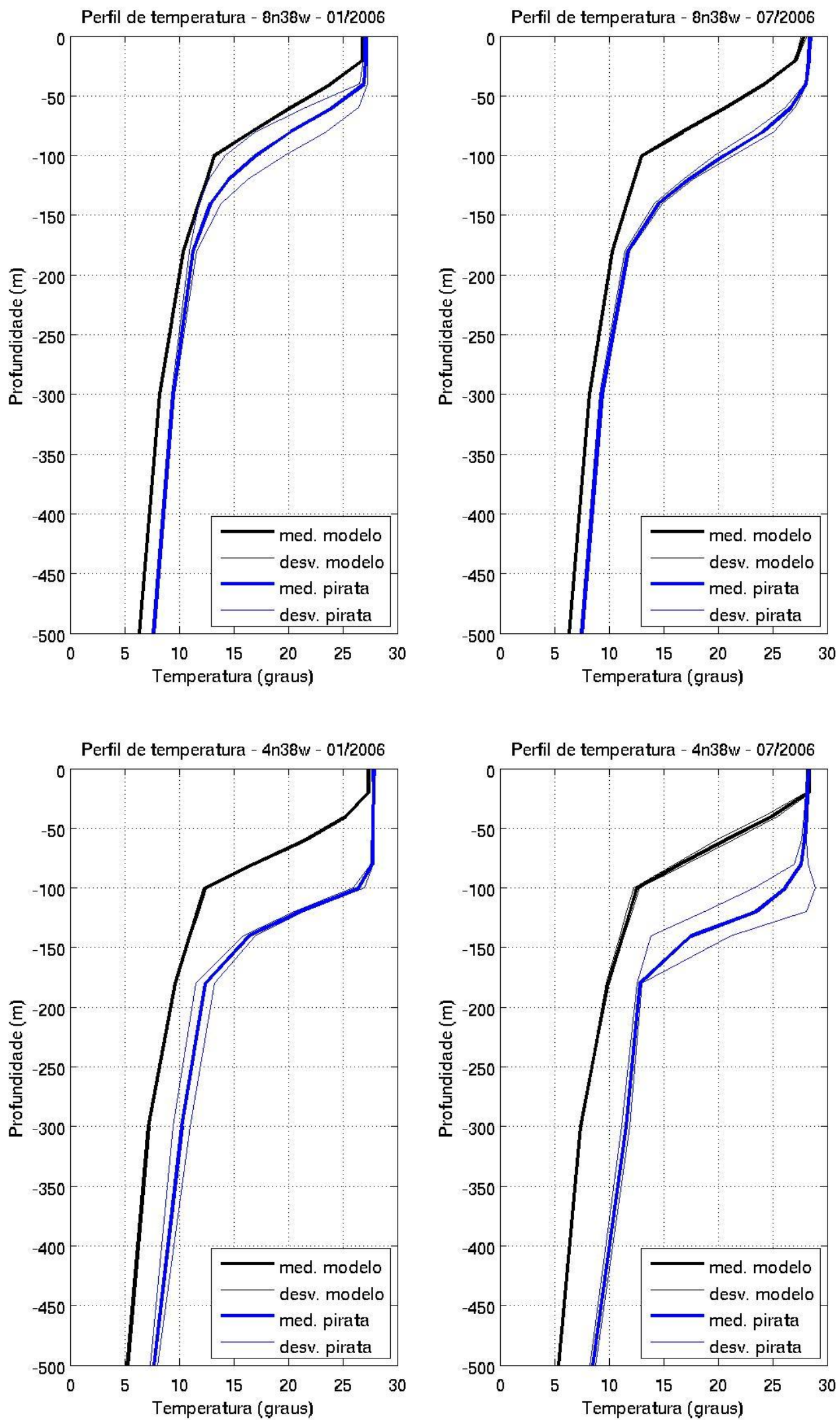

Figura 16: Perfis de temperatura do modelo e do PIRATA, para os pontos $8^{\circ} \mathrm{N}-38^{\circ} \mathrm{W}$ (acima) e $4^{\circ} \mathrm{N}$ $38^{\circ} \mathrm{W}$ (abaixo), para os meses de janeiro (esquerda) e julho (direita) de 2004. 
Tabela 5: Estatística comparativa entre dados do modelo e do PIRATA, nos perfis de temperatura dos pontos $8^{\circ} \mathrm{N}-38^{\circ} \mathrm{W}$ e $10^{\circ} \mathrm{S}-10^{\circ} \mathrm{W}$, para o ano de 2004 .

\begin{tabular}{l|c|c|c|c}
\hline \hline \multicolumn{1}{c|}{ Pontos } & $8 \mathrm{n} 38 \mathrm{w}-01 / 2004$ & $8 \mathrm{n} 38 \mathrm{w}-07 / 2004$ & $10 \mathrm{~s} 10 \mathrm{w}-01 / 2004$ & $10 \mathrm{~s} 10 \mathrm{w}-01 / 2004$ \\
\hline \hline Média PIRATA & $18,04 \pm 7,25^{\circ} \mathrm{C}$ & $18,87 \pm 7,81^{\circ} \mathrm{C}$ & $17,98 \pm 6,53{ }^{\circ} \mathrm{C}$ & $18,44 \pm 6,61{ }^{\circ} \mathrm{C}$ \\
\hline Média modelo & $16,13 \pm 7,28^{\circ} \mathrm{C}$ & $16,31 \pm 7,59{ }^{\circ} \mathrm{C}$ & $16,02 \pm 6,77^{\circ} \mathrm{C}$ & $16,50 \pm 6,92{ }^{\circ} \mathrm{C}$ \\
\hline Coef. de correl. & 0,98 & 0,97 & 0,99 & 0,97 \\
\hline Par. Wilmott & 1,00 & 0,99 & 0,99 & 0,00 \\
\hline Erro médio abs. & $0,08{ }^{\circ} \mathrm{C}$ & $0,36{ }^{\circ} \mathrm{C}$ & $0,34{ }^{\circ} \mathrm{C}$ & $0,62 \%$ \\
\hline Erro méd. Relat. & $0,59 \%$ & $2,57 \%$ & $2,67 \%$ & $0,67 \%$ \\
\hline \hline
\end{tabular}

Tabela 6: Estatística comparativa entre dados do modelo e do PIRATA, nos perfis de temperatura dos pontos $8^{\circ} \mathrm{N}-38^{\circ} \mathrm{W}$ e $4^{\circ} \mathrm{N}-38^{\circ} \mathrm{W}$, para o ano de 2006 .

\begin{tabular}{l|c|c|c|c}
\hline \multicolumn{1}{c|}{ Pontos } & $8 \mathrm{n} 38 \mathrm{w}-01 / 2006$ & $8 \mathrm{n} 38 \mathrm{w}-07 / 2006$ & $4 \mathrm{n} 38 \mathrm{w}-01 / 2006$ & $4 \mathrm{n} 38 \mathrm{w}-07 / 2006$ \\
\hline \hline Média PIRATA & $18,99 \pm 7,42^{\circ} \mathrm{C}$ & $19,66 \pm 8,00{ }^{\circ} \mathrm{C}$ & $21,18 \pm 8,04{ }^{\circ} \mathrm{C}$ & $21,81 \pm 7,72{ }^{\circ} \mathrm{C}$ \\
\hline Média modelo & $16,05 \pm 7,34{ }^{\circ} \mathrm{C}$ & $16,20 \pm 7,63{ }^{\circ} \mathrm{C}$ & $15,94 \pm 8,17{ }^{\circ} \mathrm{C}$ & $16,07 \pm 8,23{ }^{\circ} \mathrm{C}$ \\
\hline Coef. de correl. & 0,98 & 0,94 & 0,85 & 0,83 \\
\hline Par. Wilmott & 0,99 & 0,99 & 0,99 & 1,00 \\
\hline Erro abs. médio & $0,12{ }^{\circ} \mathrm{C}$ & $0,29{ }^{\circ} \mathrm{C}$ & $0,23{ }^{\circ} \mathrm{C}$ & $0,00{ }^{\circ} \mathrm{C}$ \\
\hline Erro Relativo & $0,89 \%$ & $2,02 \%$ & $1,68 \%$ & $0,02 \%$ \\
\hline \hline
\end{tabular}

Concluindo a análise comparativa dos resultados do modelo e das observações das boias do PIRATA, ao considerar os parâmetros estatísticos das Tabelas 3 a 6, seja mantendo os sinais anual e semianual ou removendo-o, pode-se considerar o modelo validado para a região amostrada.

A seguir são apresentadas análises comparativas dos resultados de temperatura na superfície do modelo com medições do sensor MODIS, para toda a área de interesse, no período de 2003 a 2009. Essas comparações são realizadas por meio das distribuições espaciais de médias e tendências após remoção dos sinais anual e semianual (Figura 17) e seus parâmetros estatísticos (Tabela 7), bem como as distribuições espaciais dos desvios padrão para as séries anual e semianual e para as 
séries residuais (totais menos os sinais anual e semianual) (Figura 18), juntamente com seus parâmetros estatísticos.
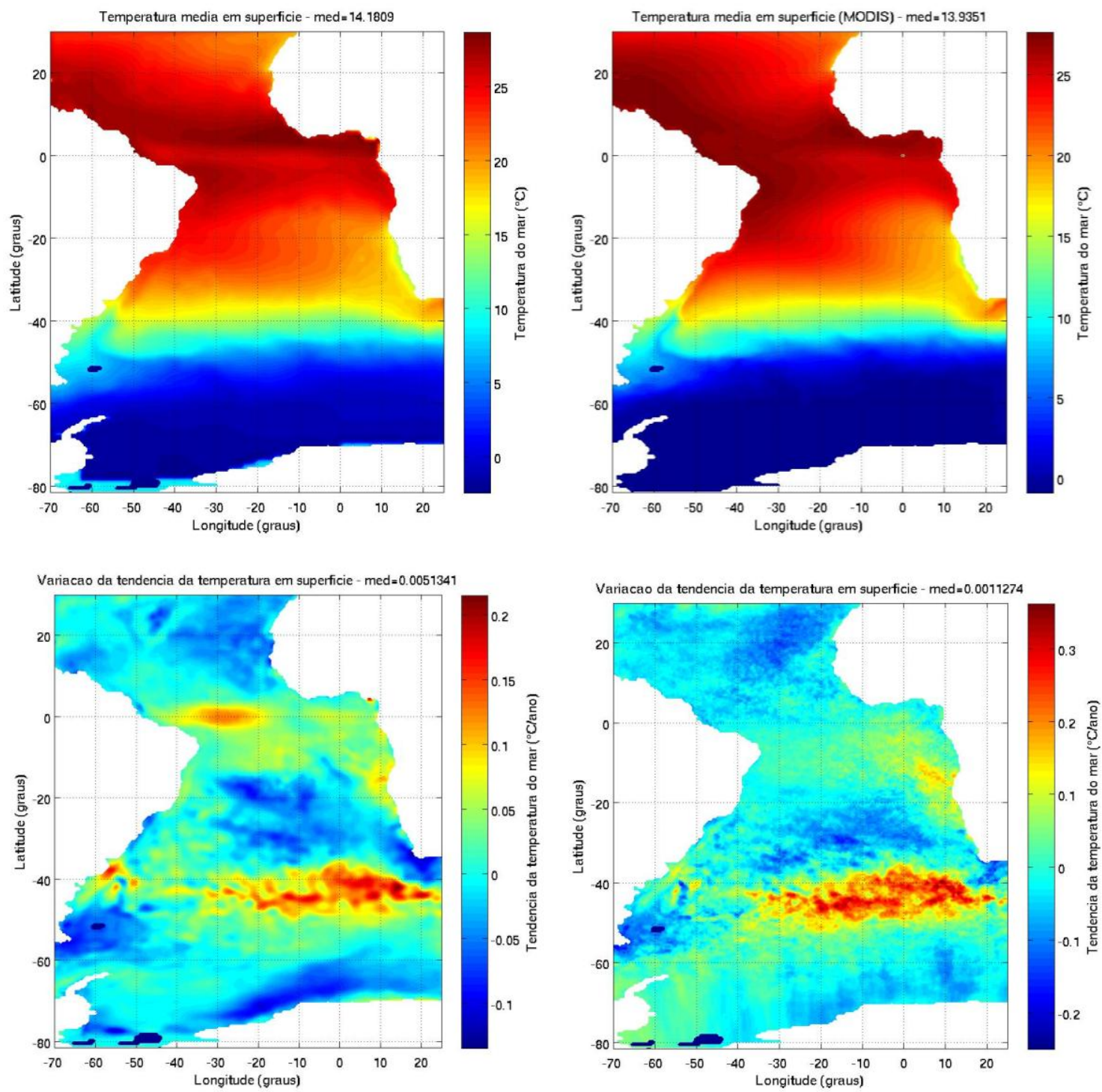

Figura 17: Distribuição espacial da média (acima) e da tendência (abaixo) da temperatura em superfície, com a remoção dos sinais anual e semianual, proveniente do modelo (à esquerda) e do sensor MODIS (à direita), no Atlântico Sul e Tropical, para o período de 2003 a 2009.

Inicialmente, foram verificados padrões muito semelhantes na distribuição das médias, com pequenas diferenças em algumas regiões (Figura 17), como uma menor advecção de águas mais frias para norte na região Sul da costa brasileira ou uma advecção de águas quentes menos intensa na região da Retroflexão da Corrente das 
Agulhas (RCA), nos cálculos do modelo. Outro destaque importante é a ocorrência de águas mais frias na região do Equador pelos cálculos do modelo, denotando um provável exagero na ressurgência equatorial modelada, o que explicaria a subestimação das temperaturas calculadas pelo modelo nos pontos validados com os dados do PIRATA, que se encontram próximo a essa região.

Tabela 7: Estatística comparativa entre modelo e MODIS das distribuições de parâmetros relacionado à temperatura residual (total menos sinais anual e semianual), para a região de estudo, no período de 2003 a 2009.

\begin{tabular}{|c|c|c|c|c|}
\hline $\begin{array}{l}\text { Distribuição das } \\
\text { Temperaturas }\end{array}$ & Média & Tendência & $\begin{array}{l}\text { Desv. padrão (anual e } \\
\text { semi) }\end{array}$ & $\begin{array}{l}\text { Desv. padrão } \\
\text { (residual) }\end{array}$ \\
\hline Média MODIS & $13,94 \pm 11,09{ }^{\circ} \mathrm{C}$ & $0,11 \pm 7,20.10^{-2} \cdot{ }^{\circ} \mathrm{C} /$ ano & $0,69 \pm 0,57{ }^{\circ} \mathrm{C}$ & $0,88 \pm 0,33{ }^{\circ} \mathrm{C}$ \\
\hline Média modelo & $14,18 \pm 10,89^{\circ} \mathrm{C}$ & $0,51 \pm 4,56 \cdot 10^{-2} \cdot{ }^{\circ} \mathrm{C} /$ ano & $0,97 \pm 0,49{ }^{\circ} \mathrm{C}$ & $0,45 \pm 0,17^{\circ} \mathrm{C}$ \\
\hline Coef. de correl. & 0,99 & 0,77 & 0,84 & 0,60 \\
\hline Par. Wilmott & 0,99 & 0,90 & 0,86 & 0,53 \\
\hline Erro abs. médio & $0,84{ }^{\circ} \mathrm{C}$ & $3,64.10^{-2} \cdot{ }^{\circ} \mathrm{C} / \mathrm{ano}$ & $0,33{ }^{\circ} \mathrm{C}$ & $0,44^{\circ} \mathrm{C}$ \\
\hline Erro Relativo & $5,94 \%$ & $70,59 \%$ & $47,94 \%$ & $49,63 \%$ \\
\hline
\end{tabular}

Considerando as séries residuais (totais menos sinais anual e semianual), o modelo apresentou uma média da distribuição de temperatura de $14,18 \pm 10,89{ }^{\circ} \mathrm{C}$ com valor máximo de $28,82{ }^{\circ} \mathrm{C}$ e mínimo de $-2,44{ }^{\circ} \mathrm{C}$, enquanto o satélite apresentou média de $13,94 \pm 11,09{ }^{\circ} \mathrm{C}$, com valor máximo de $27,78^{\circ} \mathrm{C}$ e mínimo de $-0,90{ }^{\circ} \mathrm{C}$. A diferença média de temperatura em superfície do modelo com o MODIS é de $-0,25 \pm 1,41{ }^{\circ} \mathrm{C}$, o que demonstra de uma forma geral, uma ligeira superestimação do modelo para a região de amostragem (Tabela 7).

O coeficiente de correlação linear entre as distribuições das temperaturas médias do modelo e do MODIS apresentou valor de 0,99 e o parâmetro de Wilmott, valor de 0,99 , corroborando a semelhança no comportamento das médias, já constatada visualmente. $\mathrm{O}$ erro absoluto médio apresentou valor de $0,84{ }^{\circ} \mathrm{C}$ e o erro relativo à média é de quase $6 \%$, valores esses relativamente baixos. 
Já as distribuições das tendências das temperaturas do modelo e do sensor MODIS (para as séries residuais - Figura 17) apresentaram comportamento também com similaridades grandes, mas com diferenças mais evidentes que as das distribuições das médias. O modelo apresentou uma região no equador com tendência fortemente positiva, tendência essa não visível nos dados de sensoriamento remoto. O modelo mostrou, também, uma tendência forte de aquecimento próximo à desembocadura do Rio da Prata e de esfriamento na região superior do Giro Subtropical do Atlântico Sul (GSAS) e próximo ao litoral sul do continente africano. Nos dados do MODIS essa tendência se encontra com menor intensidade.

O modelo apresentou tendência média de $0,51 \pm 4,56 \cdot 10^{-2} \cdot{ }^{\circ} \mathrm{C} /$ ano, com valores máximo de $0,22^{\circ} \mathrm{C} /$ ano e mínimo de $-0,13^{\circ} \mathrm{C} / \mathrm{ano}$, enquanto o MODIS apresentou valor médio da tendência de $0,11 \pm 7,20.10^{-2} \cdot{ }^{\circ} \mathrm{C} / \mathrm{ano}$, com máximo de $36,50.10^{-2} \cdot{ }^{\circ} \mathrm{C} /$ ano e mínimo de $-24,97 \cdot 10^{-2} .{ }^{\circ} \mathrm{C} / a n o$ (Tabela 7). A diferença média entre as tendências foi de $-0,40 \pm 4,73.10^{-2} .{ }^{\circ} \mathrm{C} / \mathrm{ano}$, representando um comportamento médio, para a região, de tendências positivas mais intensas calculadas pelo modelo, embora os extremos sejam mais intensos nos dados do MODIS.

As tendências apresentaram valor de coeficiente de correlação linear de 0,77 e parâmetro de Wilmott de 0,90, valores esses considerados altos, porém menores do que os apresentados na comparação das médias de temperatura, provavelmente por conta das disparidades nas distribuições das tendências discutidas acima. $\mathrm{O}$ erro absoluto médio apresentou valor de $3,64.10^{-2} .{ }^{\circ} \mathrm{C} /$ ano, e o erro relativo à média de 70,59\%, valores altos, também por consequência dessas disparidades (Figura 17 e Tabela 7).

Quanto aos desvios padrão dos sinais anual e semianual das temperaturas em superfície do modelo e do MODIS (Figura 18), as distribuições apresentaram similaridades, embora havendo disparidades como a ocorrência de valores maiores na região ao norte do litoral africano nas distribuições desses desvios no modelo. O modelo apresentou valor médio na distribuição do parâmetro em questão de $0,97 \pm 0,49{ }^{\circ} \mathrm{C}$, com valor máximo de $3,78{ }^{\circ} \mathrm{C}$ enquanto o MODIS apresentou média de $0,69 \pm 0,57{ }^{\circ} \mathrm{C}$, com valor máximo $4,27{ }^{\circ} \mathrm{C}$. A média das diferenças entre as distribuições dos desvios padrão é de $-0,28 \pm 0,31{ }^{\circ} \mathrm{C}$ o que demonstra, em geral, a superestimação da intensidade dos sinais anual e semianual pelo modelo, porém observando-se que os valores extremos são maiores no caso do sensor MODIS. 

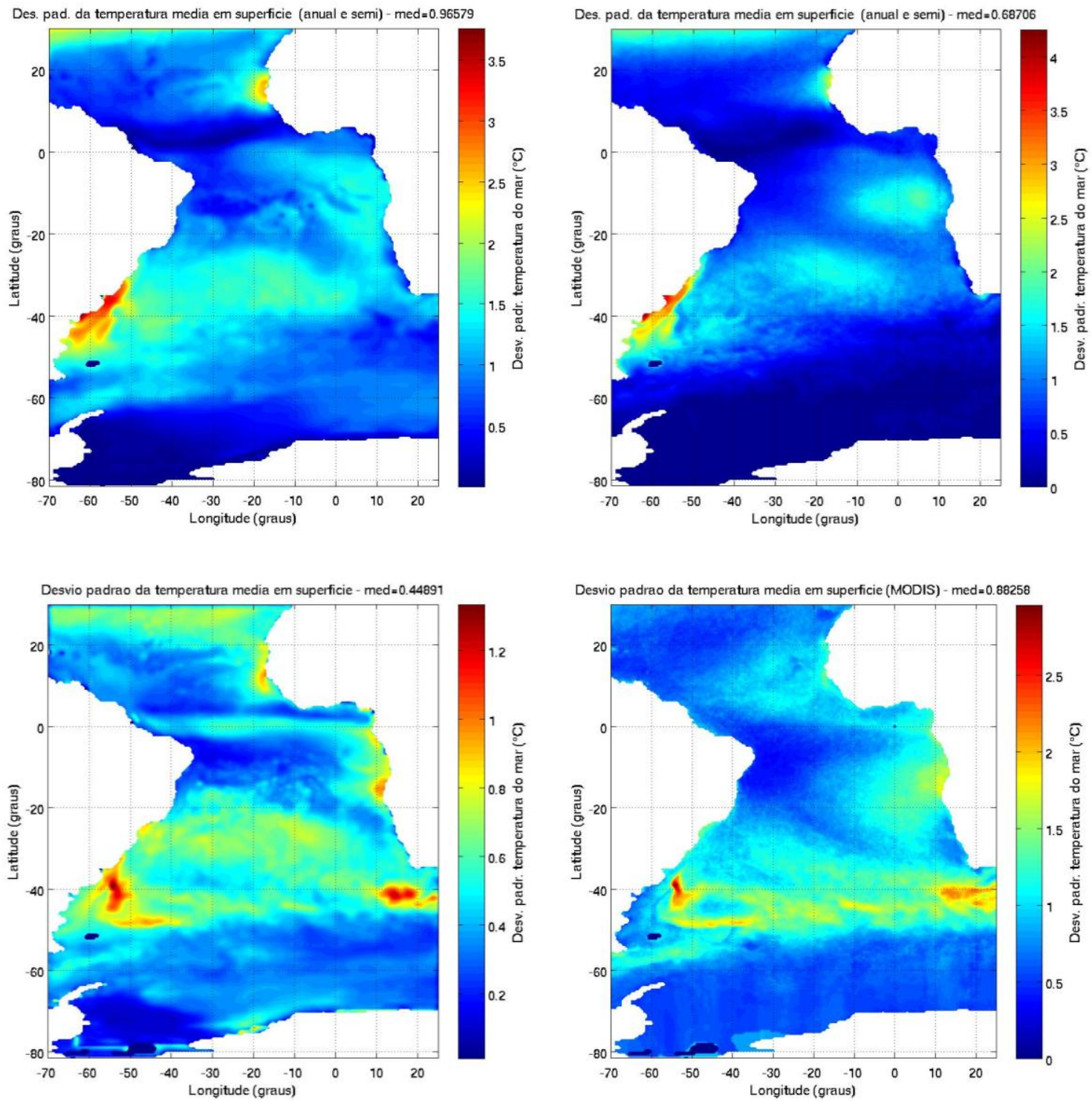

Figura 18: Distribuição espacial dos desvios padrão dos sinais anual e semianual (acima) e do sinal residual (abaixo) da temperatura em superfície, proveniente do modelo (à esquerda) e do sensor MODIS (à direita), no Atlântico Sul e Tropical, para o período de 2003 a 2009.

O coeficiente de correlação linear (para os desvios padrão dos sinais anual e semianual do modelo e do MODIS) apresentou valor de 0,84 e o parâmetro de Wilmott, valor de 0,86, ambos os valores considerados altos, reflexo das similaridades encontradas nos padrões de distribuição. O erro absoluto médio apresentou valor de $0,33{ }^{\circ} \mathrm{C}$ e o erro relativo à média apresentou valor de 47,94\%, devido às grandes diferenças encontradas nos valores das distribuições. 
As distribuições dos desvios padrão das temperaturas residuais do modelo e do MODIS apresentam diferenças bem marcantes, como maiores valores na região equatorial e pontos de ressurgência na costa africana apresentados pelo modelo (Figura 18). A média desse desvio apresentada pelo modelo é de $0,45 \pm 0,17{ }^{\circ} \mathrm{C}$, com valor máximo de $1,34{ }^{\circ} \mathrm{C}$, enquanto o sensoriamento remoto acusou média de $0,88 \pm 0,33{ }^{\circ} \mathrm{C}$, com valor máximo de $2,97{ }^{\circ} \mathrm{C}$. A diferença média entre modelo e MODIS é de $-0,43 \pm$ $0,26{ }^{\circ} \mathrm{C}$, o que mostra um comportamento do modelo, para essas variabilidades, de valores menos intensos.

O coeficiente de correlação entre os desvios padrão do modelo e do MODIS foi de 0,60 e o parâmetro de Wilmott 0,53, valores ainda superiores a 0,5, mas relativamente baixos, demonstrando as discrepâncias encontradas nas distribuições. O erro médio absoluto apresentou valor de $0,44{ }^{\circ} \mathrm{C}$ e o erro relativo à média 49,63\%, devido às discrepâncias nas distribuições.

Em decorrência dos altos índices de correlação linear e parâmetro de Wilmott, encontrados nos dados de superfície, pode-se considerar que os resultados obtidos pelo modelo, para a temperatura em superfície, possuem uma grande similaridade aos encontrados no oceano. Assim sendo, é válida a utilização desse parâmetro, estendendo seu uso para os demais parâmetros resultantes do modelo na análise em superfície.

Ademais, outros resultados da modelagem implementada, como os campos de elevação e de correntes na superfície, possuem feições e distribuições gerais similares aos estabelecidos na literatura para a região de interesse, sendo esses discutidos na sessão a seguir. 


\subsection{Caracterização da clorofila $a$ e variáveis físicas}

São apresentadas, a seguir, as distribuições horizontais dos dados em superfície das variáveis físicas resultantes do modelo hidrodinâmico e dos valores da clorofila $a$, proveniente do sensor MODIS. Esses dados são apresentados como médias e desvios

padrão de suas séries temporais, após remoção dos sinais anual e semianual, para o período de 2003 a 2009, com resolução temporal de uma semana.

As distribuições horizontais das médias das temperaturas em superfície, seus desvios padrão e tendências foram apresentadas anteriormente, juntamente com os valores de seus índices estatísticos (Figuras 17 e 18 e, Tabela 7).

A distribuição da média das temperaturas mostra um comportamento de aumento da temperatura com a diminuição da latitude apresentando, também, um gradiente acentuado em torno da latitude $40^{\circ} \mathrm{S}$, região de fluência da Corrente do Atlântico Sul (CAS). Nessa latitude ocorrem feições características de intrusão de águas frias (com desvio para norte das isotermas) na região da Confluência Brasil-Malvinas (CBM) e de intrusão de águas quentes (com desvio para sul das isotermas) na região de Retroflexão da Corrente das Agulhas (RCA). Esse padrão médio, para um período de 1993 a 2001 na região da CBM, é verificado por Teixeira et al. (2009) em tratamento de imagens do tipo Pathfinder AVHRR/NOAA (Advanced Very High Resolution Radiometer / NOAA).

São visíveis, também, os efeitos de circulação provocados pelo Giro Subtropical do Atlântico Sul (GSAS) por meio do espalhamento das isotermas (águas mais frias) para norte na região da Corrente de Benguela e para sul (águas mais quentes) na região da Corrente do Brasil. O mesmo comportamento é visto a norte, na parte sul do Giro Subtropical do Atlântico Norte (GSAN).

$\mathrm{Na}$ distribuição do desvio padrão da temperatura pode-se notar que as regiões em que se constatam os maiores valores são as que apresentam altos gradientes de temperatura e ocorrência de ressurgência costeira. Na distribuição do desvio padrão dos sinais anual e semianual nota-se que a variabilidade representada pelo sinal anual e semianual possui maior intensidade na costa brasileira, próximo à região da $\mathrm{CBM}$ e na região de ressurgência ao norte da costa africana. A variabilidade espacial da sazonalidade para temperatura em superfície, na região intertropical, foi verificada por Hastenrath (1984). 
Ao comparar os mapas da Figura 18 nota-se que os sinais anual e semianual apresentaram os maiores valores de desvios padrão. Porém, na observação do desvio padrão do sinal residual, destacam-se regiões como a de ressurgência equatorial, CBM e RCA. A assinatura mais intensa, pelos sinais anual e semianual, é verificada por Teixeira et al. (2009) na região de CBM, corroborando com o padrão de distribuição espacial para a região. O comportamento espacial do desvio padrão para o sinal residual na região de CBM também é confirmado.

A distribuição das tendências da temperatura em superfície, para o período estudado, apresentou uma média positiva para toda a região. Isso denota um aumento médio da temperatura em superfície para o período analisado (Figura 17). Essa distribuição apresentou padrão de altos valores positivos na região equatorial e no entorno da latitude $40^{\circ} \mathrm{S}$ (região de alto gradiente de temperatura). Tendências negativas foram observadas na região ao sul do continente africano, no interior do GSAS, ao sul do continente americano e próximo ao continente antártico.

Essas tendências apresentaram, nas regiões de extremos, valores da mesma ordem de grandeza dos valores encontrados nos desvios padrão, o que denota a relevância desses valores. Isso indica, também, a importância da utilização de séries temporais mais longas para verificação de uma possível consolidação dessas tendências. Um exemplo desse tipo de ocorrência é o estudo realizado por Cheng e Qi (2007) que, em observação de tendências de variabilidade do nível do mar para uma série de 13 anos, verificaram padrões de tendência opostos, que dividiam a série em dois períodos com comportamentos distintos.

A distribuição das médias temporais de salinidade em superfície (figura 19) obedece ao padrão observado por Boyer e Levitus (2002) na média anual e desvio padrão da média mensal do WOA98. Essa distribuição apresentou valor médio de 35,14 土1,99\%o, com máximo de 38,51\%o e mínimo de 15,48\%o.

A distribuição de salinidade na superfície apresentou um padrão resultante da relação entre evaporação, precipitação e vazão fluvial, com presença de pontos de baixa salinidade na desembocadura dos principais rios (Congo, da Prata e Amazonas) e região de ressurgência na costa angolana e na Plataforma da Argentina. Há um espalhamento dessas plumas de baixa salinidade que seguem as correntes locais. Na região de desembocadura do Rio da Prata, a baixa salinidade parece espalhar-se pouco para norte (litoral do Rio Grande do Sul), divergindo do padrão encontrado por Boyer e Levitus 
(2002) que apresentou um maior espalhamento para norte, até a região de Cabo frio (litoral do Rio de Janeiro).
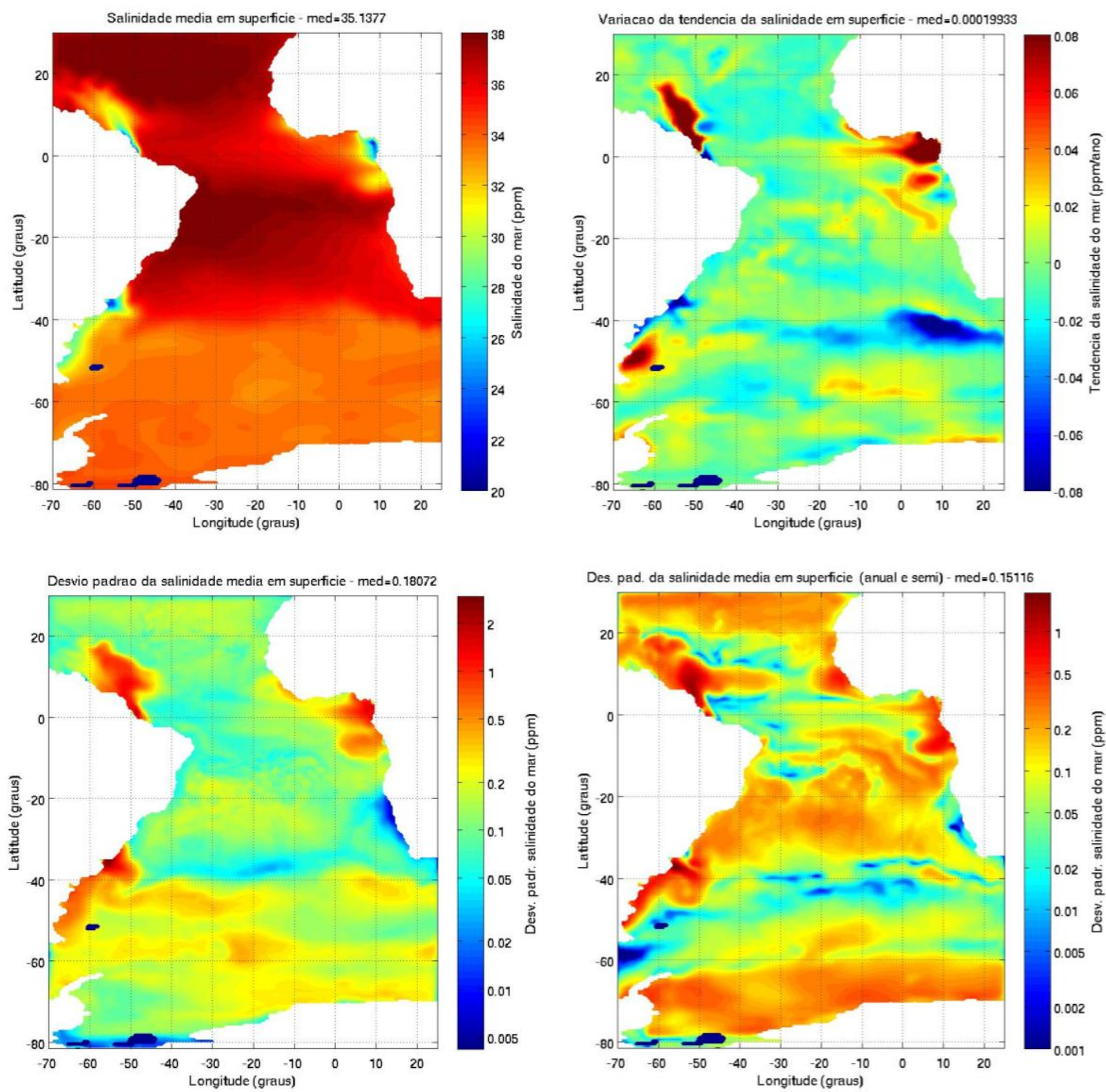

Figura 19: Distribuição espacial da média (acima, à esquerda) e da tendência (acima, à direita) da salinidade em superfície e seus respectivos desvios padrão, com a remoção dos sinais anual e semianual (abaixo, à esquerda) e apenas para os sinais anual e semianual (abaixo, à direita), no Atlântico Sul e Tropical, para o período de 2003 a 2009.

O desvio padrão da salinidade em superfície, após remoção dos sinais anual e semianual, apresentou valor médio de 0,18 \pm 0,16\%, com máximo de 2,96\%. O padrão de distribuição apresentou altos valores nas regiões de descarga de grandes rios e 
ressurgência costeira, ocorrência de baixíssimos valores na porção mais ao sul da costa africana e baixos valores no contorno que segue o Giro Subtropical do Atlântico Sul (GSAS). O desvio padrão dos sinais anual e semianual apresentou valor médio de 0,15 $\pm 0,14 \%$, com máximo de 1,91\%o. Essa média é inferior ao da série residual, notandose valores altos, além das regiões já evidenciadas no desvio padrão das séries sem esse sinal, em todo o entorno do continente antártico e dentro do giro subtropical. É notável um mínimo do desvio na região de introdução da Corrente Circumpolar Antártica (CCA) no Atlântico Sul.

A distribuição da tendência da salinidade apresentou valor médio de $0,02 \pm$

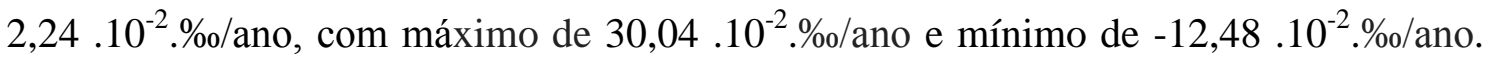
Valores positivos maiores foram detectados nas regiões de desembocadura dos rios Congo e Amazonas e na região da Plataforma Continental Argentina. Isso denota uma tendência de aumento da salinidade para o período analisado. Por outro lado, valores fortemente negativos são encontrados na desembocadura do Rio da Prata e na região ao sul do continente africano, próximo à latitude $40^{\circ} \mathrm{S}$.

A seguir, se tem as distribuições das médias de elevação da superfície, com tendências e desvios padrão (Figura 20). As elevações médias da superfície apresentaram um valor médio de $-0,56 \pm 0,79 \mathrm{~m}$, com máximo de 0,56 m e mínimo de 1,99 m. Essa distribuição apresentou padrão específico, com uma região triangular de elevação positiva característica do interior do GSAS centrada na região do Elevado Rio Grande. Há um forte gradiente na faixa de latitude de $45^{\circ} \mathrm{S}$, com elevações negativas na região polar e um núcleo negativo ao Sul da região da CBM. Esse padrão médio foi verificado por Barron et al. (2004).

O desvio padrão, após remoção dos sinais anual e semianual, apresentou valor médio de 0,03 $\pm 0,01 \mathrm{~m}$, com máximo de 0,08 $\mathrm{m}$ e mínimo de 0,01 $\mathrm{m}$. Os valores máximos foram encontrados na região costeira e adjacências do extremo sul do continente americano, com valores mais baixos na região ao norte da latitude $40^{\circ} \mathrm{S}$. O desvio padrão dos sinais anual e semianual apresentou valor médio de 0,02 $\pm 0,01 \mathrm{~m}$, com máximo de $0,13 \mathrm{~m}$, apresentando predomínio de baixos valores próximo à região equatorial e na faixa entre $40^{\circ} \mathrm{S}$ e $60^{\circ} \mathrm{S}$. Os valores mais altos foram encontrados na região próxima à desembocadura do Rio da Prata, espalhando-se para leste na mesma faixa de latitude. Schouten, Matano e Strub (2005) verificaram que, no Atlântico Equatorial, o ciclo sazonal é dominante em dados de elevação de superfície. Na figura 
20 verifica-se que a variabilidade desse sinal torna-se mais notável na faixa próximo à latitude de $40^{\circ} \mathrm{S}$.
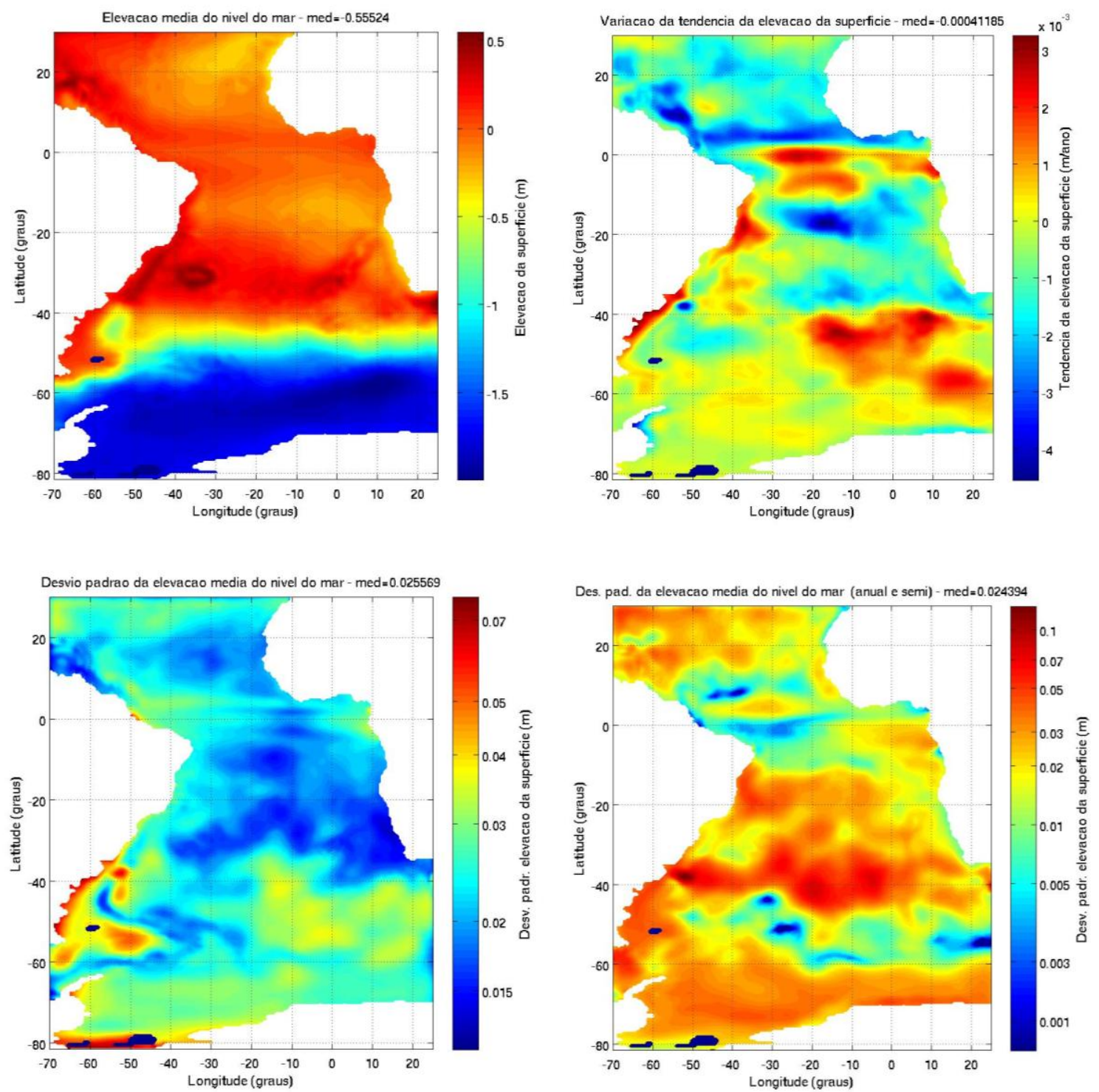

Figura 20: Distribuição espacial da média (acima, à esquerda) e da tendência (acima, à direita) da elevação da superfície do mar e seus respectivos desvios padrão, com a remoção dos sinais anual e semianual (abaixo, à esquerda) e apenas para os sinais anual e semianual (abaixo, à direita), no Atlântico Sul e Tropical, para o período de 2003 a 2009.

A distribuição das tendências de elevação da superfície teve média espacial de $-0,04 \pm 0,12.10^{-2} \cdot \mathrm{m} / \mathrm{ano}$, com máxima de $0,33 \cdot 10^{-2} \cdot \mathrm{m} /$ ano e mínima de $-0,45.10^{-}$ 
${ }^{2}$.m/ano. As tendências mais positivas concentram-se na costa sul do continente americano, na região do Equador até $10^{\circ} \mathrm{S}$ e entre $40^{\circ} \mathrm{S}$ e $60^{\circ} \mathrm{S}$, na porção mais a leste. Essas tendências possuem ordem de grandeza inferior aos desvios, o que torna as afirmações sobre as mesmas não conclusivas.

$\mathrm{Na}$ análise da distribuição global de tendências de nível do mar, proveniente de dados do TOPEX/POSEIDON para os períodos de 1993 a 1998 (CABANES, CAZENAVE, e PROVOST, 2001) e 1993 a 1998 (CAZENAVE e NEREM, 2004), se verificam, para o Atlântico Sul e Tropical, valores em módulo inferiores aos encontrados no restante do globo, em especial quando comparado ao Oceano Pacífico. Essa região apresenta, de maneira geral, valores que não ultrapassam $1.10^{-2} \mathrm{~m} / \mathrm{ano}$ (em módulo), com a região tropical apresentando valores médios entre 0 e 0,3 .10 $10^{-2} \mathrm{~m} / \mathrm{ano}$. Essa ordem de grandeza é compatível com os dados obtidos nesse trabalho, porém as distribuições espaciais são muito distintas, uma vez que são considerados períodos diferentes. Isso pode indicar variabilidade das tendências nessa região em períodos distintos, o que deixa ainda mais evidente a necessidade de análises com séries temporais maiores.

Tanto Cabanes, Cazenave, e Provost (2001) como Cazenave e Nerem (2004) associam boa parte da tendência à componente estérica (associada à expansão térmica), o que pode explicar similaridades encontradas na distribuição espacial dessas tendências com as de temperatura (figura 17).

A distribuição das médias das intensidades das correntes em superfície (figura 21) apresentou valor médio de $11,58 \pm 12,01 \mathrm{~cm} / \mathrm{s}$, com máximo de $31,72 \mathrm{~cm} / \mathrm{s}$ e mínimo de $0,97 \mathrm{~cm} / \mathrm{s}$. Os valores máximos foram encontrados na região equatorial, região da Corrente Sul Equatorial (CSE) e na costa ao norte da América do Sul, região da Corrente Norte do Brasil (CNB). Nota-se, também, região de grande intensidade de correntes ao sul do continente americano, desde a Corrente das Malvinas (CM) até a confluência com a Corrente do Brasil, e toda a faixa entre $40^{\circ} \mathrm{S}$ e $60^{\circ} \mathrm{S}$, que compreende a Corrente do Atlântico Sul (CAS) e a CCA. Esse comportamento médio é verificado para o Atlântico Tropical, com dados coletados por derivadores em diferentes períodos (LUMPKIN e GARZOLI, 2005; RICHARDSON e PHILANDER, 1987). É notável, também, o efeito batimétrico nas feições de grande intensidade de correntes no centro do GSAS, contornando o Elevado Rio Grande e um padrão meandrante na região da Cadeia Walvis. 

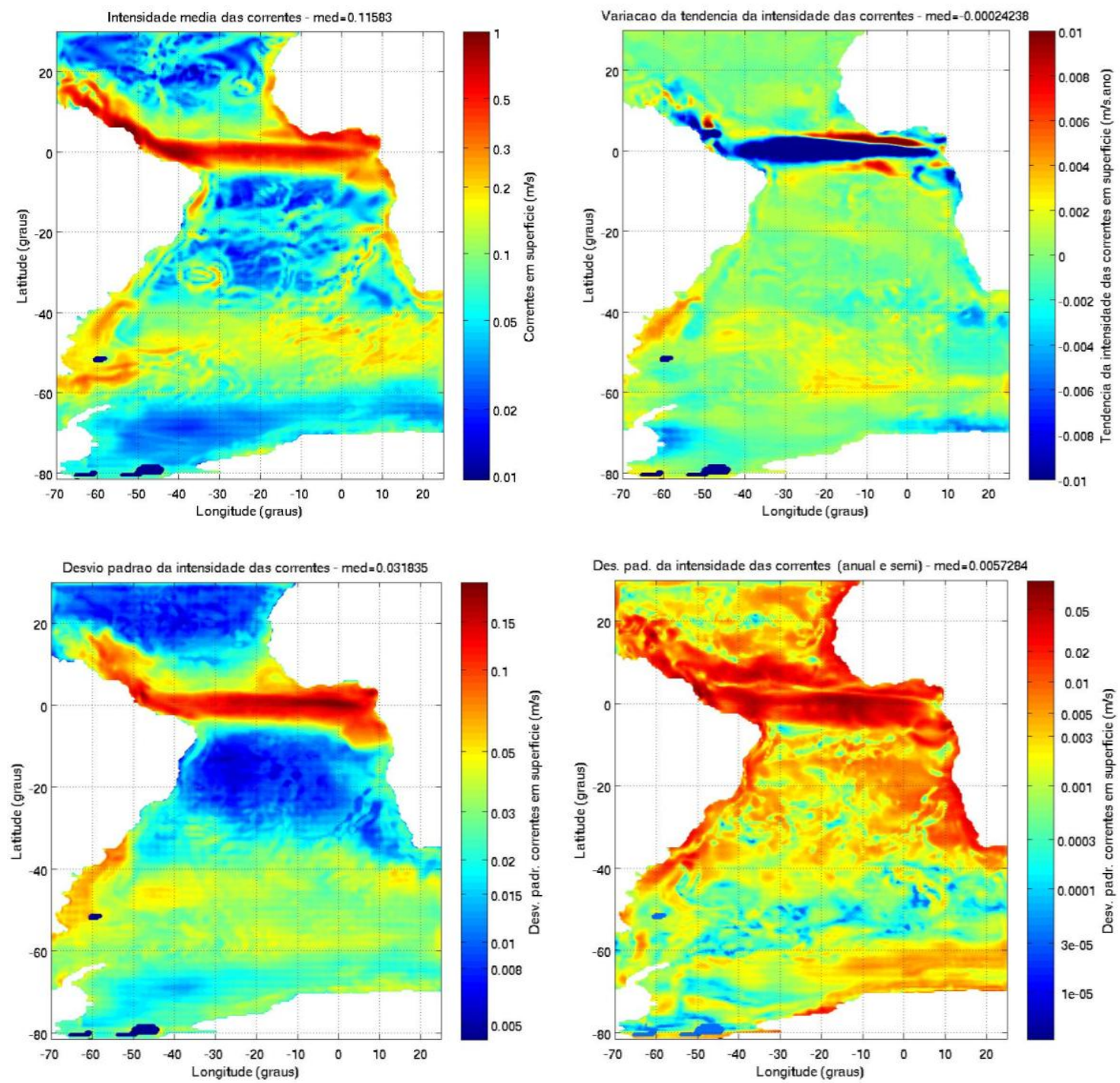

Figura 21: Distribuição espacial da média (acima, à esquerda) e da tendência (acima, à direita) da intensidade das correntes em superfície e seus respectivos desvios padrão, com a remoção dos sinais anual e semianual (abaixo, à esquerda) e apenas os sinais anual e semianual (abaixo, à direita), no Atlântico Sul e Tropical, para o período de 2003 a 2009.

O desvio padrão, após remoção do sinal anual e semianual da intensidade das correntes, apresentou média espacial de 3,18 $\pm 2,67 \mathrm{~cm} / \mathrm{s}$, com máximo de $20,82 \mathrm{~cm} / \mathrm{s} \mathrm{e}$ mínimo de $0,45 \mathrm{~cm} / \mathrm{s}$. Sua distribuição segue o padrão da distribuição das médias, com maiores desvios nas regiões de maior intensidade de correntes. Já a distribuição do desvio padrão, referente aos sinais anual e semianual, apresentou média de 0,57 $\pm 0,96$ $\mathrm{cm} / \mathrm{s}$, com máximo de $9,54 \mathrm{~cm} / \mathrm{s}$ e mínimo de aproximadamente $0 \mathrm{~m} / \mathrm{s}$, valores bem inferiores ao desvio anterior. Isso denota que o desvio padrão da intensidade das correntes não é dominado pela sazonalidade. É apresentado, também, um padrão de 
maiores valores na região da CSE e da CNB e, em contraste ao desvio com remoção desse sinal, valores baixos na região da CCA. Esse padrão para o sinal anual e semianual assemelha-se ao verificado na região equatorial por Lumpkin e Garzoli (2005).

A distribuição da tendência apresentou valores médios de $-0,02 \pm 0,33$ $\mathrm{cm} / \mathrm{s}$.ano, com máximo de 2,05 cm/s.ano e mínimo de $-2,94 \mathrm{~cm} / \mathrm{s}$.ano. É marcante a ocorrência de tendências fortemente negativas na região da CSE e da CNB, denotando um comportamento de enfraquecimento da intensidade das mesmas. Uma leve tendência positiva é encontrada na região da CM.

As distribuições das médias das concentrações de clorofila $a$, tendências e desvios padrão são apresentadas na Figura 22. A distribuição das médias da clorofila $a$ apresentou comportamento similar ao observado pela análise de longo prazo, com dados de sensoriamento remoto, realizada por Deser (2010) e Saraceno, Provost, e Piola (2005), e em interpolação ótima de dados observacionais por Reynolds e Smith (1994).

A distribuição das médias de clorofila $a$ apresentou média de 0,31 \pm 0,78 $\mathrm{mg} / \mathrm{m}^{3}$, com máximo de $25,20 \mathrm{mg} / \mathrm{m}^{3}$. Pode-se observar um padrão de altas concentrações nas regiões de ressurgência costeira, ressurgência equatorial e em altas latitudes. Esses resultados corroboram os obtidos por Wang (2003) em climatologia dos dados SeaWiFS para período de 1997 a 2007 que, também, verifica a sazonalidade da clorofila $a$ na região equatorial, descargas do rio Amazonas e regiões de ressurgência ao norte da África, como se pode observar na distribuição do desvio padrão dos sinais anual e semianual. Em estudo de Saraceno, Provost e Piola (2005) e Garcia et al. (2004) também constataram esse padrão médio verificado na região de CBM.

A distribuição do desvio padrão (após remoção do sinal anual e semianual) apresentou média de 0,22 $\pm 0,75 \mathrm{mg} / \mathrm{m}^{3}$, com máximo de 21,22 $\mathrm{mg} / \mathrm{m}^{3}$. Essa distribuição espacial tem padrão semelhante ao das médias das concentrações, com maiores valores de desvio padrão nas regiões de maior concentração média.

A distribuição espacial do desvio padrão dos sinais anual e semianual apresentou valor médio de $0,03 \pm 0,10 \mathrm{mg} / \mathrm{m}^{3}$, com máximo de $3,26 \mathrm{mg} / \mathrm{m}^{3}$, valores esses bem inferiores aos encontrados no desvio do sinal residual, evidenciando valores significativos para a sazonalidade, porém não representando a maior parte do sinal. Garcia et al. (2004), por meio de análises espectrais, verificaram e salientaram a significância do sinal anual e semianual na variabilidade da clorofila $a$, na região da Corrente das Malvinas. Essa distribuição apresentou padrão semelhante ao encontrado 
na distribuição residual, mas com assinatura mais evidente na região ao norte da faixa de $40^{\circ} \mathrm{S}$.
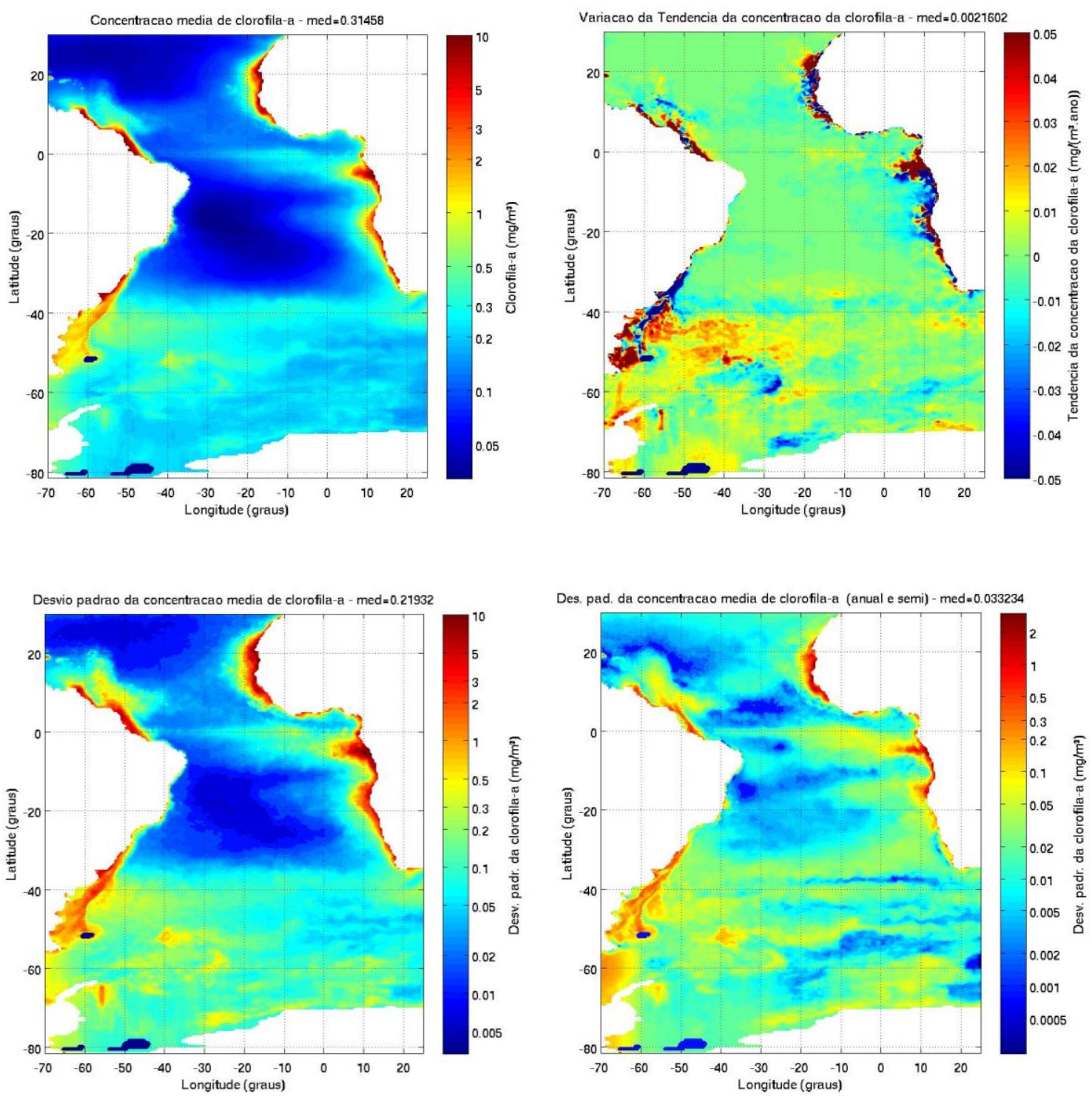

Figura 22: Distribuição espacial da média (acima, à esquerda) e da tendência (acima, à direita) da concentração de clorofila $a$ em superfície e seus respectivos desvios padrão, com a remoção dos sinais anual e semianual (abaixo, à esquerda) e apenas os sinais anual e semianual (abaixo, à direita), no Atlântico Sul e Tropical, para o período de 2003 a 2009.

Assim como em ambos os desvios padrão para salinidade, a clorofila $a$ também apresenta valores altos nas regiões de desembocadura de grandes rios, salientando a 
importância da descarga fluvial no controle da produtividade primária, tanto em uma avaliação sazonal como nas demais frequências.

O desvio padrão para o sinal residual da intensidade das correntes, também, apresentou similaridades com o mesmo desvio para clorofila $a$ no que se diz respeito às regiões de médias e altas latitudes. Nessa região houve a ocorrência de menores valores no interior do GSAS e valores altos ao Sul de $40^{\circ} \mathrm{S}$. Isso induz à ideia de melhor desenvolvimento da clorofila $a$ em regiões de maior turbulência, que propiciaria maior mistura vertical.

A distribuição da tendência apresentou média de $0,22 \pm 3,79.10^{-2} \cdot \mathrm{mg} / \mathrm{m}^{3}$.ano, com valor máximo de $116,64.10^{-2} \cdot \mathrm{mg} / \mathrm{m}^{3}$.ano e mínimo de $-188,39.10^{-2} \cdot \mathrm{mg} / \mathrm{m}^{3}$.ano. As grandes variabilidades concentraram-se nas regiões costeiras, tendo como destaque uma região de tendência negativa próximo à desembocadura do Rio da Prata. 


\subsection{Correlações entre clorofila $a$ e variáveis físicas}

A seguir serão apresentadas as distribuições do coeficiente de correlação linear, considerando a defasagem no tempo igual a zero para o Atlântico Sul e Tropical, entre a clorofila $a$ e as variáveis físicas provenientes do resultado da simulação do modelo (Figura 23).
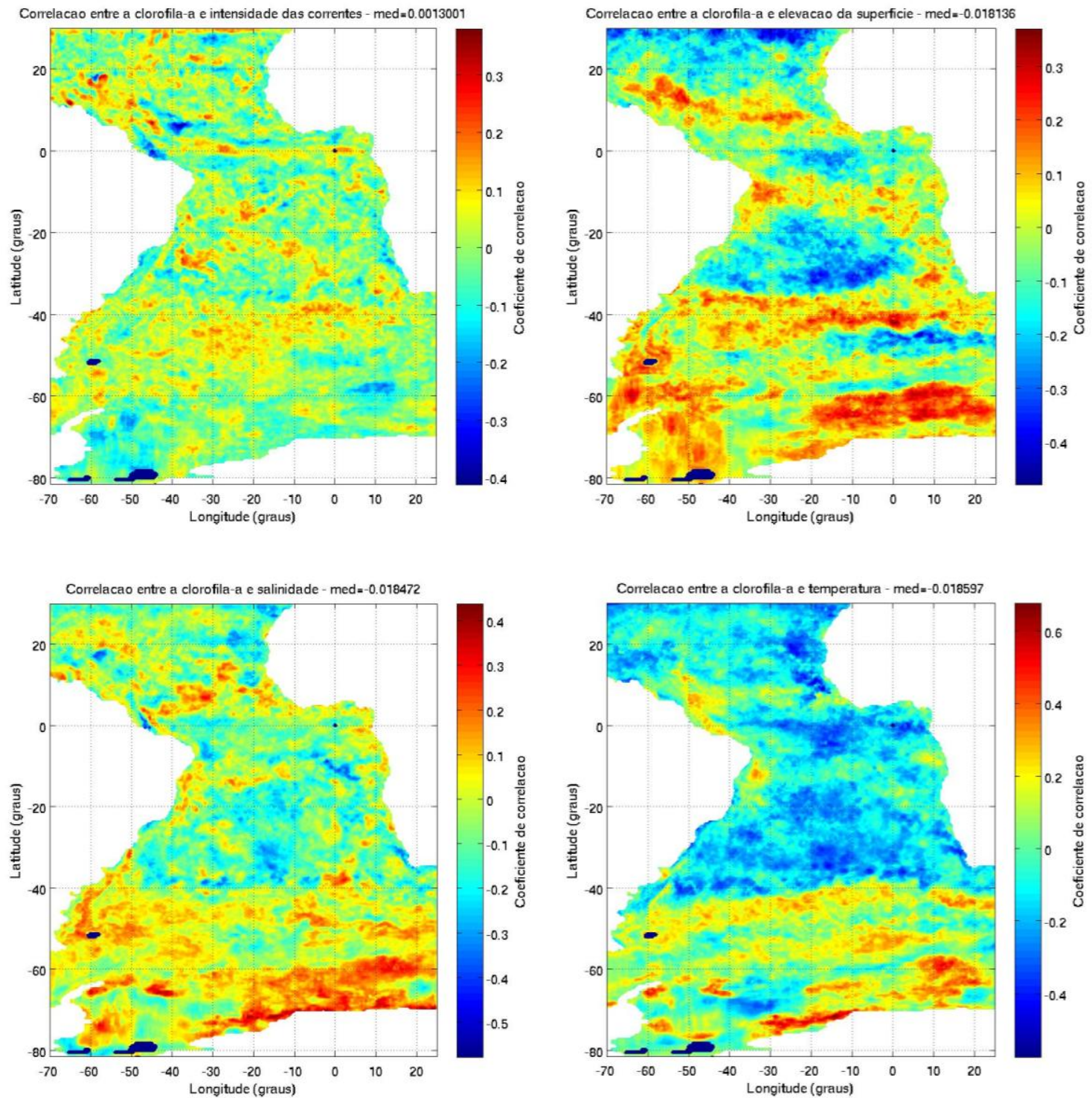

Figura 23: Distribuição espacial do coeficiente de correlação entre a clorofila $a$ e intensidade das correntes (à esquerda, acima), elevação do nível do mar (à direita, acima), salinidade (à esquerda, abaixo) e temperatura (à direita, acima), após remoção dos sinais anual e semianual, para o Atlântico Sul e Tropical, no período de 2003 a 2009. 
Observando a distribuição da correlação, considerando lag zero entre a clorofila $a$ e a intensidade das correntes, se verificou um valor médio de $0,00 \pm 0,08$, com máximo de 0,38 e mínimo de -0,41. Apesar de esses valores serem significativos, não se observou um padrão definido. É possível verificar a ocorrência de uma faixa de correlação positiva na região do Equador e um ponto de correlação negativa junto à desembocadura do Rio Amazonas.

A distribuição do coeficiente de correlação, entre a elevação de superfície e a clorofila $a$, apresentou valor médio de $-0,02 \pm 0,13$, com máximo de 0,37 e mínimo de 0,48. Apesar de ter apresentado valores relativamente próximos aos encontrados na correlação com a intensidade das correntes, essa distribuição apresentou um padrão espacial mais definido, no qual se observa que na região do triângulo de elevação positiva (GSAS) predomina um coeficiente de correlação negativa. As regiões equatorial, sul do Giro Subtropical do Atlântico Norte (GSAN) e uma faixa em torno de $45^{\circ} \mathrm{S}$ também são por correlação negativa.

A distribuição das correlações entre clorofila $a$ e salinidade apresentou valor médio de $-0,02 \pm 0,12$, com máximo de 0,44 e mínimo de -0,58. Essa distribuição não apresentou padrão espacial tão definido, mas se caracteriza pelo predomínio das correlações positivas em altas latitudes (até a latitude de $40^{\circ} \mathrm{S}$ ) e numa faixa entre o Equador e $10^{\circ}$ N. A desembocadura do Rio Amazonas apresentou correlações negativas. Esse fato sugeriria que, quanto menor a salinidade local e maior a descarga fluvial, ocorreria um aumento no aporte de nutrientes limitantes no processo de fotossíntese.

A distribuição das correlações com temperatura apresentou média espacial de $0,02 \pm 0,17$, com valor máximo de 0,68 e mínimo de -0,57. Nessa figura, pode-se verificar um padrão de distribuição bem definido, com valores positivos em altas latitudes (até $40^{\circ} \mathrm{S}$ ), confinado pela Confluência Brasil Malvinas (CBM), Corrente do Atlântico Sul (CAS) e Retroflexão da Corrente das Agulhas (RCA). Pode-se observar, também, a ocorrência de altas correlações positivas junto à descarga do Rio Amazonas e na região próxima ao litoral nordeste do Brasil.

Em médias e baixas latitudes, o aumento da temperatura impulsiona uma intensificação da termoclina que forma uma barreira térmica, dificultando a entrada de nutrientes das camadas mais profundas para a camada de mistura. Dessa forma, há uma redução da produtividade primária. Já em altas latitudes, as baixas temperaturas dificultam a formação de uma termoclina, de forma que o aumento da temperatura é um 
indicativo do aumento de radiação solar, resultando em uma maior penetração da mesma na coluna d'água e propiciando um aumento da produtividade primária.

A seguir, são apresentadas as distribuições das correlações entre clorofila $a$ e as variáveis físicas, considerando a variabilidade dessas correlações com o tempo (correlação cruzada) juntamente com suas defasagens no tempo (Figuras 24 e 25). Nessas defasagens, valores negativos significam antecedência na ocorrência da variável física em relação à biológica, enquanto que defasagens positivas significam um atraso na ocorrência da variável física, considerando a unidade de tempo igual a 8 dias (aproximadamente uma semana).

A distribuição das correlações cruzadas com a intensidade das correntes (Figura 24) apresentou valor médio de 0,01 \pm 0,15, com máximo de 0,41 e mínimo de 0,41 . Nota-se uma leve alteração na distribuição dessas correlações em relação ao lag zero, como uma faixa de correlação positiva na região equatorial, com defasagem negativa de até 10 semanas, o que significa uma precedência da variável física em relação à variável biológica. Há regiões de correlação negativa próximo à região de desembocadura do Rio Amazonas e no litoral sul e sudeste brasileiro com defasagens positivas em torno de 5 semanas.

A correlação positiva no equador é plausível ao se considerar a maior intensidade das correntes na região como resultante do aumento das intensidades dos ventos alísios na região. Sendo esse sistema de ventos responsável pela ressurgência na região, em decorrência do transporte de Ekman, mecanismo que gera componentes meridionais de correntes. Quanto maior a intensidade dos ventos maior a intensidade das correntes, sendo maior a intensidade da componente zonal das correntes. Isso geraria um maior transporte vertical nessa zona de divergência, aumentando o aporte de nutrientes de camadas mais profundas na região.

A ocorrência de valores de correlação altas em módulo, com defasagens tanto positivas como negativas, salienta a existência de um fator que influencia a variabilidade de ambas as variáveis correlacionadas não havendo, necessariamente, relação de causa e efeito entre essas variáveis.

A distribuição das correlações cruzadas entre a clorofila $a$ e a elevação do nível do mar (Figura 24) apresentou valor médio de $-0,02 \pm 0,20$, com máximo de 0,51 e mínimo de -0,48. Nota-se, nessa distribuição, um reforço do que foi encontrado anteriormente com defasagem zero. O triângulo de elevação positiva mantém correlação negativa, com defasagem praticamente zero, comportamento esse seguido nas regiões 
equatorial e do GSAN. Nas regiões de correlação positiva há um predomínio de defasagem positiva, mas com muita variabilidade.

A forte correlação negativa na região no interior do GSAS pode sugerir que o aumento da elevação de superfície é acompanhado por um aumento na profundidade (afundamento) da termoclina, afastando a região abaixo dessa camada (com mais nutrientes) da zona fótica, o que reduziria a produtividade primária. Esse tipo de evento teria uma resposta biológica quase imediata.
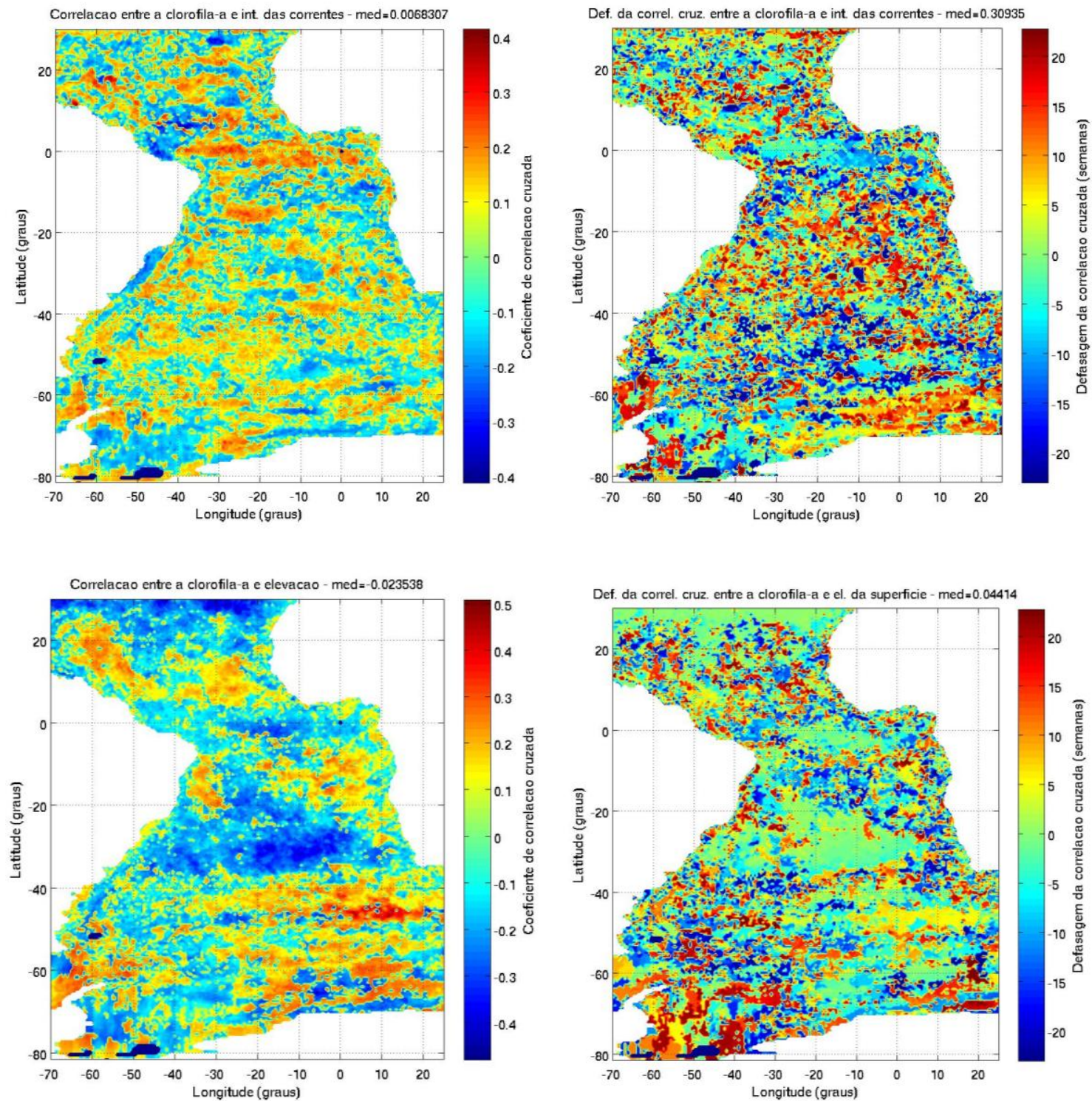

Figura 24: Distribuição espacial do coeficiente de correlação entre clorofila $a$ e intensidade das correntes (à esquerda, acima) e sua defasagem no tempo (à direita, acima), e entre clorofila $a$ e elevação do nível do mar (à direita, abaixo) e sua defasagem no tempo (à esquerda, abaixo), após remoção dos sinais anual e semianual, para o Atlântico Sul e Tropical, no período de 2003 a 2009. 
A distribuição das correlações cruzadas com a salinidade (Figura 25) apresentou valor médio de $-0,04 \pm 0,21$, com máximo de 0,48 e mínimo de $-0,64$. Nessa distribuição verificam-se similaridades com a distribuição da correlação simples, com predomínio de correlações positivas em altas latitudes e numa faixa acima do Equador, estando essas associadas a defasagens negativas de mais de 15 semanas. As correlações negativas, em especial as mais intensas em região próxima ao continente antártico, estão associadas, em geral, a defasagens positivas.

A distribuição das correlações cruzadas com a temperatura (Figura 25) apresentou valor médio de $-0,02 \pm 0,22$, com máximo de 0,68 e valor mínimo de -0,57. Essa distribuição corrobora o padrão já verificado na correlação simples, salientando a associação dessa correlação a uma resposta temporal praticamente instantânea. 

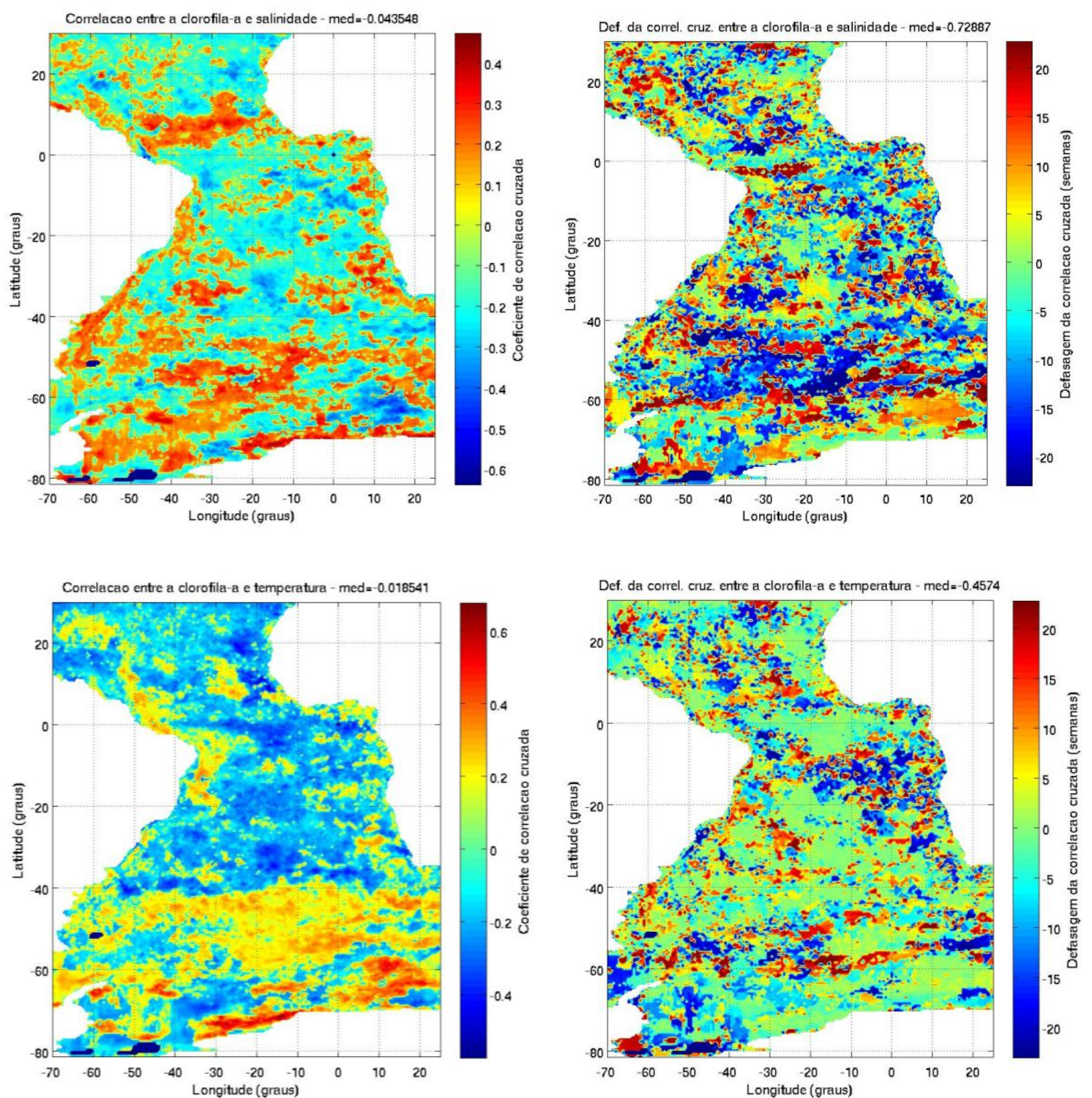

Figura 25: Distribuição espacial do coeficiente de correlação entre clorofila $a$ e salinidade (à esquerda, acima) e sua defasagem no tempo (à direita, acima), e entre clorofila $a$ e temperatura (à direita, abaixo) e sua defasagem no tempo (à esquerda, abaixo), após remoção dos sinais anual e semianual, para o Atlântico Sul e Tropical, no período de 2003 a 2009. 


\subsection{Análises no transecto $20^{\circ} \mathrm{W}$}

A seguir, são apresentadas as séries de clorofila $a$, sendo comparadas com as de temperatura e elevação da superfície, em pontos ao longo de um transecto na longitude de $20^{\circ} \mathrm{W}$. Foram escolhidas essas variáveis físicas pelo fato delas apresentarem, nas análises anteriores, os maiores valores de correlações (em módulo) juntamente a padrões espaciais melhor definidos merecendo, portanto, um estudo mais aprofundado. Esse transecto foi selecionado devido ao padrão latitudinal da distribuição das correlações para essas variáveis. As análises que seguem serão apresentadas com e sem a presença dos sinais anal e semianual das séries temporais.

Além da comparação visual das séries temporais (com e sem os sinais anual e semianual) são comparados, também, os espectros de Fourier das séries temporais (sem os sinais anual e semianual), as covariâncias cruzadas (sem os sinais anual e semianual), o espectro de Fourier dessa covariância (incluindo defasagens) e a correlação cruzada (com defasagens, sem os sinais anual e semianual).

\subsubsection{Comparação entre clorofila $a$ e elevação da superfície}

A seguir, tem-se uma comparação entre a clorofila $a$ e a elevação da superfície para o ponto $0^{\circ} \mathrm{N}-20^{\circ} \mathrm{W}$ com uma análise espectral. Inicialmente, observando a Figura 26, para as séries com e sem o sinal anual e semianual, nota-se que esses sinais realmente são marcantes nas séries. Pode-se notar um comportamento que denota uma provável correlação negativa das séries, mesmo removendo-se os sinais anual e semianual, como já havia sido verificado na distribuição espacial do coeficiente de correlação linear (Figura 23).

Na Figura 26 nota-se que a elevação da superfície e a concentração de clorofila $a$ possuem picos de sinais referentes a algumas frequências em ambos os espectros, mas com importância diferenciada para cada espectro. Nos dois espectros é observado um pico intenso no período de 0,33 anos.

Por meio do espectro da covariância cruzada, após a remoção dos sinais anual e semianual (Figura 27), pode-se ver que, no ponto em que a defasagem é igual a zero a covariância apresenta alto valor em módulo, 72,14. O espectro de Fourier dessa covariância cruzada evidenciou, como principais períodos, os de 3,51 e 0,33 anos. A 
defasagem desse espectro mostra que o sinal referente ao período de 3,51 anos é em torno de -31,71 semanas, o que representa uma antecedência da elevação da superfície em relação à concentração da clorofila $a$. O pico de período 0,33 anos possui defasagem 5,87 semanas.

Schneider e Schoönwiese (1989) verificaram que o espectro de variância do Índice de Oscilação Sul (IOS) apresentou picos significativos com períodos de 2,3, 2,9, 3,5 e 6 anos. Fenômenos de El Niño-Oscilação Sul (ENOS) apresentam componentes interanuais que variam entre 2.3 e 3.4 anos e uma componente de baixa frequência de 6 anos ou mais, sendo o período de 2.3 anos consistente com periodicidade média do ENOS (TIMMERMANN, 2001). Dessa forma, podemos associar o sinal de período 3,51 anos aos fenômenos ENOS.

Alvarez-Ramirez, Echeverria e Rodriguez (2010) associam o sinal referente ao período de 0,33 anos no espectro de frequência de índice relacionado à Oscilação do Atlântico Norte (OAN), a efeitos ressonantes não lineares.

As correlações cruzadas, apresentadas na mesma figura, confirmam o padrão verificado na covariância cruzada, em que o primeiro ponto de correlação significativo possui correlação de $-0,27$ com defasagem de 1 semana. 

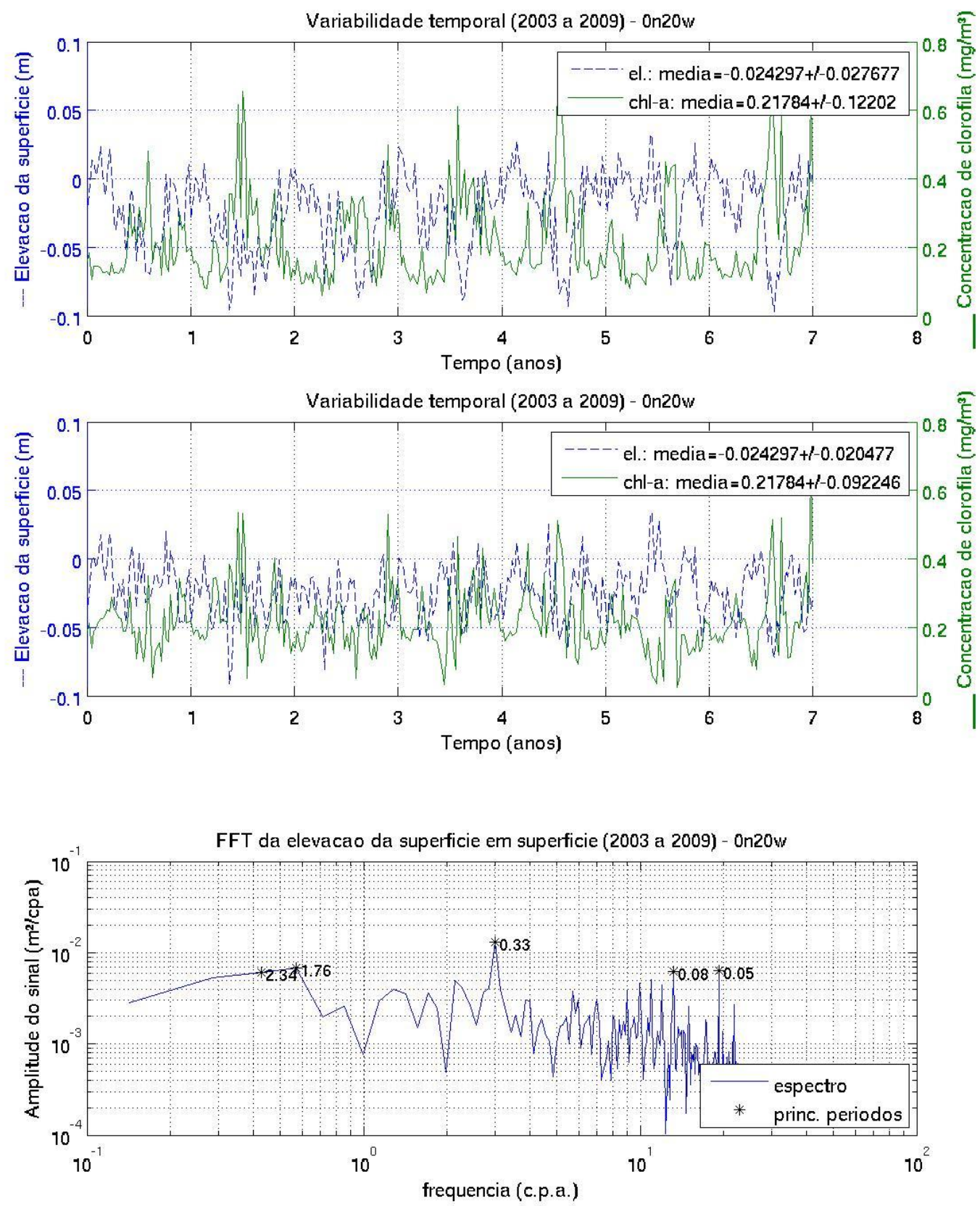

FFT da concentracao de clorofila (2003 a 2009) - On20w

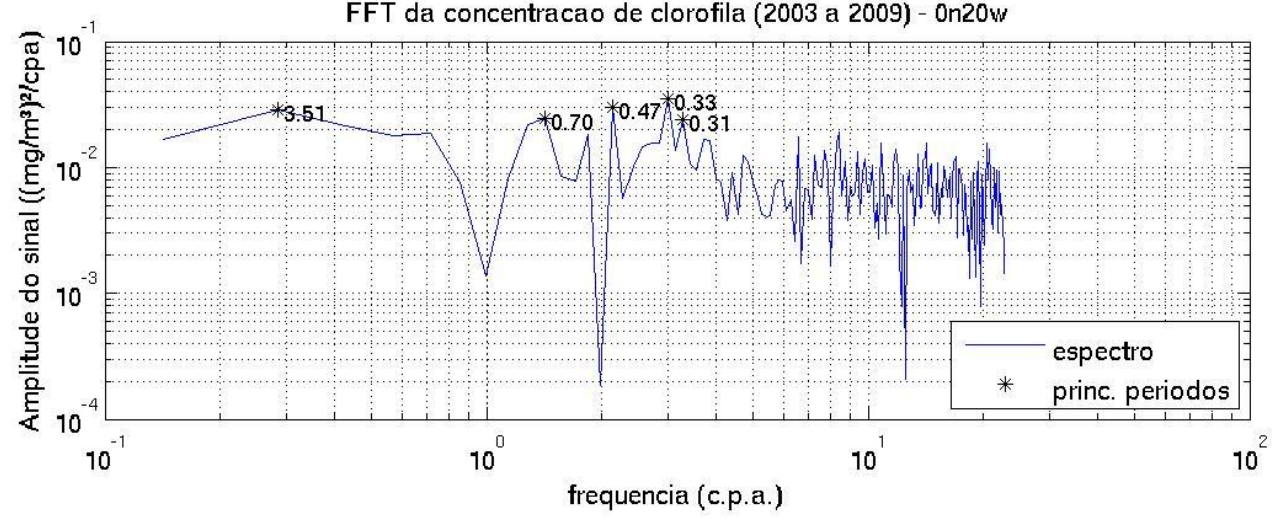

Figura 26: Séries temporais de clorofila $a$ e de elevação da superfície completas ( $1^{\circ}$ gráfico de cima para baixo) e sem os sinais anual e semianual ( $2^{\circ}$ gráfico) e espectros de Fourier para clorofila $a$ ( $3^{\circ}$ gráfico) e elevação de superfície ( $4^{\circ}$ gráfico) sem os sinais anual e semianual, para o ponto $0^{\circ} \mathrm{N}-20^{\circ} \mathrm{W}$. 

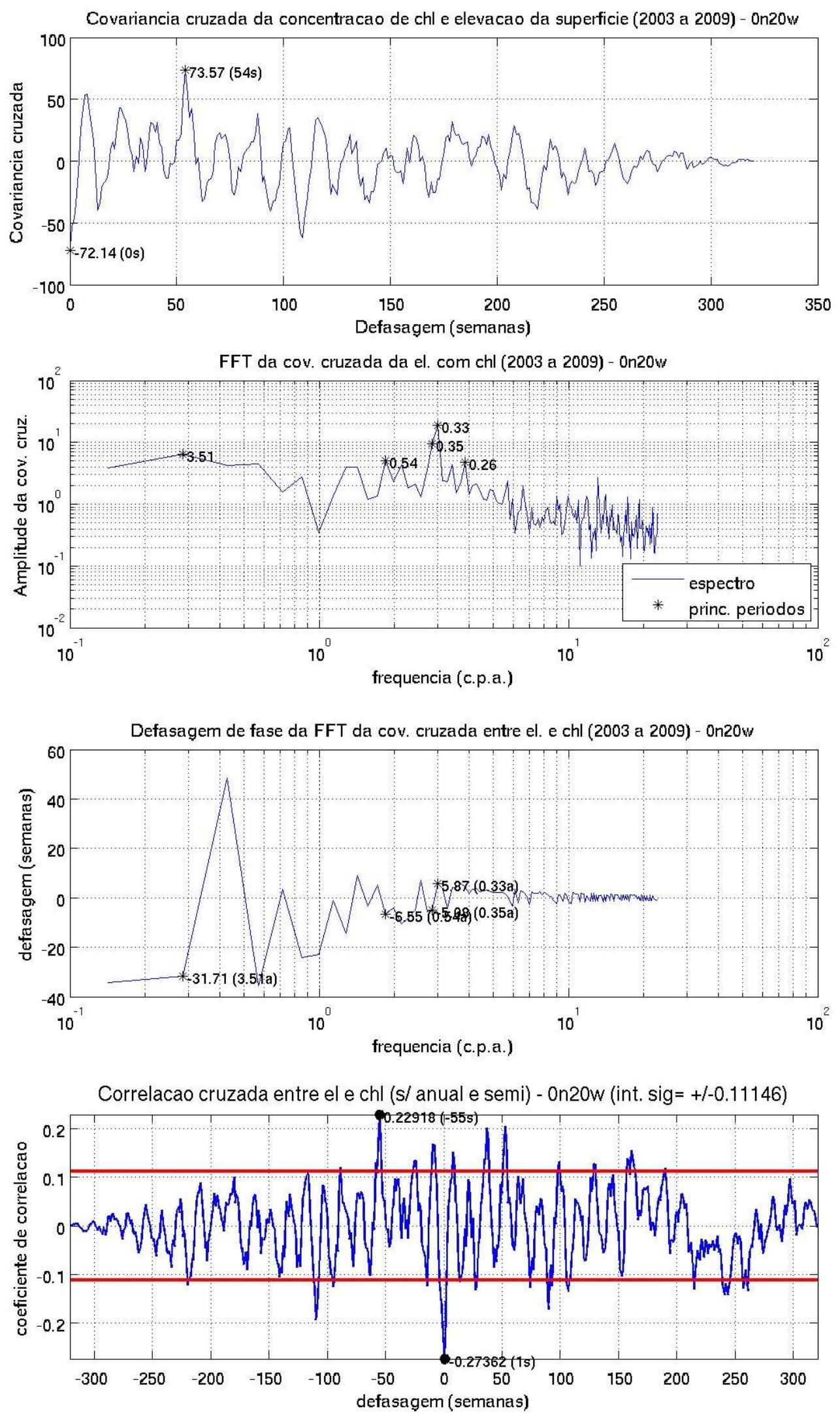

Figura 27: Covariância cruzada das séries de clorofila $a$ e de elevação da superfície ( $1^{\circ}$ gráfico, de cima para baixo), seu respectivo espectro de Fourier ( $2^{\circ}$ gráfico), as defasagens desse espectro ( $3^{\circ}$ gráfico) e a correlação cruzada das séries ( $4^{\circ}$ gráfico), para o ponto $0^{\circ} \mathrm{N}-20^{\circ} \mathrm{W}$. 
A seguir, são analisadas as séries de clorofila a elevação de superfície para o ponto $40^{\circ} \mathrm{S}-20^{\circ} \mathrm{W}$ (Figuras 28 e 29 ). Observando as séries temporais originais notouse um padrão evidente de correlações positivas, com pequeno atraso do sinal da elevação de superfície. Após remoção do sinal anual e semianual pode-se notar, ainda que de forma não tão evidente, que o comportamento se inverte.

Os espectros de Fourier das séries de clorofila $a$ e nível do mar apresentaram valor alto de amplitude para o período 1,76 anos (Figura 28). Schneider e Schoönwiese (1989) verificaram também, em seu estudo, que o espectro de variância do índice associado à Oscilação do Atlântico Norte (OAN) apresentava picos consideráveis nos períodos de 1,7, 2,2 e 7,5 anos. Portanto, esse sinal de 1,76 anos pode ter relação com o sinal analisado no índice associado à OAN.

A variabilidade da covariância cruzada em relação às defasagens no tempo mostrou uma covariância negativa, com pequeno valor em módulo, para uma defasagem igual a zero, sendo logo seguida de um pico positivo de valor de covariância superior a 30 e defasagem de 4 semanas (Figura 29). Esse ponto geográfico encontra-se, na distribuição de correlações entre elevação de superfície e clorofila $a$, em uma área de transição entre correlações positivas e negativas (Figura 24).

O espectro de Fourier da covariância cruzada salienta o período de 1,76 anos, que apresentou defasagem de $-6,41$ semanas, o que representa um atraso no sinal da clorofila $a$ em relação à elevação da superfície. Outros períodos importantes são os de 0,25, 0,22 e 0,33 anos, que apresentam defasagem no tempo quase zero (Figura 29). O período de 0,25 anos, por se tratar de um submúltiplo do sinal anual, pode também estar relacionado a um efeito ressonante associado à sazonalidade.

A correlação cruzada apresentou como maior valor em módulo -0,16, apresentando defasagem no tempo de 4 semanas, um tempo de resposta relativamente pequeno. 

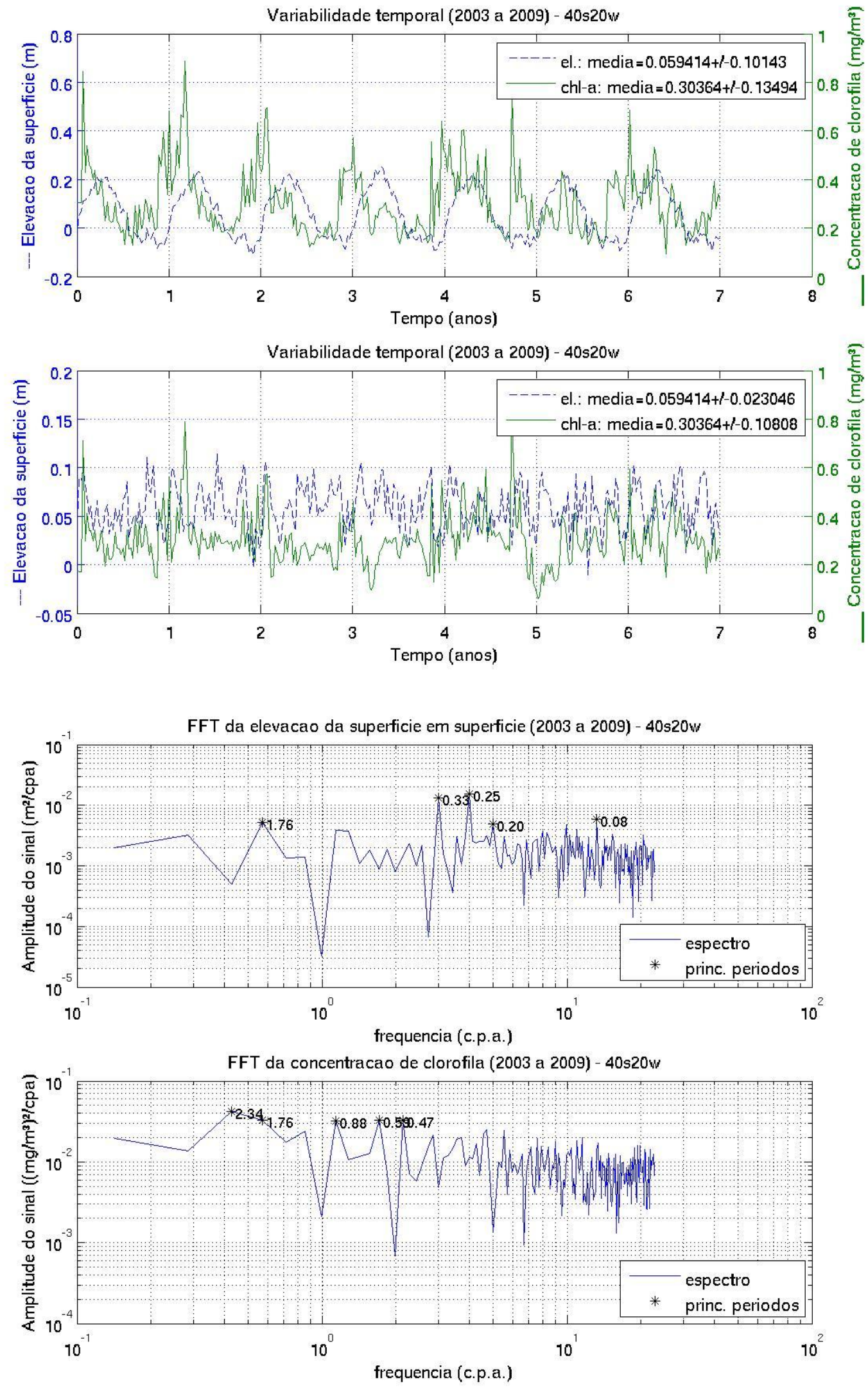

Figura 28: Séries temporais de clorofila $a$ e de elevação da superfície completas $\left(1^{\circ}\right.$ gráfico de cima para baixo) e sem os sinais anual e semianual ( $2^{\circ}$ gráfico) e espectros de Fourier para clorofila $a$ ( $3^{\circ}$ gráfico) e elevação de superfície ( $4^{\circ}$ gráfico) sem os sinais anual e semianual, para o ponto $40^{\circ} \mathrm{S}-20^{\circ} \mathrm{W}$. 

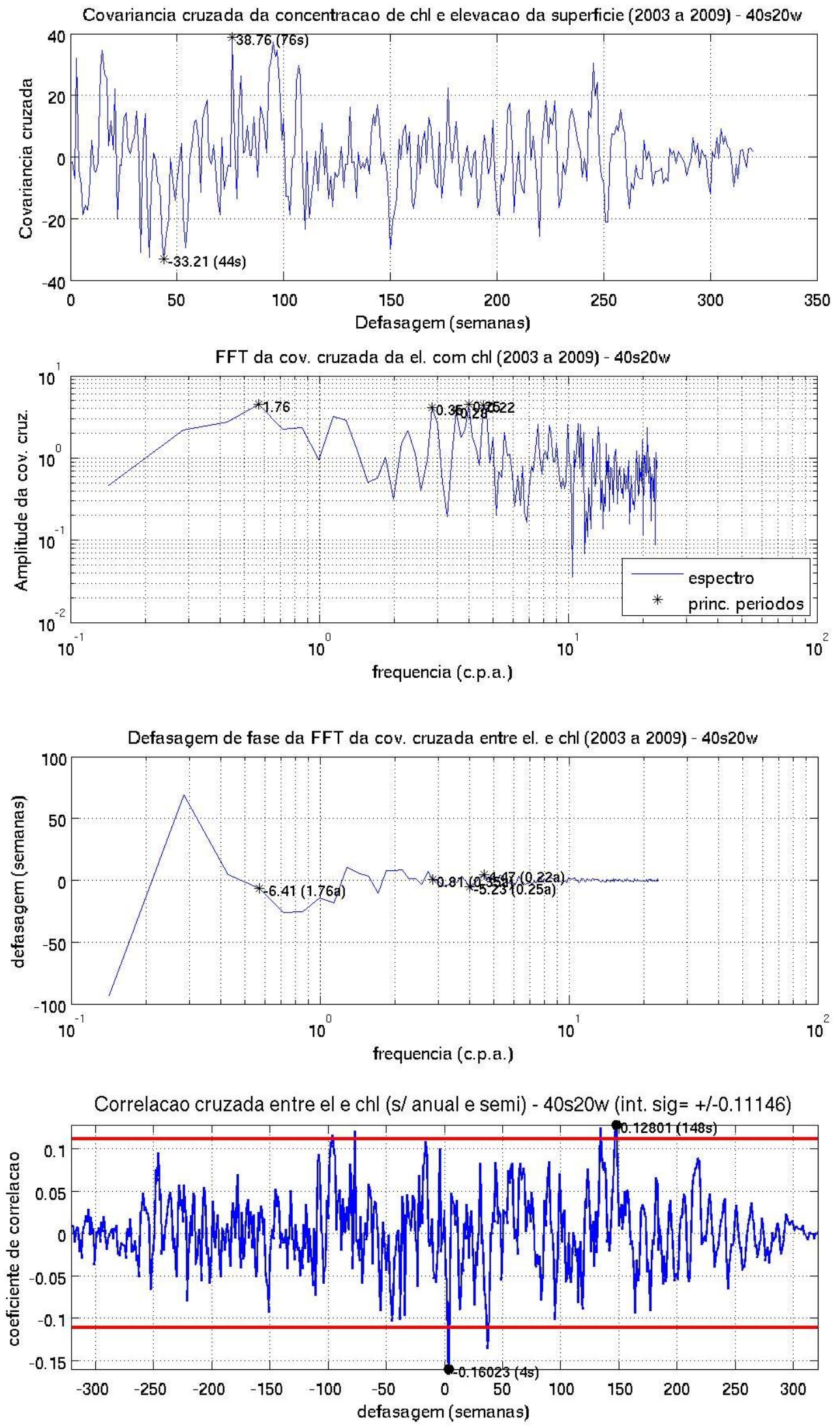

Figura 29: Covariância cruzada das séries de clorofila $a$ e de elevação da superfície ( $1^{\circ}$ gráfico, de cima para baixo), seu respectivo espectro de Fourier ( $2^{\circ}$ gráfico), as defasagens desse espectro ( $3^{\circ}$ gráfico) e a correlação cruzada das séries ( $4^{\circ}$ gráfico), para o ponto $40^{\circ} \mathrm{S}-20^{\circ} \mathrm{W}$. 
Nos gráficos referentes ao ponto $60^{\circ} \mathrm{S}-20^{\circ} \mathrm{W}$ (Figuras 30 e 31), as séries temporais de elevação de superfície e clorofila $a$ não apresentaram sinais anual e semianual evidentes. Os espectros de Fourier das variáveis aparentemente não apresentam semelhanças, com exceção do período de 0,28 anos, presente em ambos os espectros (Figura 30). O espectro de Fourier referente à clorofila $a$ apresenta sinal com grande amplitude no período equivalente a 7,02 anos que provavelmente está relacionado à própria extensão da série.

A correlação cruzada (Figura 31) apresentou na defasagem zero valor negativo, com módulo superior a 30, seguida por covariância positiva e valor também superior a 30, com defasagem em torno de 10 semanas. Esse ponto geográfico situa-se, na distribuição das correlações entre elevação de superfície e clorofila a, em uma região de transição entre correlações positivas e negativas (Figura 24).

O espectro de Fourier da covariância cruzada apresentou, como principais picos, os de período de 0,25, 0,33, 0,70 anos (Figura 31). Em análise da Magnitude Quadrática da Coerência para anomalias de temperatura da superfície do mar e Índice de Oscilação Sul (IOS), Campos et al. (1999) encontraram picos espectrais de frequências 0,12 e 0,055 cpm (equivalentes aos períodos de 0,7 e 1,5 anos, respectivamente), relacionando-os aos fenômenos de ENOS. O pico de 0,25 anos, por ser submúltiplo do sinal anual, pode estar relacionado a efeitos ressonantes dessa sazonalidade.

O período equivalente a 0,7 anos apresentou defasagem no tempo de $-12,75$ semanas, o que representa um atraso de fase do sinal na série de clorofila a em relação à série de elevação da superfície do mar. Os demais sinais apresentaram defasagem no tempo quase zero.

A correlação cruzada apresentou, como valor mais próximo da defasagem zero, a correlação de 0,12 (com defasagem de 3 semanas), confirmando comportamento observado pela covariância cruzada (Figura 31). 

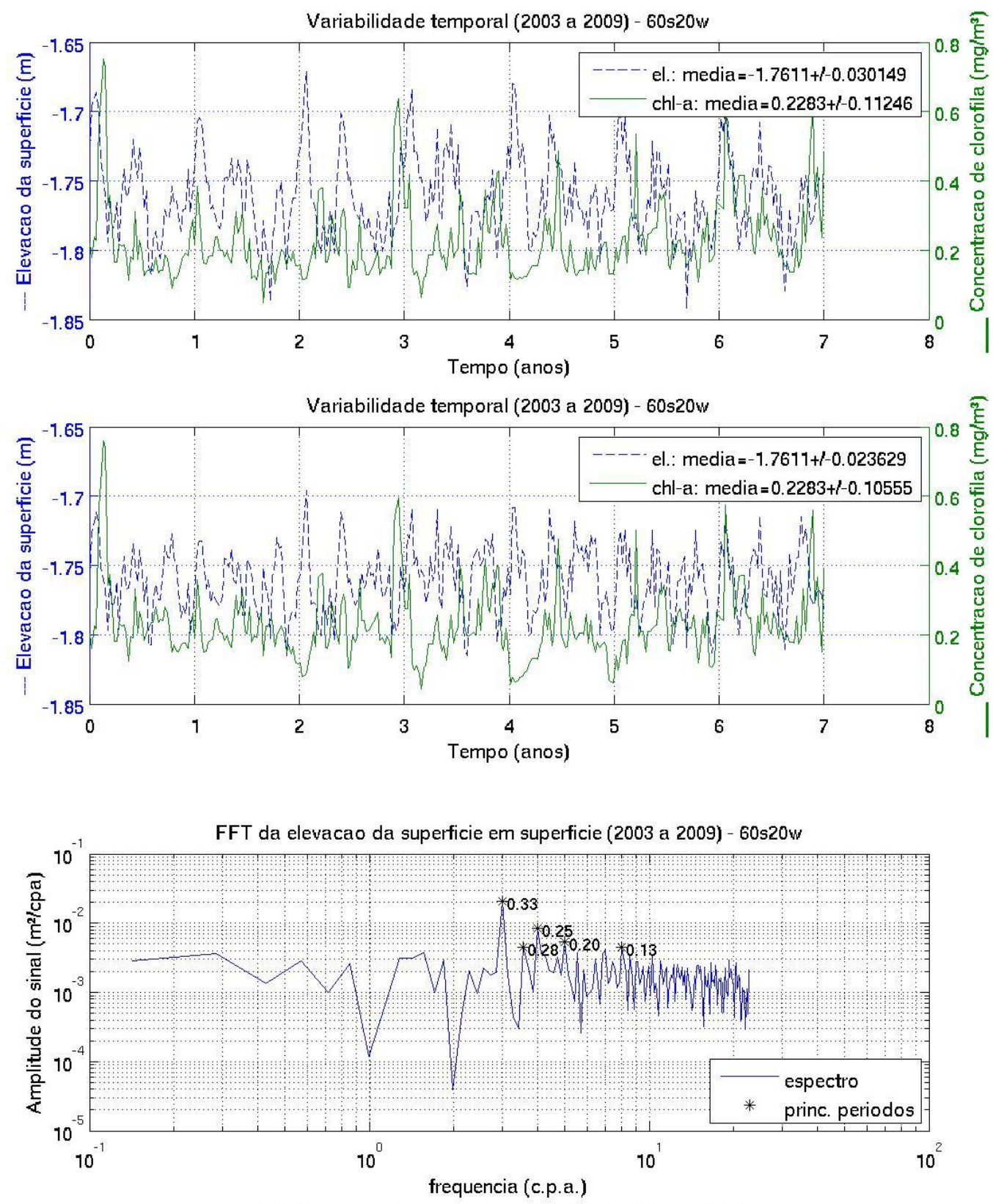

FFT da concentracao de clorofila (2003 a 2009) - 60s20w

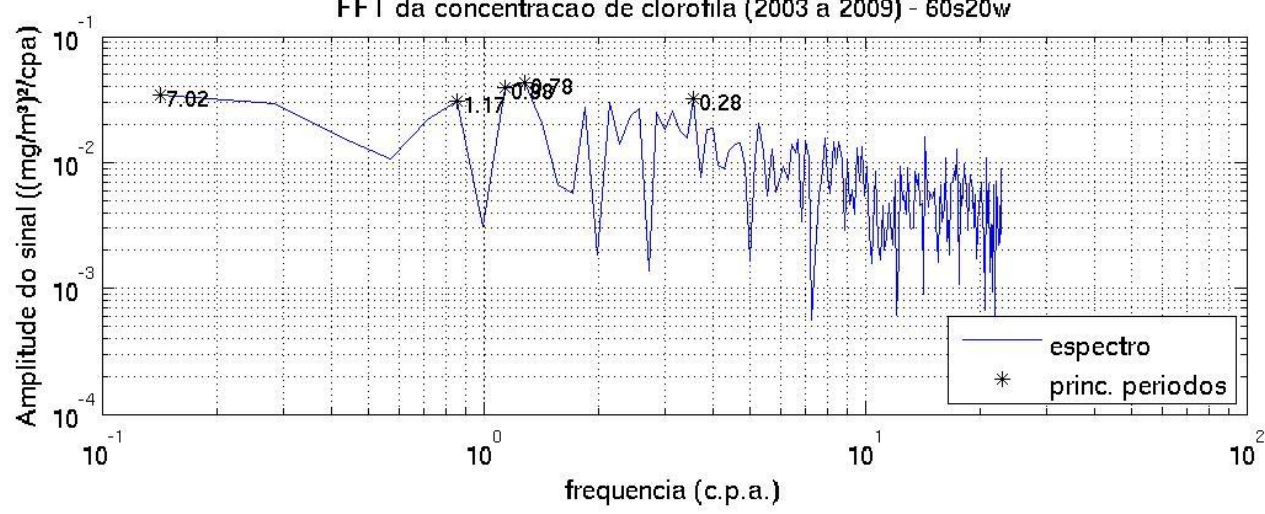

Figura 30: Séries temporais de clorofila $a$ e de elevação da superfície completas ( $1^{\circ}$ gráfico de cima para baixo) e sem os sinais anual e semianual ( $2^{\circ}$ gráfico) e espectros de Fourier para clorofila $a$ ( $3^{\circ}$ gráfico) e elevação de superfície ( $4^{\circ}$ gráfico) sem os sinais anual e semianual, para o ponto $60^{\circ} \mathrm{S}-20^{\circ} \mathrm{W}$. 

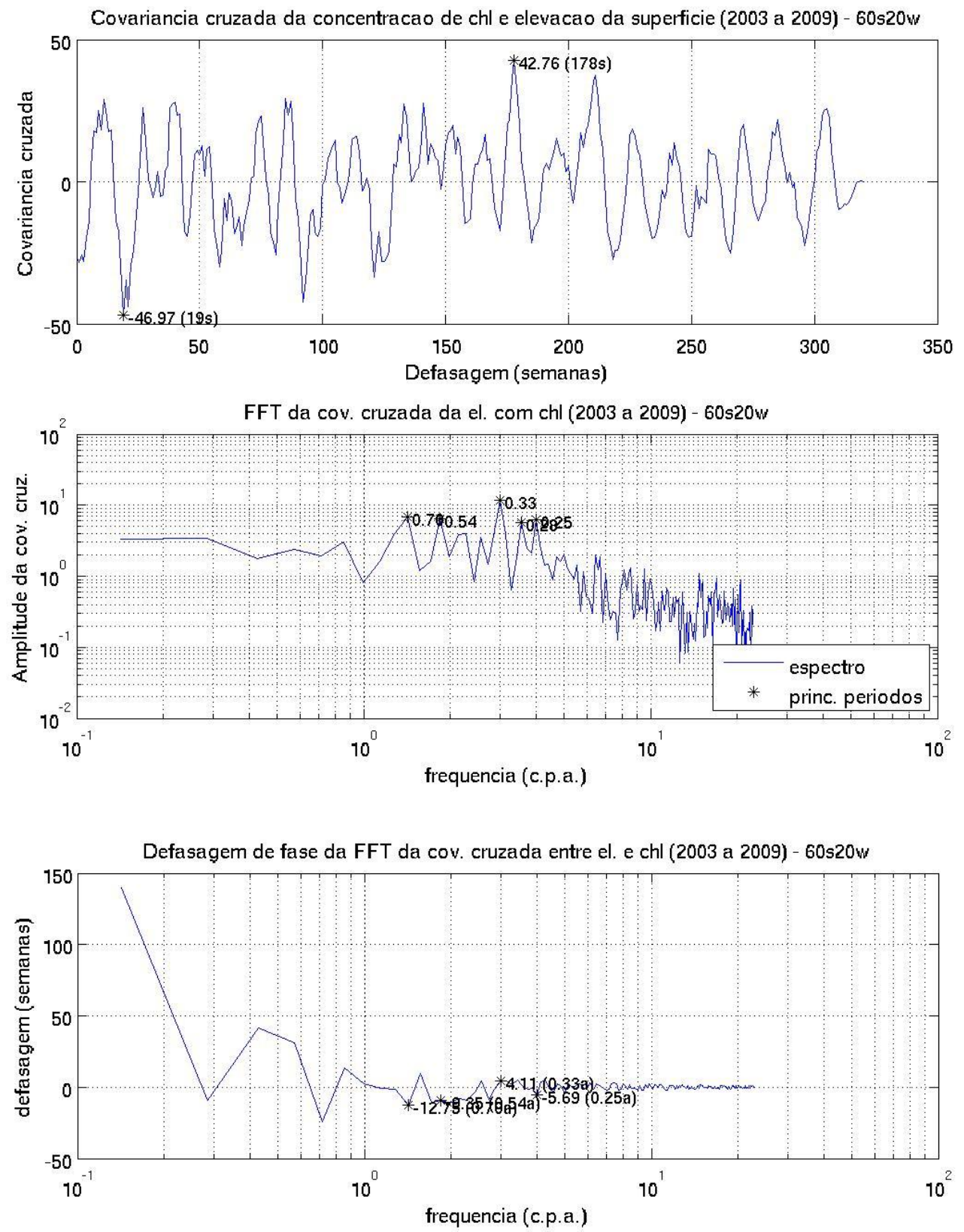

Correlacao cruzada entre el e chl (s/ anual e semi) -60 s20 (int. sig $=+/-0.11146$ )

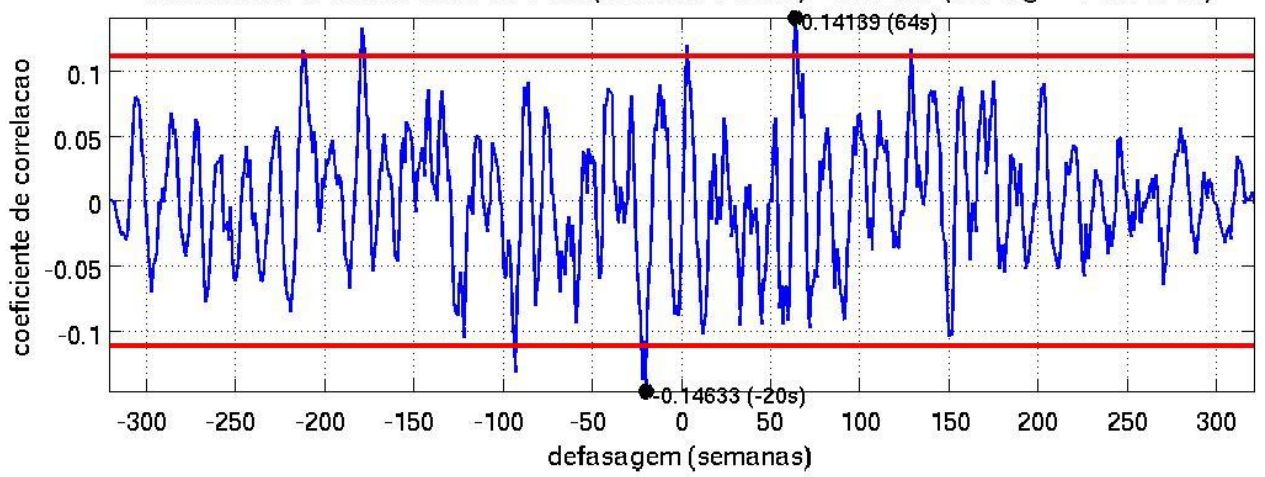

Figura 31: Covariância cruzada das séries de clorofila $a$ e de elevação da superfície ( $1^{\circ}$ gráfico, de cima para baixo), seu respectivo espectro de Fourier ( $2^{\circ}$ gráfico), as defasagens desse espectro ( $3^{\circ}$ gráfico) e a correlação cruzada das séries ( $4^{\circ}$ gráfico), para o ponto $60^{\circ} \mathrm{S}-20^{\circ} \mathrm{W}$. 


\subsubsection{Comparação entre clorofila $a$ e temperatura em superfície}

A seguir, é feita a comparação entre as séries de clorofila $a$ e de temperatura da superfície para o ponto $0^{\circ} \mathrm{N}-20^{\circ} \mathrm{W}$ e suas análises espectrais. Inicialmente, ao observar a Figura 32, as séries temporais completas apresentam claramente a assinatura da sazonalidade, com um padrão de correlação negativa. Após a remoção dos sinais anual e semianual, esse padrão se mantém, mas de maneira menos evidente.

Nos espectros de Fourier de cada uma das séries temporais, pode-se verificar que a clorofila apresenta espectro com grande similaridade ao espectro de temperatura, evidenciando os mesmos períodos de 0,33, 2,34 e 1,76 anos. A temperatura apresentou, também, o sinal de 0,89 anos que pode ser um resíduo do sinal anual removido da série (Figura 32).

A covariância cruzada mostrou, para esse ponto no Equador, um valor de 64,76 com defasagem igual a zero (Figura 33), o que corrobora com o que já havia sido encontrado na distribuição espacial dos coeficientes de correlação linear (Figura 23). Esse comportamento é similar ao encontrado na análise da elevação de superfície, porém, com valor de covariância menor (Figura 27).

Assim, como o ocorrido na elevação de superfície, o espectro de Fourier da covariância cruzada apresentou maior amplitude para os períodos de 0,33 e 3,51 anos, porém, com evidência do sinal de 0,70 anos. O sinal de período 3,51 anos apresentou defasagem de -41,56 semanas, enquanto que o de 0,70 anos apresentou defasagem em torno de 10 semanas e o de 0,33 anos, -7,43 semanas (Figura 33).

A correlação cruzada confirma o padrão apresentado pela covariância, com valor de -0,36 e defasagem zero. Essa correlação possui valor, em módulo, superior ao encontrado para a elevação da superfície. 

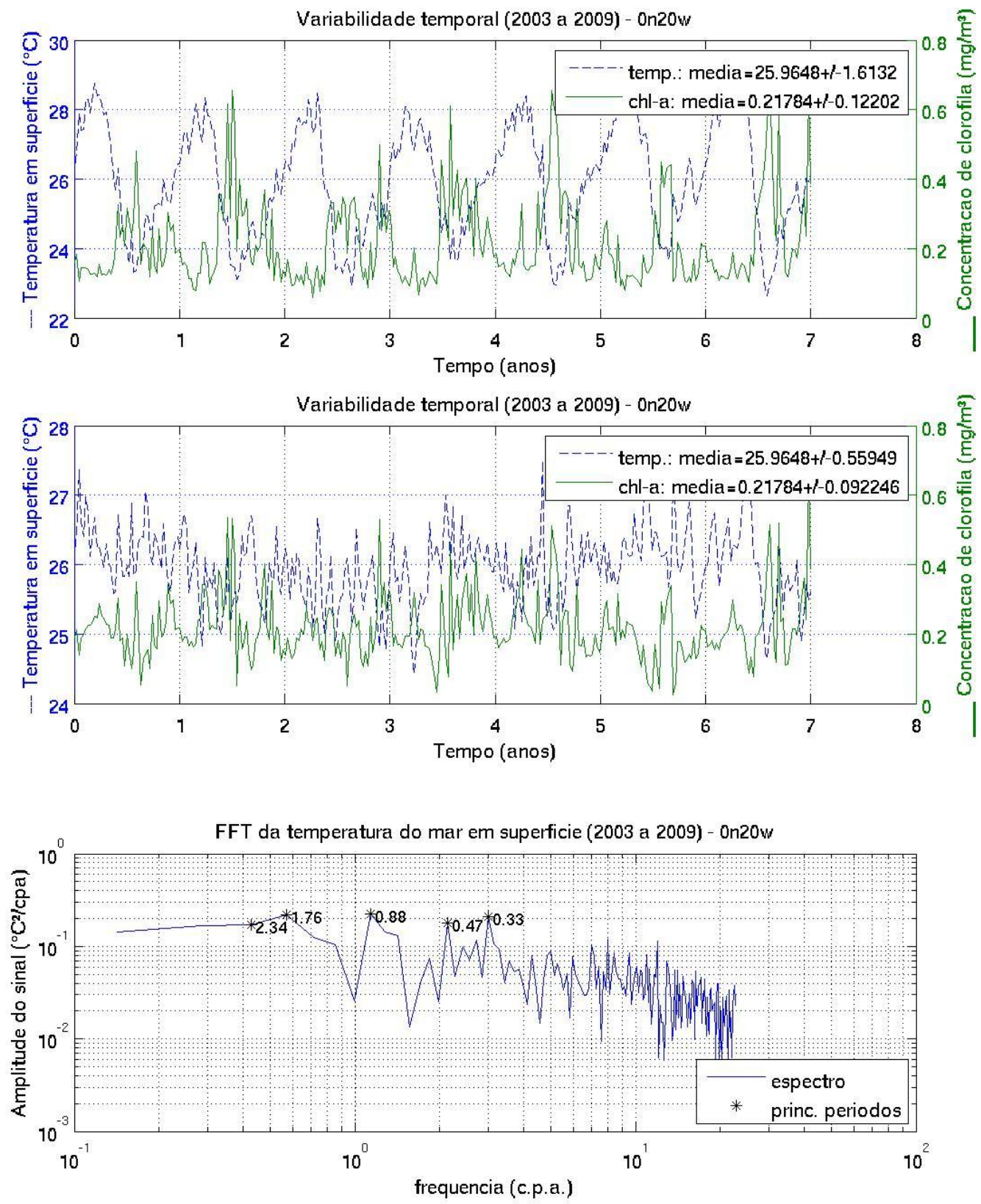

FFT da concentracao de clorofila (2003 a 2009) - On20w

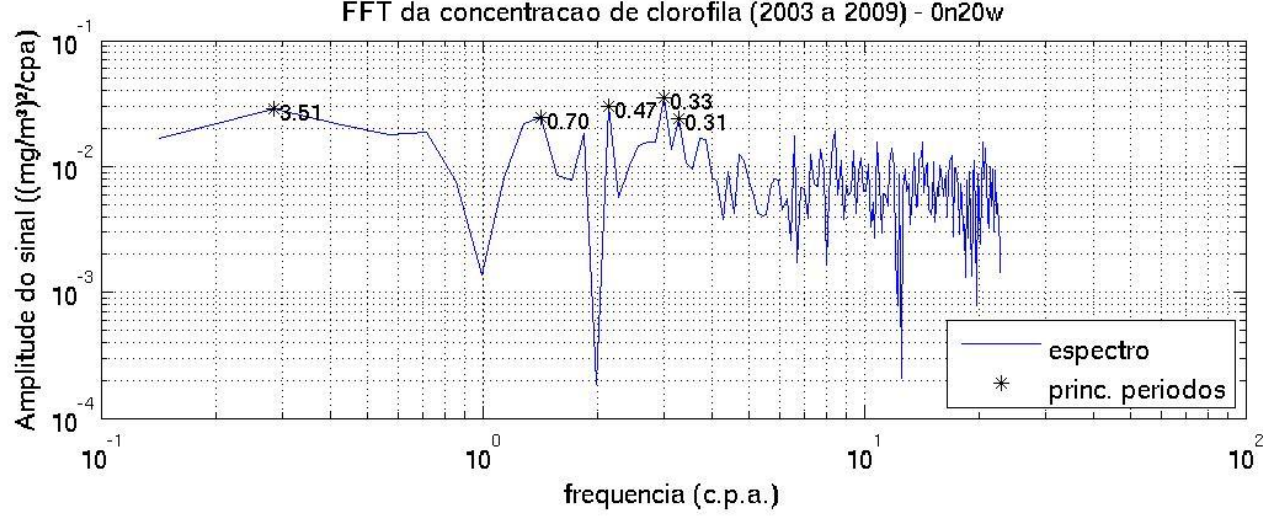

Figura 32: Séries temporais de clorofila $a$ e de temperatura da superfície completas ( $1^{\circ}$ gráfico de cima para baixo) e sem os sinais anual e semianual ( $2^{\circ}$ gráfico) e espectros de Fourier para clorofila $a\left(3^{\circ}\right.$ gráfico) e elevação de superfície ( $4^{\circ}$ gráfico) sem os sinais anual e semianual, para o ponto $0^{\circ} \mathrm{N}-20^{\circ} \mathrm{W}$. 

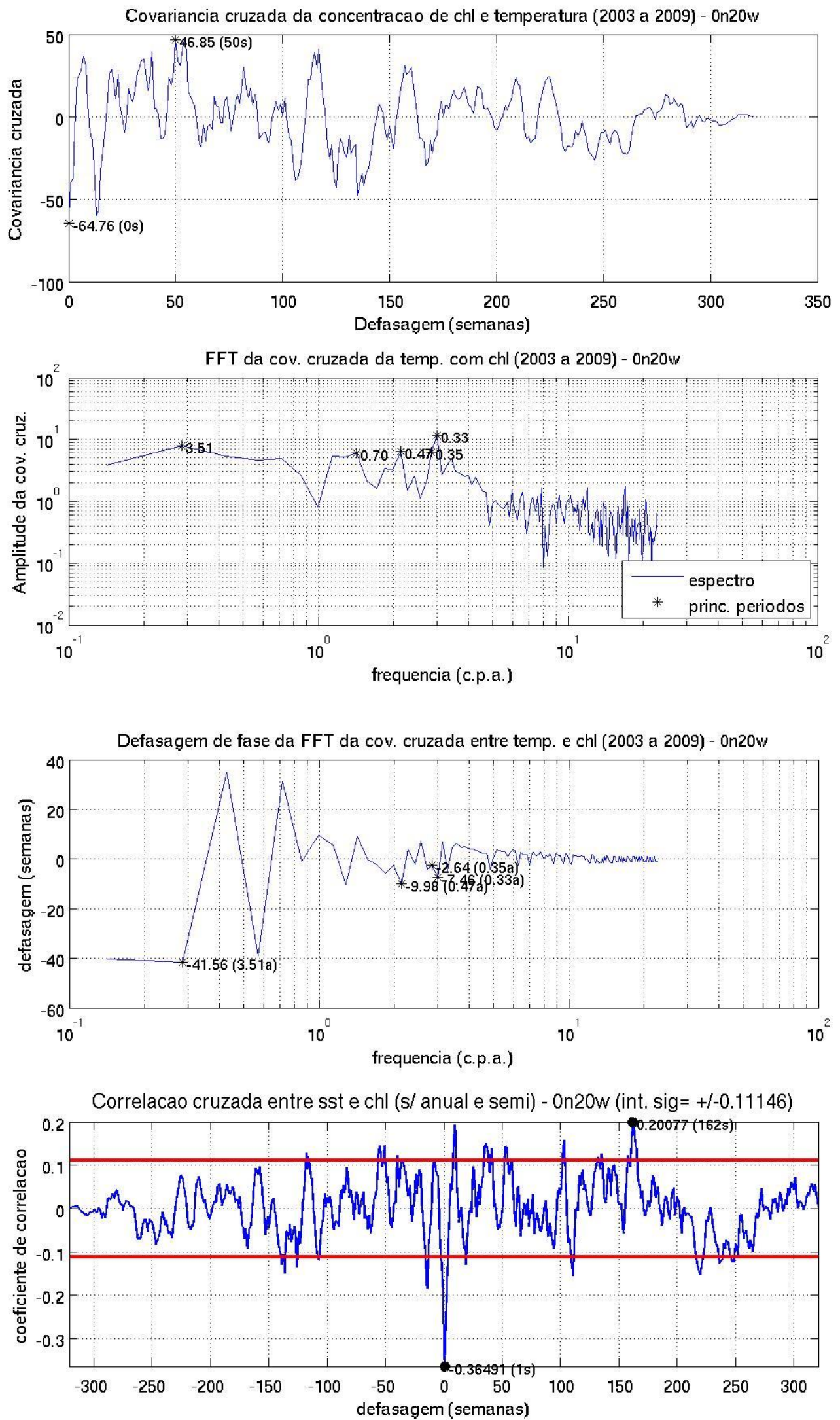

Figura 33: Covariância cruzada das séries de clorofila $a$ e de temperatura da superfície ( $1^{\circ}$ gráfico, de cima para baixo), seu respectivo espectro de Fourier ( $2^{\circ}$ gráfico), as defasagens desse espectro ( $3^{\circ}$ gráfico) e a correlação cruzada das séries ( $4^{\circ}$ gráfico), para o ponto $0^{\circ} \mathrm{N}-20^{\circ} \mathrm{W}$. 
Nas Figuras 34 e 35 tem-se a comparação entre as séries de clorofila $a$ e temperatura da superfície para o ponto $40^{\circ} \mathrm{S}-20^{\circ} \mathrm{W}$. Ao observar a Figura 34, verificase que as séries temporais completas, assim como para elevação da superfície, apresentam a assinatura clara da sazonalidade, com um padrão de correlação positiva de pequena defasagem no tempo. Após a remoção dos sinais anual e semianual, esse padrão se inverte, embora de maneira não muito evidente.

Observando os espectros de Fourier das duas séries nota-se que, em ambos, apenas o sinal referente ao período de 0,88 anos é evidenciado, o qual, numa primeira análise, parece constituir um resíduo do sinal anual removido (Figura 34).

A covariância cruzada (Figura 35) apresentou, assim como na elevação de superfície, covariância negativa, porém com valor (em módulo) superior a 50, para uma defasagem igual a zero. Esse fato corrobora com os valores encontrados na distribuição espacial de correlações entre temperatura do mar em superfície e clorofila $a$ (Figura 25).

Para o espectro de Fourier da covariância cruzada (Figura 35), diferentemente do encontrado na elevação de superfície, são notórios os períodos de 0,47 anos (com defasagem de 7,26 semanas), 1,17 anos (com defasagem de -24,34 semanas), 7,02 anos (com defasagem de 131,13 semanas) e 3,51 anos (com 45,14 semanas de defasagem).

A correlação cruzada apresentou valor superior ao encontrado para elevação de superfície, -0,24, com a mesma defasagem no tempo. Esse comportamento de resposta imediata foi verificado, anteriormente, na distribuição espacial das correlações cruzadas. 

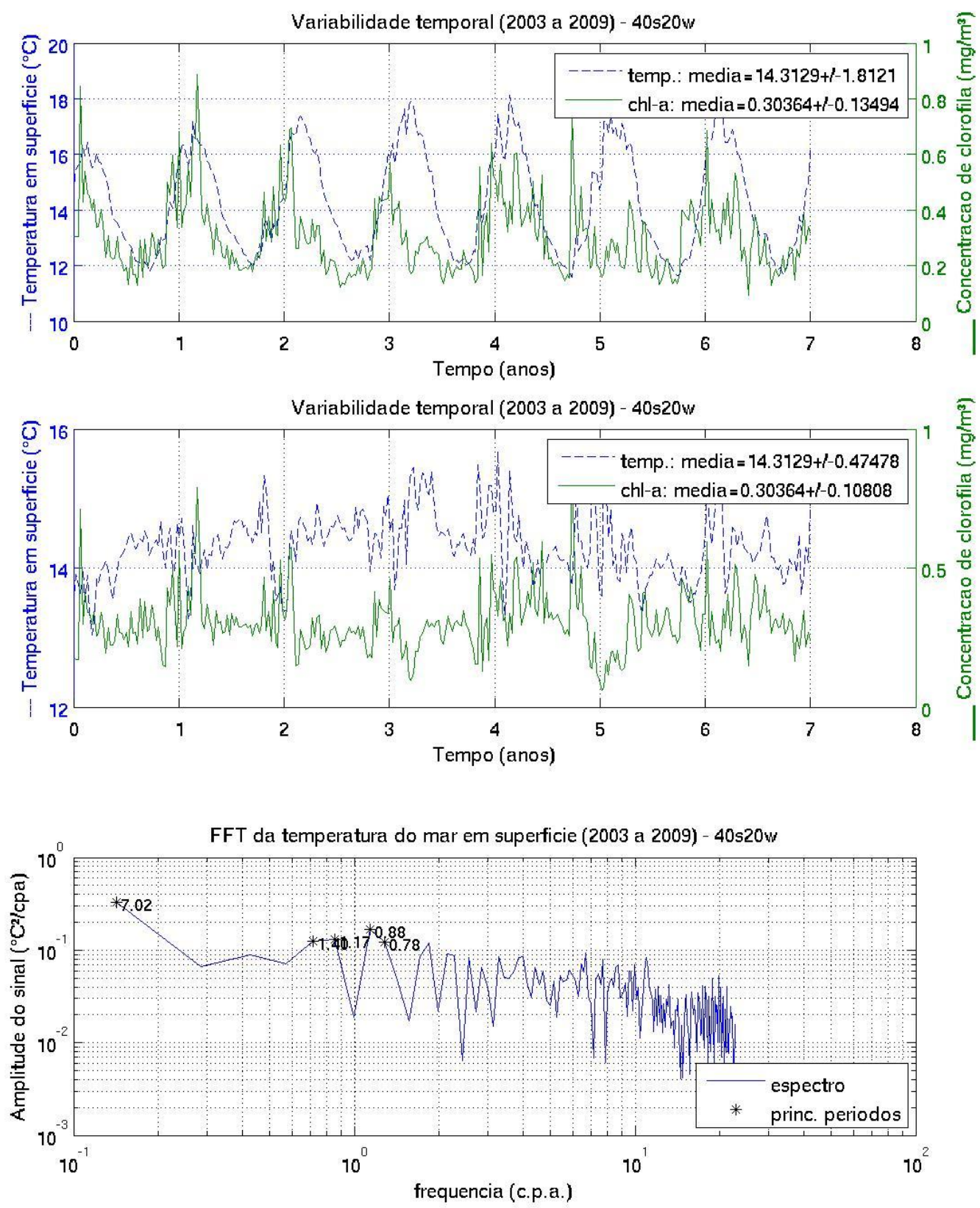

FFT da concentracao de clorofila (2003 a 2009) - 40s20w

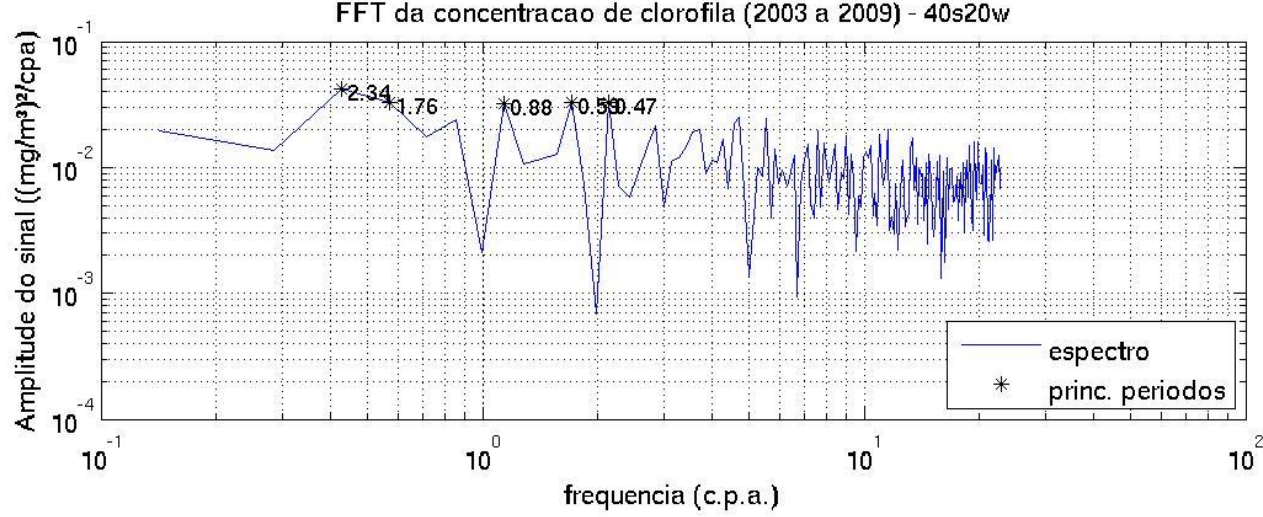

Figura 34: Séries temporais de clorofila $a$ e de temperatura da superfície completas $\left(1^{\circ}\right.$ gráfico de cima para baixo) e sem os sinais anual e semianual ( $2^{\circ}$ gráfico) e espectros de Fourier para clorofila $a\left(3^{\circ}\right.$ gráfico) e elevação de superfície ( $4^{\circ}$ gráfico) sem os sinais anual e semianual, para o ponto $40^{\circ} \mathrm{S}-20^{\circ} \mathrm{W}$. 

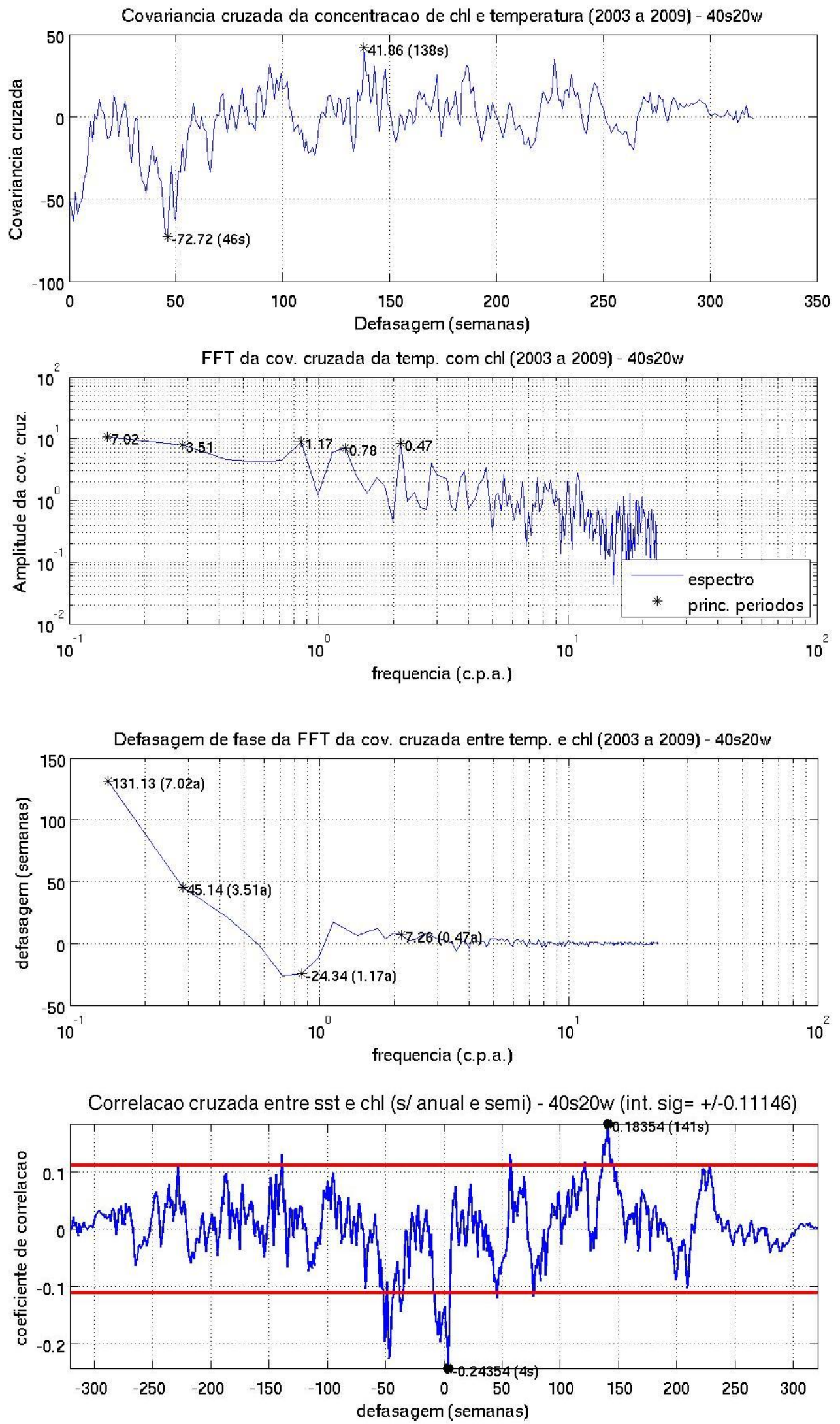

Figura 35: Covariância cruzada das séries de clorofila $a$ e de temperatura da superfície ( $1^{\circ}$ gráfico, de cima para baixo), seu respectivo espectro de Fourier ( $2^{\circ}$ gráfico), as defasagens desse espectro ( $3^{\circ}$ gráfico) e a correlação cruzada das séries ( $4^{\circ}$ gráfico), para o ponto $40^{\circ} \mathrm{S}-20^{\circ} \mathrm{W}$. 
As séries temporais de temperatura em superfície e clorofila $a$, para o ponto $60^{\circ} \mathrm{S}-20^{\circ} \mathrm{W}$ (Figura 36), contrariamente ao verificado na análise envolvendo a elevação de superfície, apresentaram sinais anual e semianual muito evidentes, com comportamento que sugere uma correlação positiva. Após a remoção desses sinais, esse comportamento já não é tão evidente. Os espectros de Fourier das variáveis, aparentemente, apresentam os pontos de período de 0,78 e 1,18 anos evidentes, diferentemente do encontrado para elevação de superfície.

A análise da correlação cruzada (Figura 37) apresentou para defasagem igual a zero valor positivo e inferior a 20 , contrariando o que ocorreu na elevação de superfície. Esse ponto é seguido por um ponto de covariância negativa, com valor superior a $30 \mathrm{e}$ defasagem em torno de 6 semanas.

O espectro de Fourier da covariância cruzada apresentou, como principais picos, os de período de 1,17anos, 3,51 anos e 0,70 anos. O período de 0,70 já foi detectado na análise da elevação da superfície, com defasagem também próxima a 12 semanas. O período de 1,17 anos apresentou defasagem de 23,45 dias e o de 3,51 anos, defasagem de $-0,48$ dias.

A correlação cruzada apresentou, como primeiro ponto significativo, a correlação de 0,24, com defasagem de 20 semanas (Figura 37). 

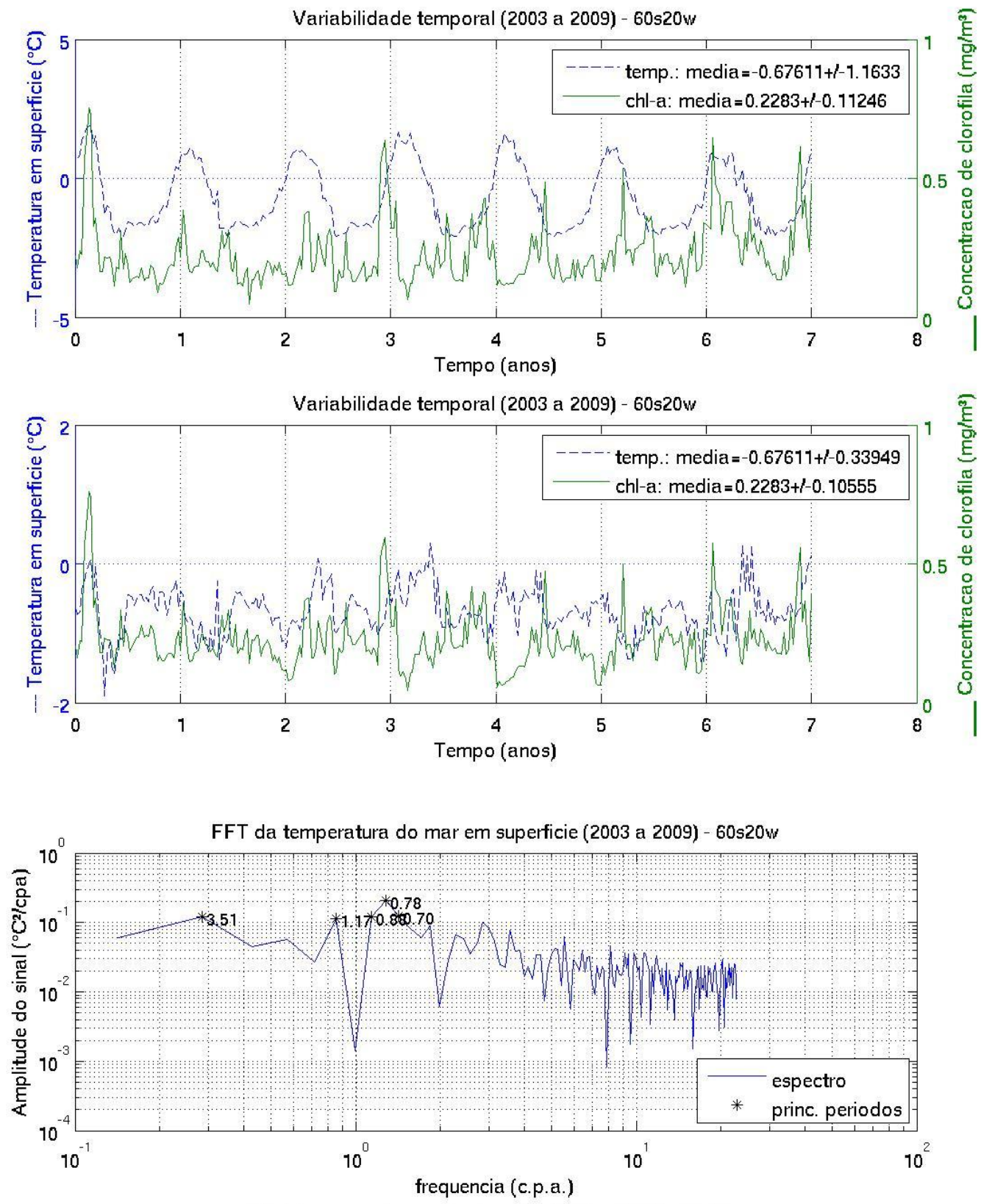

FFT da concentracao de clorofila (2003 a 2009) - 60s20w

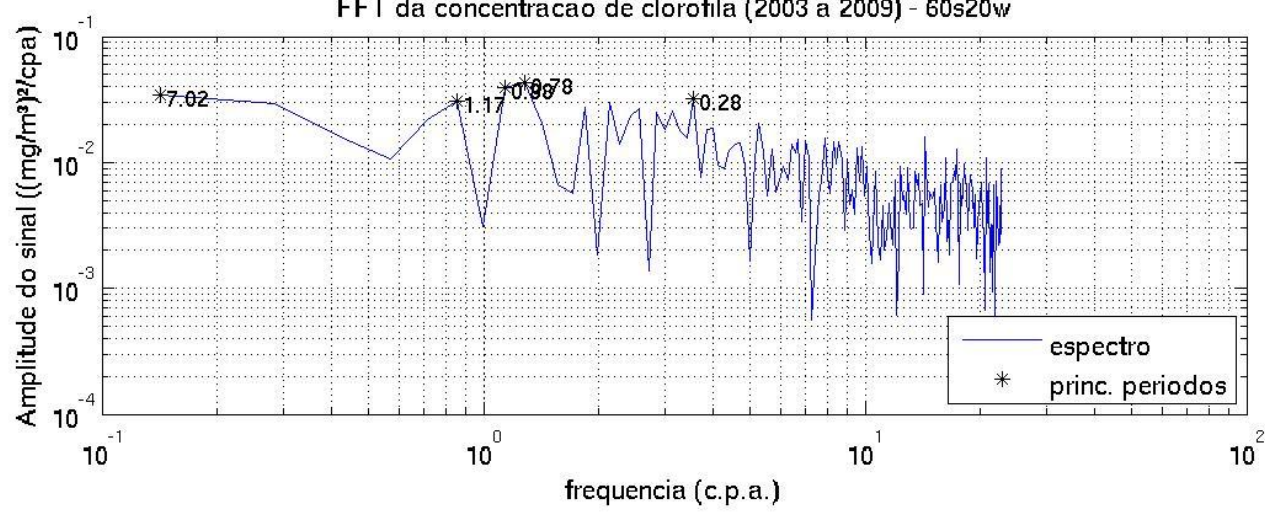

Figura 36: Séries temporais de clorofila $a$ e de temperatura da superfície completas ( $1^{\circ}$ gráfico de cima para baixo) e sem os sinais anual e semianual ( $2^{\circ}$ gráfico) e espectros de Fourier para clorofila $a\left(3^{\circ}\right.$ gráfico) e elevação de superfície ( $4^{\circ}$ gráfico) sem os sinais anual e semianual, para o ponto $60^{\circ} \mathrm{S}-20^{\circ} \mathrm{W}$. 

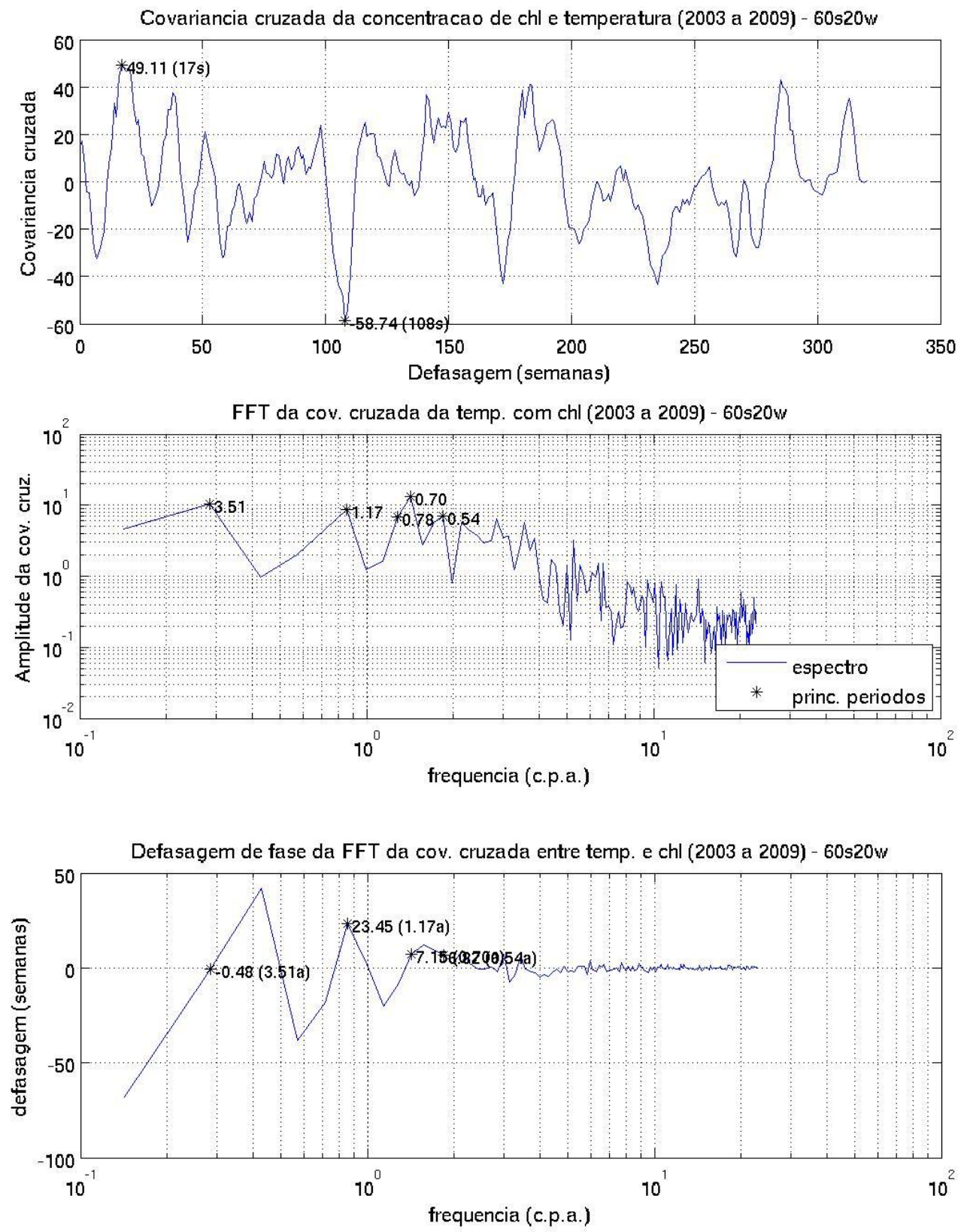

Correlacao cruzada entre sst e chl ( $\mathrm{s} /$ anual e semi) - 60s20w (int. sig $=+/-0.11146$ )

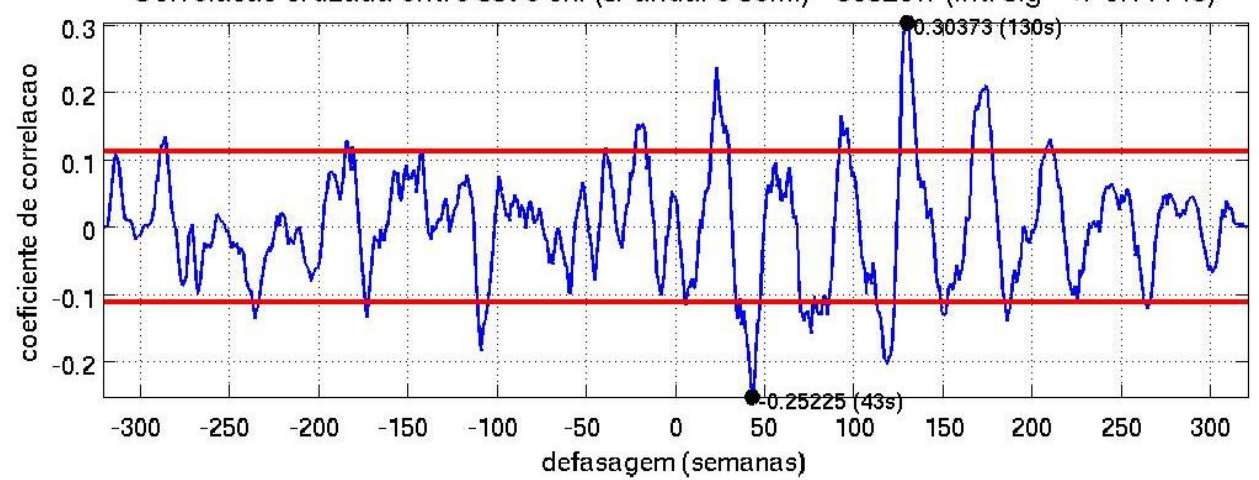

Figura 37: Covariância cruzada das séries de clorofila $a$ e de temperatura da superfície ( $1^{\circ}$ gráfico, de cima para baixo), seu respectivo espectro de Fourier ( $2^{\circ}$ gráfico), as defasagens desse espectro ( $3^{\circ}$ gráfico) e a correlação cruzada das séries ( $4^{\circ}$ gráfico), para o ponto $60^{\circ} \mathrm{S}-20^{\circ} \mathrm{W}$. 


\subsubsection{Covariância cruzada no transecto $20^{\circ} \mathrm{W}$}

A seguir serão apresentadas as distribuições latitudinais, para a longitude $20^{\circ} \mathrm{W}$, da amplitude do sinal do espectro de Fourier da covariância cruzada entre a clorofila $a$ e as variáveis físicas (Figura 38). Essas imagens foram dispostas para uma melhor visualização latitudinal da variação das propriedades nesse transecto.

Para a intensidade das correntes e elevação de superfície, nota-se maior amplitude para sinais de baixa frequência (período superior a 3 anos), com grande variabilidade no tempo de resposta, oscilando positiva e negativamente com valores superiores a 1 ano. Esses sinais se concentram nas faixas de $10^{\circ} \mathrm{N}$ a $30^{\circ} \mathrm{N}$, entre $30^{\circ} \mathrm{S}$ e $40^{\circ} \mathrm{S}$ e em faixas em torno de $60^{\circ} \mathrm{S}$ a $70^{\circ} \mathrm{S}$, concentrando-se no período de 7 anos (equivalente à extensão da série). Picos no espectro com períodos de 6 e 7,5 anos já foram citados anteriormente, em análises de IOS e do índice associado à OAN (SCHNEIDER E SCHOÖNWIESE,1989), o que novamente salienta a limitação da análise em virtude da curta extensão das séries. É verificado um fraco sinal no período de 2,3 anos, com defasagem quase instantânea, mais saliente ente o equador e $10^{\circ} \mathrm{S}$.

Para a elevação de superfície é evidente a presença, em todo o transecto, de um sinal forte de período de 0,33 anos e um sinal menos intenso e mais localizado, entre $35^{\circ} \mathrm{S}$ e $60^{\circ} \mathrm{S}$, de período de 0,25 anos. Esses períodos já foram associados anteriormente a efeitos ressonantes na análise de índice relacionado à OAN. No transecto analisado também se verifica um fraco sinal com período de 1,4 anos (em aproximadamente $15^{\circ} \mathrm{S}$ ) e um com 1,7 anos (em aproximadamente $35^{\circ} \mathrm{S}$ ) com defasagem quase nula.

Os transectos para salinidade e temperatura apresentam amplitudes mais marcantes para determinadas frequências, com assinaturas evidentes em menores frequências. As defasagens se apresentam com padrão semelhante ao encontrado para as outras variáveis físicas (com respostas mais imediatas para maiores frequências), porém com regiões de alternância de sinal melhor definidas. Esses sinais de baixa frequência se concentram no período de 7 anos (extensão das séries temporais). Esses transectos, assim como para elevação de superfície, apresentam assinatura do sinal de período de 0,33 anos em boa parte dos mesmos, intensificando-se nas regiões polares. 

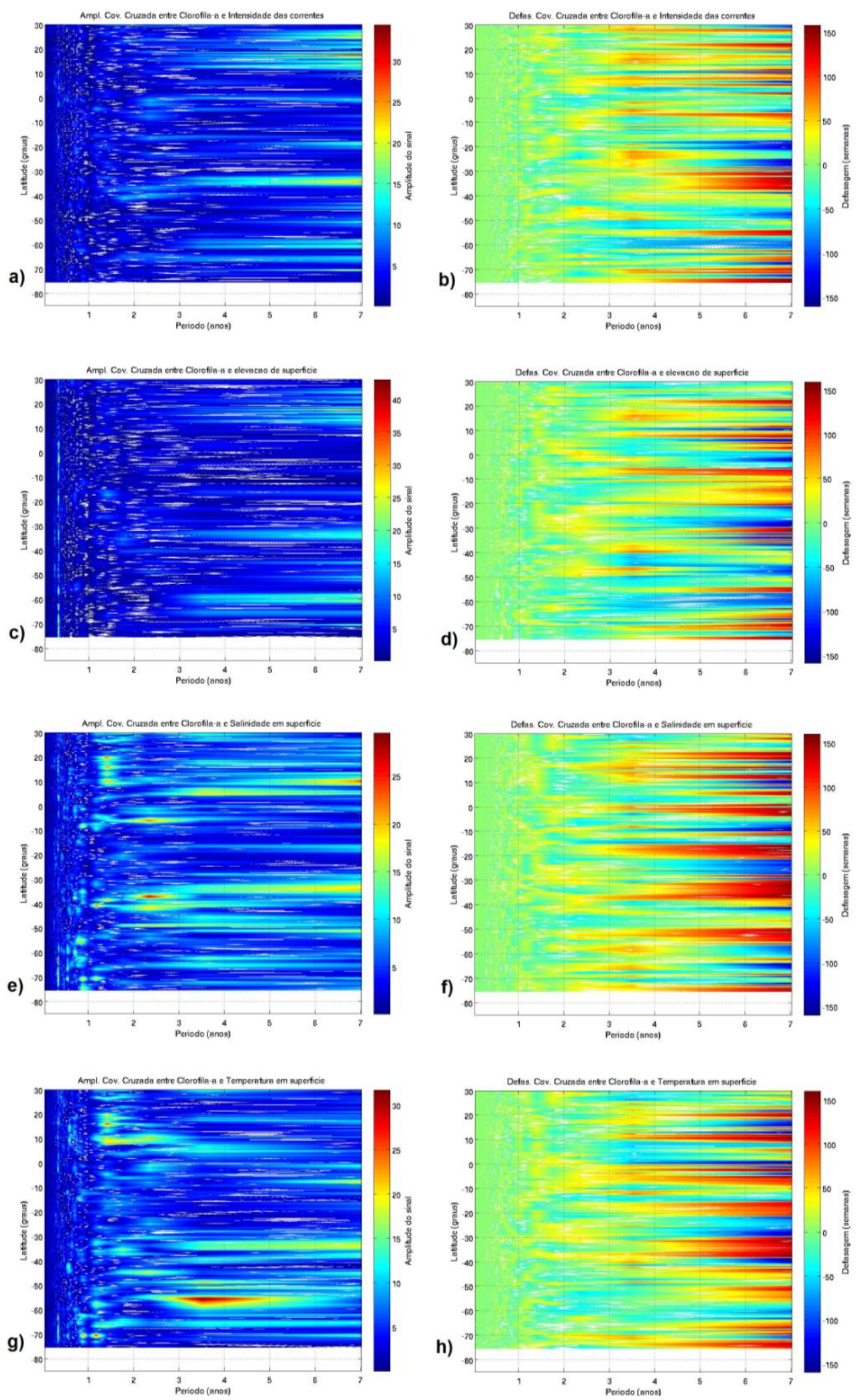

Figura 38: Variabilidade latitudinal para a longitude $20^{\circ} \mathrm{W}$ da amplitude do sinal do espectro de Fourier da covariância cruzada entre clorofila $a$ e intensidade das correntes [a) ] e sua respectiva defasagem no tempo [ b) ], entre clorofila $a$ e elevação do nível do mar [ c) ] e sua defasagem no tempo [ d) ], entre clorofila $a$ e salinidade [ e) ] e sua defasagem [ f) ], e entre clorofila $a$ e temperatura [ g) ] e sua defasagem [ h) ], após remoção dos sinais anual e semianual, para o Atlântico Sul e Tropical, no período de 2003 a 2009. 
Para altas latitudes, assim como nos outros parâmetros físicos, para salinidade e temperatura, são destacados sinais de menores frequências (período maiores que 2,3 anos) concentrados ente $30^{\circ} \mathrm{S}$ a $40^{\circ} \mathrm{S}$ e entre o equador e $10^{\circ} \mathrm{S}$, apresentando em ambas regiões defasagens positivas em torno de 1 ano. Principalmente para altas latitudes verificam-se sinais em torno do período de 1 ano, que podem ser resíduos do método pontual de remoção dessa sazonalidade. Também se verifica, principalmente na região entre $10^{\circ} \mathrm{N}$ e $20^{\circ} \mathrm{N}$, sinal com período médio de 1,4 anos apresentando defasagem positiva inferior a 6 meses. Essa região é afetada por ressurgência costeira (costa Norte africana).

Para temperatura, o maior destaque é dado à ocorrência de um sinal com alto valor de amplitude concentrado na faixa entre $50^{\circ} \mathrm{S}$ a $60^{\circ} \mathrm{S}$, também com presença menos intensa em $5^{\circ} \mathrm{N}$, com maiores valores em torno do período de 3,5 anos, e apresentando defasagem negativa de menos de 6 meses. Há também a ocorrência menos intensa de sinais se concentrando em torno do período de 2,3 anos em $10^{\circ} \mathrm{N}$ e $45^{\circ} \mathrm{S}$ com defasagem praticamente imediata (menos de 10 semanas). A ocorrência desses mesmos sinais é verificada para a salinidade, porém com maior intensidade para o sinal de período de 2,3 anos, concentrando-se entre o equador e $5^{\circ} \mathrm{S}$ e em torno de $45^{\circ} \mathrm{S}$ (região de maior gradiente de salinidade). Os picos nos períodos de 3,5 e 2,3 anos já foram associados anteriormente aos fenômenos ENOS.

Outros sinais são verificados com menor intensidade, como para o período de 1,7 anos, bem evidente em $35^{\circ} \mathrm{S}$, com defasagem negativa em torno de 6 meses para temperatura, e uma faixa no período de 0,7 anos e defasagem praticamente instantânea, concentrado em altas latitudes, tanto no espectro de temperatura como no de salinidade, mas com maior evidência para a temperatura. A assinatura do sinal de 0,7 anos se assemelha ao verificado para 0,33 anos. Os períodos de 1,7 anos, bem como de 0,7 e 1,5 anos, já haviam sido anteriormente relacionados aos fenômenos de ENOS. 


\section{CONCLUSÕES}

Os resultados obtidos no presente trabalho permitem concluir que, primeiramente, em relação à validação do modelo, a adaptação do POM utilizada apresentou resultados satisfatórios para temperatura quando comparados estatisticamente a séries temporais em superfície de boias do PIRATA fundeadas próximo ao Equador. A forte correlação entre as séries temporais do POM e do PIRATA (que já era evidente numa constatação visual), considerando os sinais anual e semianual, manteve-se após a remoção desses sinais (Figuras 9 a 14), apresentando valores significativos de coeficientes de correlação linear e parâmetros de Wilmott, e valores para quantificação de erros relativamente baixos (ver Tabelas 3 e 4). Ainda sim, houve certa subestimação $\left(0,56{ }^{\circ} \mathrm{C}\right)$ das temperaturas de superfície calculadas pelo modelo.

$\mathrm{Na}$ comparação de resultados do modelo com medições de temperatura superficial do MODIS, para toda a região de estudo, nota-se também uma forte concordância nos resultados (Figuras 17 e 18), desta vez, com o modelo apresentando superestimação média de $0,25^{\circ} \mathrm{C}$. Analisando-se as distribuições das saídas do modelo e das observações do MODIS, para médias, tendências e desvios padrão (considerando separadamente os sinais anual e semianual e o sinal residual) obtiveram-se valores coeficientes de correlação linear e parâmetros de Wilmott relativamente altos (ver Tabela 7).

Ao comparar os perfis de temperatura do modelo com os das boias PIRATA, se verificou maior subestimação das temperaturas do modelo, com média em torno de $3,09^{\circ} \mathrm{C}$, e da profundidade da termoclina (Figuras 15 e 16), evidenciando necessidade de otimização dos procedimentos numéricos de transmissão de energia térmica das camadas superficiais para o fundo.

Além dos procedimentos de calibração e validação com dados do PIRATA e do MODIS, a comparação das demais variáveis resultantes do modelo com resultados obtidos na literatura salienta a validade do modelo, principalmente quanto aos valores próximos à superfície. Pode-se concluir assim que os resultados obtidos pelo modelo na camada superficial são válidos para análises de correlação com dados biológicos de superfície. 
A observação das distribuições das variáveis físicas e de clorofila $a$ (Figuras 17 a 22) demonstraram padrões de distribuição consistentes com os verificados na literatura, assim como padrões de tendências de grande interesse. Entretanto, a relativamente pequena extensão das séries temporais analisadas não permite conclusões definitivas em relação às tendências calculadas.

A análise, em separado, dos desvios padrão referentes aos sinais anual e semianual em contraste com o restante dos sinais (parte residual) permite determinar a magnitude de suas respectivas influências. Esses desvios padrão possuem significativas diferenças nas distribuições espaciais e, de uma forma geral, os sinais anual e semianual apresentam assinatura significativa no desvio padrão total, mas o sinal residual também apresenta valores elevados, em especial para a clorofila $a$, onde o mesmo apresenta valores superiores aos encontrados para a sazonalidade referente aos ciclos anual e semianual.

As distribuições para clorofila $a$ apresentam semelhanças com as dos demais parâmetros considerados - temperatura, salinidade, elevação e intensidade da corrente na superfície - mas com significativas diferenças em determinadas regiões da área de estudo. Isso dá indícios da ocorrência de um comportamento não uniforme na distribuição espacial das correlações entre as variáveis (Figura 23).

A distribuição das correlações entre clorofila $a$ e variáveis físicas resultantes do modelo (após remoção dos sinais anual e semianual) indica valores de correlação relativamente altos, sendo os maiores valores de correlação (em módulo) os de temperatura em superfície. Embora as correlações tenham apresentado padrões de distribuição espacial diferenciados para cada variável, excetuando a intensidade das correntes em superfície, houve uma característica comum - a grande dependência latitudinal das distribuições, delimitando assim regiões de comportamento distinto (Figura 23).

Um ponto marcante nas análises realizadas foi a diferenciação do comportamento das correlações nas regiões de baixa concentração de clorofila $a$ (no interior do Giro Subtropical) com as regiões de alta concentração (em áreas costeiras e em altas latitudes). Foi obtido um padrão geral de correlações negativas nas regiões de baixa concentração e positivas nas regiões de alta concentração, excetuando o Equador (região de alta concentração de clorofila $a$, que se caracterizou por uma correlação negativa). Esse comportamento se confirma nas correlações cruzadas salientando, de modo geral, uma resposta biológica praticamente imediata no interior do GSAS e na 
região do equador e atrasos nas respostas biológicas para as demais regiões (Figuras 24 e 25).

A análise das covariâncias cruzadas para temperatura e elevação de superfície com a clorofila $a$ apresentou resultados que confirmam o padrão apresentado pela correlação cruzada (Figuras 26 a 37). A análise espectral destacou a forte assinatura de um sinal com período de 0,33 anos na maioria das séries de covariância cruzada. Um sinal com período de 0,25 anos também aparece de forma recorrente nas covariâncias entre clorofila $a$ e elevação de superfície. Esses dois sinais apresentam pequena defasagem no tempo podendo ser relacionados, aparentemente, a efeitos ressonantes associados ao sinal anual.

Outros sinais que atingem grandes amplitudes na maior parte dos pontos analisados são os que apresentam os seguintes períodos:

- $\quad$ 3,51 anos, que apresentou variação em fase de quase 1 ano. Esse sinal aparece em todos os pontos geográficos analisados na covariância cruzada entre clorofila $a$ e temperatura em superfície, com defasagem positiva em $40^{\circ} \mathrm{S}$ e negativa no equador e em $60^{\circ} \mathrm{S}$ (Figuras 32 a 37);

- $\quad 0,70$ anos, que apresentou defasagem em torno de 10 semanas, se apresentando no Equador para covariância cruzada com a temperatura em superfície e em $60^{\circ} \mathrm{S}$ para ambas as covariâncias - temperatura e elevação da superfície;

- 1,17 anos, que ocorre apenas nas covariâncias cruzadas da clorofila $a$ com a temperatura em superfície para os pontos $40^{\circ} \mathrm{S}$ e $60^{\circ} \mathrm{S}$, apresentando defasagem em torno de 24 semanas, sendo negativa para $40^{\circ} \mathrm{S}$ e positiva em $60^{\circ} \mathrm{S}$.

Os períodos de 3,51 anos e 0,70 anos são encontrados na literatura, em séries de IOS (Índice de Oscilação Sul), o que leva à conclusão que esses sinais podem estar associados a efeitos relacionados a fenômenos ENOS (El Niño - Oscilação Sul), em especial no que diz respeito às correlações entre clorofila $a$ e temperatura em superfície.

Esses fenômenos aparecem com grandes variações espaciais nos espectros de Fourier das covariâncias cruzadas entre a clorofila $a$ e cada uma das variáveis físicas, tanto em relação à magnitude de sua assinatura como em relação à fase, como é verificado em analise para todas as variáveis físicas no transecto $20^{\circ} \mathrm{S}$. Nessa análise verifica-se também que os sinais para maiores frequências mostram-se mais evidentes para as covariâncias cruzadas da clorofila $a$ com a temperatura e a salinidade. 
Dessa forma, pode-se concluir que, realmente, há um comportamento espacial muito característico das correlações entre as variáveis físicas e clorofila $a$, mesmo removendo-se os sinais anual e semianual. Apesar de sua grande importância, esses sinais não são responsáveis por boa parte da variabilidade das concentrações de clorofila a. Salienta-se, também, que essa variabilidade espacial também ocorre no campo das frequências, onde se denota a provável influência de fenômenos ENOS, tanto nas variáveis físicas como na clorofila $a$.

Como sugestão para trabalhos futuros, é necessário um aprofundamento na pesquisa sobre as causas das variabilidades espaciais das correlações e atrasos de fase, além de uma melhor compreensão de como os fenômenos ENOS influenciam o comportamento dessas correlações. 


\section{BIBLIOGRAFIA}

ALVALÁ, R. C. S. et al. 2006. Os satélites meteorológicos de nova geração e suas contribuições para as previsões de tempo e clima. Anais $\mathbf{1}^{\mathbf{0}}$ Simpósio de Geotecnologias no Pantanal, Campo Grande, Brasil. Embrapa Informática Agropecuária/INPE, p.770-780.

ALVAREZ-RAMIREZ, J.; ECHEVERRIA, J. C.; RODRIGUEZ, E. 2010. Is the North Atlantic Oscillation modulated by solar and lunar cycles? Some evidences from Hurst autocorrelation analysis. Advances in Space Research, v.47, p.748-756.

BAPTISTA, M. C. 2000. Uma análise do campo de vento de superfície sobre o oceano Atlântico Tropical e Sul usando dados do escaterômetro do ERS. Dissertação de Mestrado, Instituto Nacional de Pesquisas Espaciais, São José dos Campos, 118p.

BARRON, C. N. et al. 2004. Sea Surface Height Predictions from the Global Navy Coastal Ocean Model during 1998-2001. J. Atmos. Oceanic Technol., v.21, p.18761893.

BLUMBERG, A. F., MELlOR, G. L. 1987. A description of a three-dimensional coastal ocean circulation model. In: Three-Dimensional Coastal Ocean Models, v. 4, p.1 - 16, American Geophysical Union, Washington D.C., USA, 208 p.

BOURLÈS, B. et al. 2008. The PIRATA Program: History, Accomplishments, and Future Directions. Bull. Am. Meteorol. Soc., v. 89(8), p.1111-1125.

BOYER, T. P.; LEVITUS, S. 2002. Harmonic analysis of climatological sea surface salinity. J. Geophys. Res., v. 107(C12), p.(7)1-(7)14.

CABANES, C.; CAZENAVE, A.; PROVOST, C. L. 2001. Sea level rise during past 40 years determined from satellite and in situ observations. Science, v.294, p.840-842. 
CAMARGO, R., HARARI, J. 2001. Operational forecast of surges in the Southwestern Atlantic. Proceedings of the $\mathbf{2 0}^{\text {th }}$ International Conference on Offshore Mechanics and Arctic Engineering - OMAE 2001, Rio de Janeiro, Brasil, p.5.

CAMARGO, R.; HARARI, J.; FRANÇA, C. A. S. 2006. Downscaling the ocean circulation on Western South Atlantic: hindcasting, monitoring and forecasting purposes. The 8th International Conference on Southern Hemisphere Meteorology and Oceanography - 8 ICSHMO, Foz do Iguaçu, Brasil, p.507-511.

CAMPBELL, J. W. 1995. The lognormal distribution as a model for bio-optical variability in the sea. J. Geophys. Res., v.100, p13237-13254.

CAMPOS, E. J. D. et al. 1995. Physical Oceanography Of The Southwest Atlantic Ocean. Oceanography, v.8(3), p.87-91.

CAMPOS, E. J. D. et al. 1999. Interannual variability of the sea surface temperature in the South Brazil Bight. Geophys. Res. Lett., v. 26, p.2061-2064.

CANALS, M. et al. 1992. Caracterización geológica de la región de enlace entre la Cuenca de Bransfield y la Dorsal Sur de Scotia (Antártida). Acta Geologica Hispanica, v.27(3-4), p.89-110.

CARDER, K.L. et al. 2004. Performance of the MODIS semi-analytical ocean color algorithm for chlorophyll-a. Space Research, v.33, p.1152-1159.

CAZENAVE, A.; NEREM, R. S. 2004. Present-day sea level change: Observations and causes. Rev. Geophys., v.42, p.RG3001.

CHENG, X; QI, Y. 2007. Trends of sea level variations in the South China Sea from merged altimetry data. Global and Planetary Change, v.57, p.371-382.

CHU, P. C.; LU, S.; CHEN, Y. 2001. Evaluation of the Princeton Ocean Model using the South China Sea Monsoon Experiment (SCSMEX) Data. Atmos. Oceanic Technol., v.18, p.1521-1539. 
CIRANO, M. et al. 2006. A circulação Oceânica de larga-escala na região do Atlântico Sul com base no modelo de circulação global OCCAM. Rev. Bras. de Geof., v.24(2), p. $209-230$.

DESER, C. et al. 2010. Sea Surface Temperature Variability: Patterns and Mechanisms. Annu. Rev. Mar. Sci., v.2, p.115-143.

EGBERT, G. D.; BENNETT, A. F. ; FOREMAN , M. G. G. 1994. TOPEX/POSEIDON tides estimated using a global inverse model. J. Geophys. Res., v.99(C12), p.24,82124,852 .

EMERY, W.J.; THOMSON, R.E. 2001. Data Analysis Methods in Physical Oceanography. 2nd Ed. Elsevier Science, Amsterdam. 658p.

EZER,T.; MELLOR, G. L. 1994. Diagnostic and prognostic calculations of the North Atlantic circulation and sea level using a sigma coordinate ocean model. J. Geophys. Res., v. 99, p.14,159-14,171.

EZER,T.; MELLOR, G. L. 1997. Simulations of the Atlantic Ocean with a free surface sigma coordinate ocean model. J. Geophys. Res., v.102(C7), p.15,647-15,657.

EZER,T.; MELLOR, G. L. 2000. Sensitivity studies with the North Atlantic sigma coordinate Princeton Ocean Model. Dynamics of Atmospheres and Oceans, v.32, p. $185-208$.

GARCIA, C. A. E. et al. 2004. Chlorophyll variability and eddies in the BrazilMalvinas Confluence region. Deep-Sea Research II, v.51, p.159-172.

GORGON, A. L. 1989. Brazil-Malvinas Confluence - 1984. Deep-Sea Res., v.36(3), p.359-384.

HARARI, J.; CAMARGO, R.; FRANÇA, C. A. S. 2005. Simulations and predictions of the tidal and general circulations in the South and Tropical Atlantic: high resolution grids in the Brazilian shelves. Afro-America Gloss News, Revista do Global Sea Level Observing System (GLOSS), patrocinada pela Comissão Oceanográfica Intergovernamental (COI), http://www.mares.io.usp.br/aagn/ ind.html, v.9(1), p. 7. 
HARARI, J. ; ABREU, C. V. W. de . 2007. Estudo das relações entre as variabilidades do clima e da pesca desembarcada no Estado de São Paulo. Book of Abstracts SHEWC 2007 - Safety, Heath and Environmental World Congress, Santos (SP, Brasil), v.1, p.53.

HARRISON, W. G.; COTA. G. F. 1991. Primary production in polar waters: relation to nutrient availability. Polar Research, v. 10(1), p. 87-104.

HASTENRATH, S. 1984. Interannual Variability and Annual Cycle: Mechanisms of Circulation and Climate in the Tropical Atlantic Sector. Mon. Wea. Rev., v.112, p.1097-1107.

HETLAND, R. D.; DIMARCO, S. F. 2012. Skill assessment of a hydrodynamic model of circulation over the Texas-Louisiana continental shelf. Ocean Modelling, v. 43-44, p.64-76.

KAHRU, M. et al. 2007. Sea level anomalies control phytoplankton biomass in the Costa Rica Dome area. Geophys. Res. Lett., v.34, p.L22601,1- L22601,5.

KALNAY, E. et al. 1996. The Ncep/Ncar 40-year reanalysis project. Bull. Am. Meteorol. Soc., v.77, p.437 - 470 .

KAMPEL, M. et al. 2005. Estimativa por satélite da concentração de clorofila a superficial na costa sudeste brasileira, região oeste do Atlântico Sul: Comparação dos algoritmos SeaWiFS. Anais XII Simpósio Brasileiro de Sensoriamento Remoto, Goiânia, Brasil, INPE, p.3633-3641.

KAVAK, M. T.; KARADOGAN, S. 2012. The relationship between sea surface temperature and chlorophyll concentration of phytoplanktons in the Black sea using remote sensing techniques. J. Environ. Biol., v.33(2), p.493-8.

KUMAR, N. et al. 1979. Origin of "paired" aseismic rises: Ceara and Sierra Leone rises in the equatorial, and the Rio Grande Rise and Walvis Ridge in the South Atlantic. Marine Geology, v.30, p.175-191. 
LEWIS, K.; ALLEN, J. I. 2009. Validation of a hydrodynamic-ecosystem model simulation with time-séries data collected in the western English Channel. J. Mar. Syst., v.77, p.296-311.

LUMPKIN, R.; GARZOLI, S. L. 2005. Near-surface circulation in the Tropical Atlantic Ocean. Deep-Sea Research I v.52, p.495-518.

METSAMAA, L.; KUTSER, T. 2008. On Suitability of MODIS Satellite Chlorophyll Products for the Baltic Sea Conditions. Env. Res., Eng. Manag.. no.2(44), p.4-9.

O’BRIEN, J. J. 1985. Advanced Physical Oceanographic Numerical Modeling. D. Reidel Publishing Company. Dordrecht, 608p.

PEREIRA, N. E. S. 2009. Análise das correlações entre meteorologia, hidrodinâmica e produção primária no Atlântico Sul e Tropical, através de modelagem numérica e sensoriamento remoto. Monografia de Bacharelado, Instituto Oceanográfico da Universidade de São Paulo, São Paulo, 43p.

PEREIRA, N. E. S.; HARARI, J. 2010. Comparative study of meteorology, hydrodynamics and primary production in South and Tropical Atlantic Ocean through numerical modeling and remote sensing. Resumos do III Congresso Brasileiro de Oceanografia CBO 2010. Rio Grande, RS. v.1, p.3971-3973.

PEREIRA, R. C.; SOARES-GOMES, A. 2002. Biologia Marinha. Editora Interciência. Rio de Janeiro, 382p.

PETERSON, R. G.; STRAMMA, L. 1991. Upper-level circulation in the South Atlantic Ocean. Prog. Oceanog. v. 26, p. 1-73.

RAVEN, P. H.; EVERT, R.F.; EICHHORN, S.E. 2001. Biologia Vegetal. $6^{\mathrm{a}}$ ed. Editora Guanabara Koogan. Rio de Janeiro, 906p.

REYNOLDS, R. W.; SMITH, T. M. 1994. Improved Global Sea Surface Temperature Analyses Using Optimum Interpolation. J. Climate, v.7, p.929-948. 
RICHARDSON, P. L.; PHILANDER, S. G. H. 1987. The Seasonal Variations of Surface Currents in the Tropical Atlantic Ocean: A Comparison of Ship Drift Data With Results From a General Circulation Model. J. Geophys. Res., v. 92(C1), p.715-724.

SAHA, S. et al. 2010. The NCEP Climate Forecast System Reanalysis. Bull. Amer. Meteor. Soc., v.91, p.1015-1057.

SARACENO, M.; PROVOST, C.; PIOLA, A. R. 2005. On the relationship between satellite-retrieved surface temperature fronts and chlorophyll a in the western South Atlantic. J. Geophys. Res., v.110, p.C11016.

SCHOUTEN, M. S.; MATANO, R. P.; STRUB, T. P. 2005. A description of the seasonal cycle of the equatorial Atlantic from altimeter data. Deep-Sea Research I, v.52, p.477-493.

SCHNEIDER, U.; SCHOÖNWIESE, C. D. 1989. Some statistical characteristics of El Niño/southern oscillation and north Atlantic oscillation índices. Atmósfera, v.2, p.167180.

SOUZA, R. B. 2005. Oceanografia por Satélites. Editora Oficina de Textos. São Paulo. 336p.

SPIEGEL, M. R. 1992. Theory and Problems of Probability and Statistics. 2nd ed. New York: McGraw-Hill, 298p.

STRAMMA, L.; SCHOTT, F. 1999. The mean flow field of the tropical Atlantic Ocean. Deep-Sea Res. II, v.46, p.279-303.

TEIXEIRA, C. E. P. et al. 2009. On the temporal variability of the sea surface temperature in the Southwestern Atlantic based on the analysis of "Pathfinder AVHRR/NOAA" images. Revista Brasileira de Cartografia, v.61(03), p.207-221.

TIMMERMANN, A. 2001. Changes Of ENSO Stability Due To Greenhouse Warming. Geophys. Res. Lett., v.28(10), p.2061-2064. 
VUOLO, J. H. 1992. Fundamentos da Teoria dos Erros. $2^{\text {a }}$ ed. Sao Paulo: Editora Edgard Blücher LTDA, 249p.

WANG, X. et al. 2003. Phytoplankton carbon and chlorophyll distributions in the equatorial Pacific and Atlantic: A basin-scale comparative study. J. Mar. Syst., v.109110, p.138-148.

WILMOTT, C. J. 1981.On the validation of models. Physical Geography. v.2(2), p.184-194.

WILSON, C; ADAMEC, D. 2001. Correlations between surface chlorophyll and sea surface height in the tropical Pacific during the 1997-1999 El Niño-Southern Oscillation event. J. Geophys. Res., v. 106(C12), p.31,175-31,188. 